Portland State University

PDXScholar

Spring 5-22-2015

\title{
Study of Prestige and Resource Control Using Fish Remains from Cathlapotle, a Plankhouse Village on the Lower Columbia River
}

J. Shoshana Rosenberg

Portland State University

Follow this and additional works at: https://pdxscholar.library.pdx.edu/open_access_etds

Part of the Archaeological Anthropology Commons, and the Indigenous Studies Commons Let us know how access to this document benefits you.

\section{Recommended Citation}

Rosenberg, J. Shoshana, "Study of Prestige and Resource Control Using Fish Remains from Cathlapotle, a Plankhouse Village on the Lower Columbia River" (2015). Dissertations and Theses. Paper 2356.

https://doi.org/10.15760/etd.2353

This Thesis is brought to you for free and open access. It has been accepted for inclusion in Dissertations and Theses by an authorized administrator of PDXScholar. For more information, please contact pdxscholar@pdx.edu. 
Study of Prestige and Resource Control Using Fish Remains from Cathlapotle, a Plankhouse Village on the Lower Columbia River

by

J. Shoshana Rosenberg

A thesis submitted in partial fulfillment of the requirements for the degree of

\section{Master of Science}

in

Anthropology

Thesis Committee:

Virginia L. Butler, Chair

Kenneth M. Ames

Shelby L. Anderson

Portland State University

2015 
C 2015 J. Shoshana Rosenberg 


\begin{abstract}
Social inequality is a trademark of Northwest Coast native societies, and the relationship between social prestige and resource control, particularly resource ownership, is an important research issue on the Northwest Coast. Faunal remains are one potential but as yet underutilized path for examining this relationship. My thesis work takes on this approach through the analysis of fish remains from the Cathlapotle archaeological site (45CL1). Cathlapotle is a large Chinookan village site located on the Lower Columbia River that was extensively excavated in the 1990s. Previous work has established prestige distinctions between houses and house compartments, making it possible to examine the relationship between prestige and the spatial distribution of fish remains. In this study, I examine whether having high prestige afforded its bearers greater access to preferred fish, utilizing comparisons of fish remains at two different levels of social organization, between and within households, to determine which social mechanisms could account for potential differences in access to fish resources. Differential access to these resources within the village could have occurred through household-level ownership of harvesting sites or control over the post-harvesting distribution of food by certain individuals.

Previous work in this region on the relationship between faunal remains and prestige has relied heavily on ethnohistoric sources to determine the relative value of taxa. These sources do not provide adequate data to make detailed comparisons between all of the taxa encountered at archaeological sites, so in this study I utilize optimal foraging theory as an alternative means of determining which fish taxa were preferred. Optimal foraging theory provides a universal, quantitative analytical rule for ranking fish that I
\end{abstract}


was able to apply to all of the taxa encountered at Cathlapotle. Given these rankings, which are based primarily on size, I examine the degree to which relative prestige designations of two households (Houses 1 and 4) and compartments within one of those households (House 1) are reflected in the spatial distribution of fish remains. I also offer a new method for quantifying sturgeon that utilizes specimen weight to account for differential fragmentation rates while still allowing for sturgeon abundance to be compared to the abundances of other taxa that have been quantified by number of identified specimens (NISP).

Based on remains recovered from $1 / 4$ " mesh screens, comparisons between compartments within House 1 indicate that the chief and possibly other elite members of House 1 likely had some control over the distribution of fish resources within their household, taking more of the preferred sturgeon and salmon, particularly more chinook salmon, for themselves. Comparisons between households provide little evidence to support household-based ownership of fishing sites. A greater abundance of chinook salmon in the higher prestige House 1 may indicate ownership of fishing platforms at major chinook fisheries such as Willamette Falls or Cascades Rapids, but other explanations for this difference between households are possible. Analyses of a limited number of bulk samples, which were included in the study in order to examine utilization of very small fishes, provided insufficient data to allow for meaningful intrasite comparisons. These data indicate that the inhabitants of Cathlapotle were exploiting a broad fish subsistence base that included large numbers of eulachon and stickleback in addition to the larger fishes. This study provides a promising approach for examining 
prestige on the Northwest Coast and expanding our understanding of the dynamics between social inequality and resource access and control. 


\section{Acknowledgements}

Thank you so much to Virginia Butler for being an exceptional advisor who pushed me to do my best work. This project would not have been possible without your guidance. I am greatly indebted to everyone whose previous work on Cathlapotle made this project possible. In particular, thank you to Ken Ames for your enthusiasm about my work and many rounds of helpful notes. Thank you to Shelby Anderson for stepping in at the last minute to join my thesis committee and for the insightful comments you provided. I received assistance with my analysis from several people: Virginia Butler completed a portion of the fish identification prior to my work on the project, Kathryn Mohlenhoff measured a portion of the salmon vertebrae, and Emma Bailey and Nathan Jereb helped sort fish remains from the bulk sample matrix. Finally, thank you to my fellow students whose company made the countless hours spent in lab staring at fish bones bearable and to my parents who have given me endless support. 


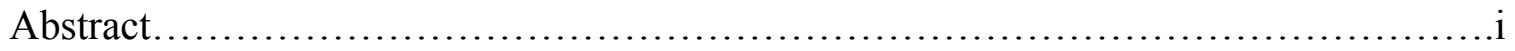

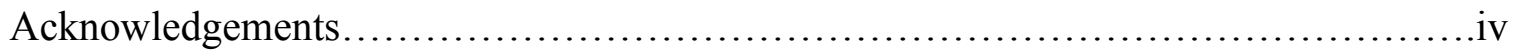

List of Tables..............................................................

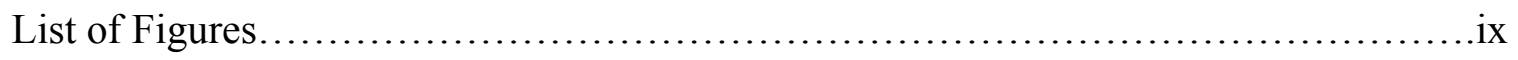

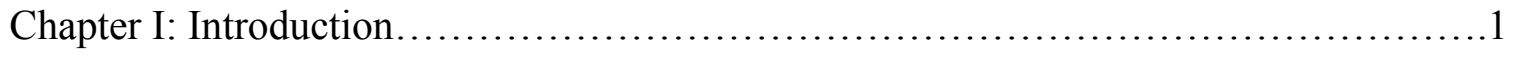

Chapter II: Background.................................................6

The Chinookans of the Lower Columbia River Valley and the Northwest Coast Household ...........................................................6

Social Inequality on the Northwest Coast.................................. 12

Resource Ownership and Control of Resource Distribution.....................17

Social Prestige-Based Faunal Studies in the Pacific Northwest..................23

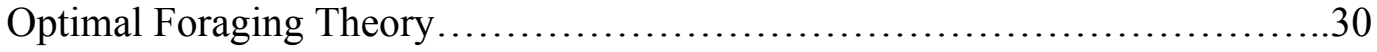

Modeling Optimal Foraging Decisions...............................33

Resource Depression and Resource Management......................35

Using Prey Size to Rank Prey ..................................... 39

Site Description.................................................... 41

Relative Prestige at Cathlapotle.........................................44

Project Goals and Expectations.........................................46

Chapter III: Materials and Methods.............................................50

Sample and Analysis...................................................50

Species-Level Identification of Salmonid Vertebrae.........................52

Estimating Representation of Fish in Bulk Samples...........................54

Chapter IV: Results......................................................59

Descriptive Summary of Fish Remains, 1/4" Mesh Screens......................59

Descriptive Summary of Fish Remains, Bulk Samples........................ 70

Summary of Taxonomic Frequencies by Social Unit.........................77

Prey Ranks of Fish at Cathlapotle.......................................80

Estimating Sturgeon Abundance: Controlling for Identifiability and

Fragmentation in the $1 / 4$ " Mesh Samples.................................. 84

Evaluation of Expectations: 1/4" Mesh Samples...............................92

Evaluation of Expectations for Salmon Species: 1/4" Mesh Samples..............95

Evaluation of Expectations: Bulk Samples (4 mm, $2 \mathrm{~mm}$, and $1 \mathrm{~mm}$ Mesh

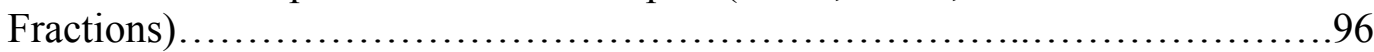

Analysis of Burning in Bulk Samples................................... 102 
Sturgeon-Eulachon Comparisons......................................106

Chapter V: Discussion, Conclusions, and Future Work.......................... 108

Implications for Resource Control: 1/4” Mesh Samples.......................108

Implications for Resource Control: Bulk Samples..........................112

Conclusions........................................................116

Future Work....................................................... 117

References Cited.......................................................... 119

Appendix A: Excavation Units for each House/Compartment and Fish Bone Analyst for each Unit, $1 / 4 "$ Mesh Samples.......................................... 131

Appendix B: Locations and Excavation Volumes (L) of Analyzed Bulk Samples......132

Appendix C: NISP of Taxa Identified in each Fraction of each Analyzed Bulk

Sample................................................................ 133 


\section{List of Tables}

Table 1. Synthesis of prestige-based faunal studies in the Pacific Northwest. $.24-25$

Table 2. Surface Area $\left(\mathrm{m}^{2}\right)$ and Volume $\left(\mathrm{m}^{3}\right)$ Excavated from each

House/Compartment.

Table 3. Sample Sizes of Bulk Samples..........................................58

Table 4. Timing of Salmon Runs in the Lower Columbia River and Presence in the Lewis River.

Table 5. Sizes of Minnow and Sucker Species at Cathlapotle.

Table 6. NISP of Pre- versus Post-Contact Fish Remains Identified from 1/4" Mesh Samples by Social Unit. .78

Table 7. NISP of Fish Taxa Identified from 1/4” Mesh Samples by Social Unit. 79

Table 8. NISP of Fish Taxa from Bulk Samples by Social Unit. .80

Table 9. Approximate Adult Body Size of Fish from the Lower Columbia Identified at

Cathlapotle.

Table 10. Frequency of Sturgeon Specimens Unidentifiable Versus Identifiable to Element, Houses 1 and 4.

Table 11. Frequency of Sturgeon Specimens Unidentifiable Versus Identifiable to Element, House 1 Compartments.

Table 12. Weight (g) of Sturgeon Specimens Unidentifiable Versus Identifiable to Element, Houses 1 and 4

Table 13. Weight (g) of Sturgeon Specimens Unidentifiable Versus Identifiable to Element, House 1

Compartments .86

Table 14. Comparison of Weights (g) of Sturgeon Specimens Identifiable Versus Unidentifiable to Element, Houses 1 and 4. .88

Table 15. Comparison of Weights (g) of Sturgeon Specimens Identifiable Versus Unidentifiable to Element, House 1 Compartments 
Table 16. Comparison of Sturgeon Specimen Weights (g) with Specimens Unidentifiable

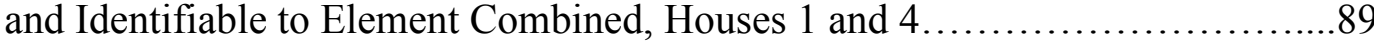

Table 17. Comparison of Sturgeon Specimen Weights (g) with Specimens Unidentifiable and Identifiable to Element Combined, House 1 Compartments...................89

Table 18. Frequencies of Fish Taxa Recovered from Bulk Samples by Screen Size.....115 


\section{List of Figures}

Figure 1. Cathlapotle site location map, showing locations of major historic fisheries in

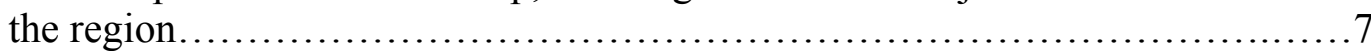

Figure 2. Plan view of Cathlapotle showing locations of houses, compartments, and excavation units.

Figure 3. Frequencies of fish taxa (1/4" mesh screens) within House 1 compartments with raw sturgeon counts, unadjusted for weight.

Figure 4. Frequencies of fish taxa ( $1 / 4$ " mesh screens) within House 1 compartments with sturgeon counts scaled by weight.

Figure 5. Proportion of fish taxa in Houses 1 and 4 ( $1 / 4 "$ mesh screen).

Figure 6. Percent contributions of each fish taxon to total fish assemblage within each house ( $1 / 4 "$ mesh screens).

Figure 7. Percent contributions of each fish taxon to total fish assemblage within each compartment group in House 1 ( $1 / 4$ " mesh screens)....

Figure 8. Percent contributions of chinook versus non-chinook salmon within each house...........................................................96

Figure 9. Percent contributions of chinook versus non-chinook salmon within each compartment group in House 1.

Figure 10. Frequency of fish taxa identified in all analyzed bulk samples (4 mm, $2 \mathrm{~mm}$, and $1 \mathrm{~mm}$ fractions).

Figure 11. Frequency of fish taxa identified in all analyzed bulk samples (4 mm, $2 \mathrm{~mm}$, and $1 \mathrm{~mm}$ fractions), excluding sturgeon fragments and salmon vertebral fragments from the $1 \mathrm{~mm}$ fraction

Figure 12. Percent contributions of each fish taxon to total fish assemblage within each house (bulk sample $4 \mathrm{~mm}, 2 \mathrm{~mm}$, and $1 \mathrm{~mm}$ fractions).

Figure 13. Percent contributions of each fish group to total fish assemblage within each compartment group in House 1 (bulk sample $4 \mathrm{~mm}, 2 \mathrm{~mm}$, and $1 \mathrm{~mm}$ fractions).

Figure 14. Percent of specimens from each fish group with evidence of burning (bulk sample $4 \mathrm{~mm}, 2 \mathrm{~mm}$, and $1 \mathrm{~mm}$ fractions). 
Figure 15. Percentage of burned versus unburned specimens within each house (bulk sample $4 \mathrm{~mm}, 2 \mathrm{~mm}$, and $1 \mathrm{~mm}$ fractions)..............................105

Figure 16. Percentage of burned versus unburned specimens within each compartment group in House 1 (bulk sample 4 mm, 2 mm, and $1 \mathrm{~mm}$ fractions)...............105

Figure 17. Comparison of sturgeon and eulachon contributions within each house (bulk sample $4 \mathrm{~mm}, 2 \mathrm{~mm}$, and $1 \mathrm{~mm}$ fractions)................................107

Figure 18. Comparison of sturgeon and eulachon contributions within each compartment group in House 1 (bulk sample $4 \mathrm{~mm}, 2 \mathrm{~mm}$, and $1 \mathrm{~mm}$ fractions).............107 


\section{Chapter I: Introduction}

Native Northwest Coast societies, from Alaska down to Northern California, are well known for their high levels of cultural complexity in the absence of agriculture. Several fundamental features were shared among the vast diversity of groups who inhabited this region, including high population densities, large residential groups, partial to full sedentism, heavy reliance on aquatic resources (particularly anadromous fish and sea mammals), food storage, ownership of resources or territories, and social inequality marked by material wealth, inherited social rank, and slavery (Ames 1994; Ames and Maschner 1999; Saleeby 1983; 1977; Suttles 1968). The household was the primary social and economic unit throughout the Northwest Coast, and commonly each household had its own internal prestige hierarchy, including a household head or chief, free people of varying ranks, and often slaves. In addition to a household's internal hierarchy, households themselves could hold varying levels of prestige (Hajda 1984, 2013). In this study, I am interested in the relationship between social inequality and resource use, in particular the systems of ownership and power that may have given individuals or households of higher prestige greater access to preferred food resources. I will be examining the possible connection between prestige and resource control through the fish remains from Cathlapotle, a large Chinookan village located in the Lower Columbia River Valley.

One method by which access to resources could have been controlled is resource ownership. Resource ownership was a key feature of Northwest Coast society throughout the region, and this ownership is characterized by considerable variation 
along the coast (Ames 1994, 1995; Richardson 1982). It was generally the important resource patches or procurement sites that were owned, but there was also territory-based ownership, more often to the north in British Columbia and southeast Alaska (Richardson 1982). Resource ownership was most frequently vested in households or kin/local groups, but individual- or village-based ownership also occurred. Richardson argues that in the southern subarea, among the Chinookans and Southern Coast Salish of northwest Oregon and western Washington, village communities owned key resources, fishing sites in particular. However, as Hajda (1984) points out, Richardson's assessment of this area relies primarily on data from the Southern Coast Salish of the Puget Sound region, and ethnographic data on ownership patterns among the Chinookans are particularly limited. The archaeological record may help advance our understanding of ownership where the ethnographic data are lacking.

Ownership of the resource base was not the only means by which access to certain resources could be controlled or limited. Households were the basic economic unit on the Northwest Coast, and, as such, food harvested and processed by household members was expected to be shared within the household. However, foods may not have been shared equally amongst all household members (Ames 1995; Ray 1938; Suttles 1974). Northwest coast chiefs had the power to seize resources produced by their slaves for themselves, and among the Chinook, whose chiefs appear to have had more power than elsewhere on the coast, a chief's control over the distribution of resources within the household may have extended to resources produced by free individuals as well (Ray 1938). 
Faunal studies have great potential for providing information about social inequality because members of different social groups often have differential access to food resources. Faunal studies of prestige and social inequality have been undertaken for prehistoric and historic sites throughout the world (Ashby 2002; Crabtree 1990; Curet and Pestle 2010; Emery 2003; Jackson and Scott 2003; Kirch and O'Day 2003; Peres et al. 2010; Schulz and Gust 1983), including in the Pacific Northwest, where archaeologists have utilized faunal evidence as indicators of prestige at aboriginal village sites (Coupland 2006; Coupland et al. 2003; Gardner-O’Kearney 2010; Huelsbeck 1994; Matson 2003; Moss 1993; Speller et al. 2005; Wessen 1988, 1994). Researchers in the Pacific Northwest have frequently drawn on ethnohistoric accounts to determine the relative value of taxa. Using such data, they have only been able to apply prestige designations either to a limited number of taxa or to relatively broad taxonomic groups, and they have often relied on ad hoc arguments, cherry-picking the prestige information that fits other patterns for the site.

While ethnohistoric accounts have the potential to provide useful information for ranking taxa, they suffer from several shortcomings. Because they are qualitative, comparing between a wide variety of taxa is difficult; these accounts might tell us that a certain food was considered prestigious, but they are less likely to provide information on exactly how prestigious compared to another valued food. In addition, ethnohistoric accounts on resource prestige or preference are usually only available for a limited subset of utilized resources. For example, the $19^{\text {th }}$-century records of fisheries on the Lower Columbia focus primarily on salmon, sturgeon (Acipenser spp.), and eulachon (Thaleichthys pacificus) despite archaeological evidence that the Chinookans utilized a 
broad fish resource base (Butler 1992; Butler and Martin 2013; Boyd and Hajda 1987; Frederick 2007; Martin 2006; Ray 1938; Saleeby 1983).

As an alternative to relying on ethnohistoric accounts and ad hoc arguments, optimal foraging theory provides an independent, quantitative, and universal analytical tool for determining which prey should be preferred and ranking prey based on this preference. In optimal foraging theory, foragers are assumed to rank prey types based on energetic efficiency and base their foraging decisions on these rankings. Because energetic efficiency cannot be measured directly in archaeological studies, researchers often use prey size as a proxy for efficiency, with the largest-bodied prey being ranked the highest (Broughton 1994; Broughton et al. 2011; Griffiths 1975; Schoener 1979). Optimization always occurs within the contextual constraints of both the intrinsic abilities and requirements of the individual and the external natural or social environment (Lupo 2007). For example, resource ownership on the Northwest Coast could have acted as an external control, limiting who had access to high-ranked, preferred prey items.

In this study, I will use the tenets of optimal foraging theory to assign prey ranks to the fish taxa identified at Cathlapotle. Given these prey preferences, my goal is to determine if prestige afforded its bearers greater access to preferred prey. Differential access to preferred prey may have resulted either from differential access to harvesting sites, i.e., through ownership, or from individuals exercising power over the postharvesting distribution of resources. Through my analysis of the Cathlapotle fish remains, I will be exploring whether either of these forms of resource control was operating within the village. Regarding resource ownership, I want to know if there was household-based ownership of fish harvesting sites. Regarding post-harvesting distribution of resources, I 
want to know if the chief or other elites exercised control over the distribution of fish resources within the household.

This thesis is organized into five chapters. In Chapter 2, I discuss Northwest Coast households, social inequality, and resource control, including patterns of resource ownership on the Northwest Coast, with emphasis given to the Chinookan peoples and what is known from the Lower Columbia Valley. I review previous faunal studies of prestige in the Pacific Northwest and introduce Optimal Foraging Theory as a theoretical basis for determining prey preference. Chapter 2 concludes with an introduction to the study site and a review of my project goals and expectations. In Chapter 3, I present the study materials and methods for identification and analysis, and in Chapter 4, I present the results of my analysis, with an emphasis on comparisons across different social units in the village. Chapter 4 includes descriptive summaries of the fish taxa identified in the assemblage. In Chapter 5, I discuss the implications of my results regarding the possibility of a connection between resource control and prestige, summarize my conclusions, and suggest directions for future work. 


\section{Chapter II: Background}

\section{The Chinookans of the Lower Columbia River Valley \\ and the Northwest Coast Household}

Cathlapotle, the study site for this project, was a Chinookan village located towards the southern end of the Northwest Coast culture area in the Lower Columbia River Valley (Figure 1). The Lower Columbia Valley stretches the nearly 200 miles along the Columbia from the river's channel constriction near The Dalles down to its mouth at the Pacific Ocean, including settlements on surrounding tributaries and along Willapa Bay just north of the estuary. This area was home to the Chinookan peoples, named after the Chinooks who lived at the mouth of the Columbia. The Chinookan peoples were connected by proximity and a shared language family but had no unifying political structure. As elsewhere on the Northwest Coast, Chinookan villages were politically independent (Boyd and Hajda 1987; Hajda 1984; Ray 1938; Saleeby 1983; Silverstein 1990; Sobel, Ames, and Losey 2013). 


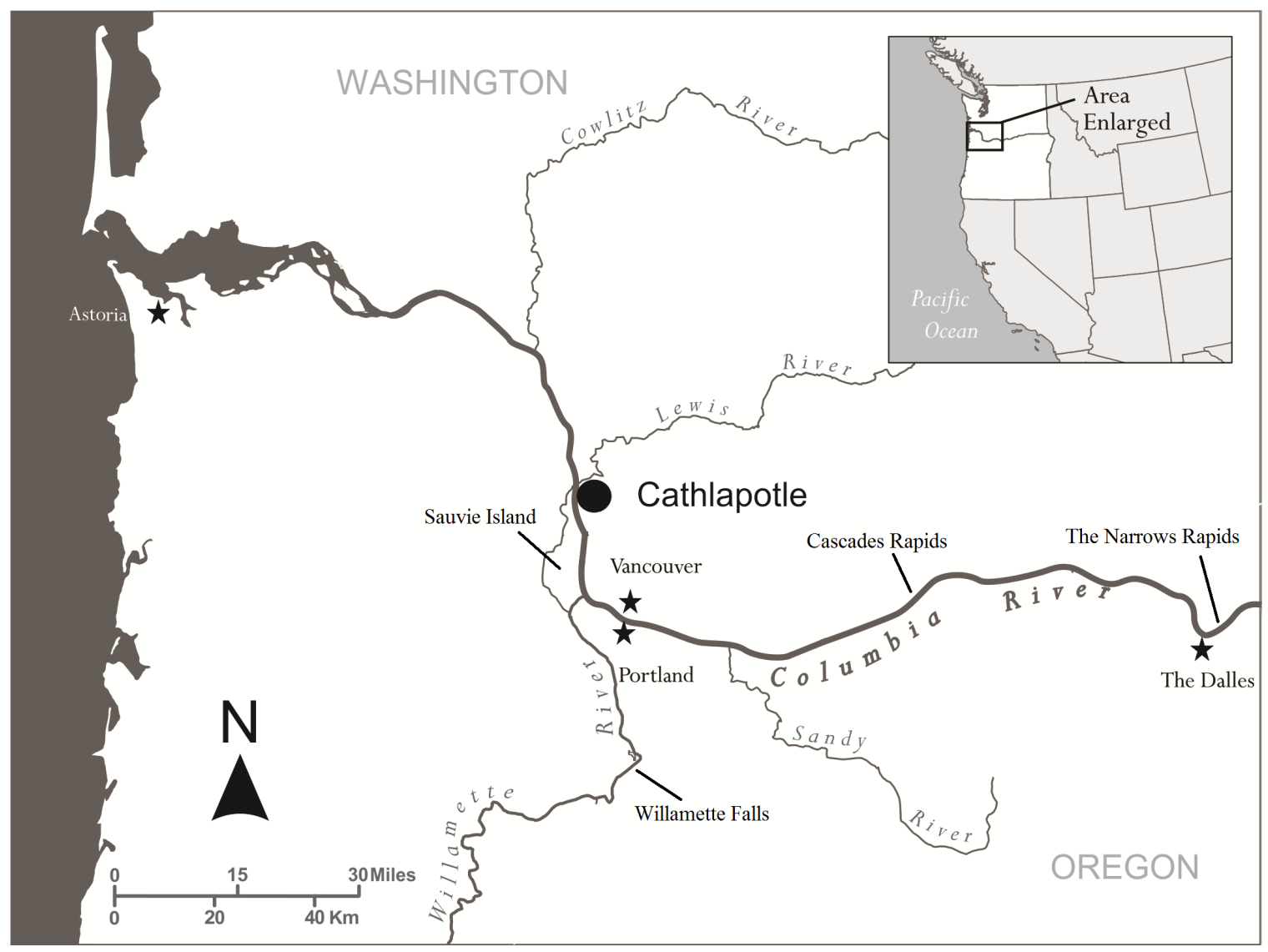

Figure 1. Cathlapotle site location map, showing locations of major historic fisheries in the region (Cascades Rapids, The Narrows Rapids, and Willamette Falls).

Saleeby (1983) divides the Lower Columbia into three useful environmental and cultural zones: the Cascades Zone, which reaches from The Dalles through the Columbia Gorge to the west side of the Cascade Range; the Coast Zone, which reaches from the Pacific east through the Coast Range; and the Portland Basin, which sits between the Coast and Cascade Ranges. This latter productive middle zone is centered around the confluence of the Willamette and Columbia Rivers where the floodplain is flat and marshy. Chinookan villages tended to be located at the mouths of tributaries and were particularly clustered at the major fisheries of Cascades Rapids (near Bonneville Dam), The Narrows Rapids (near The Dalles, including Celilo Falls and Five-Mile Rapids), and 
Willamette Falls (near Oregon City), as well as in the estuarine zone at the coast and around Sauvie Island in the Portland Basin (Boyd and Hajda 1987; Saleeby 1983). Cathlapotle was part of this latter village cluster on the north shore (Washington State side) of the Columbia River, across the river from Sauvie Island and at the mouth of the Lewis River tributary (Figure 1).

The Chinookan village was the primary community in the Lower Columbia Valley. Villages in this region ranged in size from 40 to over 600 individuals and were usually made up of multiple plankhouses, consisting of households of 10 to 100-plus members each (Ames 2008; Ames and Sobel 2013). The average household included three to four nuclear families who, along with their slaves, occupied a single plankhouse and together formed an extended family usually related patrilineally (Ames and Sobel 2013; Hajda 1984; Ray 1938). Use of the cedar post-and-beam plankhouse in this region dates back at least 2,800 years, and the structures themselves were maintained for decades or centuries through the generations (Ames and Sobel 2013; Shepard 2014).

The household was the primary social and economic unit throughout the Northwest Coast. When applied on the Northwest Coast, the term "household" may refer to either of two levels of integration (Matson 2003; Mitchell and Donald 1988). At the smaller scale is the nuclear family along with some attached non-kin such as slaves, which Mitchell and Donald (1988) refer to as the independent household. Multiple independent households that were associated through kin ties combined to create the extended household. The extended household often shared a single large dwelling, with the independent households occupying separate areas, often distinct compartments, of the shared plankhouse. While independent households had some degree of autonomy in their 
economic activities, the extended household, which fits Hayden and Cannon's definition of a residential corporate group, was characterized by close interpersonal bonds and communal life and was the long-term unit of production and consumption (Ames 1994, Hayden and Cannon 1982). The extended household is the unit that most archaeologists refer to when they apply the simple label household, a practice continued here (Gahr et al. 2006).

Each Northwest Coast household commonly had its own internal prestige hierarchy, including a household head or chief, free people of varying ranks, and often slaves. Unlike elsewhere on the Northwest Coast, where chiefs were household chiefs only, the Chinookans had village chiefs. A chief's leadership rights extended over only a single household or, in the case of the Chinookans, a single village (Hajda 2013; Silverstein 1990; Suttles 1968). Households within Chinookan villages differed in prestige, and it is likely that the village chief was the head of the most prestigious household in the village (Hajda 1984, 2013). Archaeological data from sites in the Lower Columbia Valley indicate that while different families within a household may have emphasized particular economic activities, all families, from the highest to the lowest rank, participated in the household production (Ames 2008; Ames and Sobel 2013).

A large part of household production related to food storage, which was central to Northwest Coast life. The reliance of Northwest Coast peoples on storage necessitated complex divisions of labor as well as part- and full-time specialists in order to accomplish the time-constrained simultaneous tasks that go into preserving many foods (Ames and Maschner 1999). The plankhouses themselves, in addition to being places of residence for household members, were food production "factories," where foods were processed, 
cooked, preserved, and stored for winter (Ames and Maschner 1999:147; Ames and Sobel 2013). This centrality of the household — and by extension the plankhouse—in food production held throughout the Northwest Coast.

The plankhouse village is often referred to as the winter or permanent settlement. Chinookan plankhouse villages were permanent in that their locations were fixed on the landscape, but residency was not necessarily year-round. Seasonal movement up and down the river between winter villages and temporary villages or camps is documented in the ethnohistoric literature. This movement was tied to resource availability, often following anadromous fish to important fishing sites such as Cascades Rapids and Willamette Falls (Boyd and Hajda 1987; Ellis 2013; Hajda 1984; Saleeby 1983). This pattern is documented for both the Coast and Cascades Zones, but the mobility pattern in the middle zone is less clear, as ethnohistoric data for the Portland Basin are particularly scarce (Saleeby 1983). Saleeby argues that villages in parts of the Portland Basin, most notably in the vicinity of Sauvie Island, were year-round settlements. The area around Sauvie Island is where Lewis and Clark recorded the highest population density on the Columbia, supported by a diverse, dependable resource base where each season offered a variety of resources exploited by the Chinookans. The Portland Basin villages were also conveniently positioned in a central location for trade between villages at the coast and the Cascades. It is thus likely that long-distance travel to participate in both trade and seasonal resource acquisition was unnecessary for residents of villages centered around Sauvie Island.

The arrival of Euroamericans in the Lower Columbia Valley brought massive changes to the region and had particularly devastating consequences for the Chinookans. 
Direct contact first occurred between Europeans and the Chinookans with the arrival of the maritime Vancouver expedition in 1792, and along with this contact came the earliest ethnohistoric descriptions. Lewis and Clark, whose journey took them through the region between the fall of 1805 and spring of 1806 , provide the most detailed early accounts of the Chinookans. The continental fur trade arrived at the Lower Columbia in 1811, marking the start of a permanent Euroamerican presence in the area (Saleeby 1983; Sobel, Ames, and Losey 2013). Trade was fundamental to the Chinookan economic system prior to Euroamerican contact, but the arrival of the fur trade in the region intensified its importance. Competition among households for control over trade grew, as did household production of goods sought by fur traders. At the same time, European trade items such as glass beads, metal bracelets, and iron daggers became valued as prestige goods (Sobel 2012; Sobel, Ames, and Losey 2013). Social inequalities may have become more pronounced as the prestige and wealth of those leaders who were successful at cornering the market increased (Hajda 1984).

In the early 1830 s, a deadly malaria epidemic broke out in the region, probably originating around Fort Vancouver. It was devastating to the Chinookans, whose population crashed by over 95\% (Boyd 1999, 2011; Saleeby 1983). The Portland Basin, at the heart of the outbreak, was the hardest hit by the epidemic, partially accounting for the scarcity of ethnographic data from this area (Saleeby 1983). Prior to this, the aboriginal population density in the Lower Columbia Valley was among the highest in North America. Lewis and Clark's population figures are considered the best from the early contact period (Ames 2008; Boyd 1999; Hajda 1984; Saleeby 1983). They provided two different estimates, one of 9,800 taken during the fall of 1805 and one of 
17,840 taken during the spring of 1806 (Boyd and Hajda 1987). Boyd and Hajda argue that this difference is due to a springtime influx of visitors from outside the Lower Columbia. Using Lewis and Clark's figures, Boyd (1999) gives a conservative precontact population estimate of 14,000 . Following the 1830 s epidemic, the Chinookan population may have been as low as 175 people (Saleeby 1983 citing Taylor and Hoaglin 1962). The accounts of Chinookans that followed (e.g., Verne Ray's 1938 ethnography of the Chinook) were thus based on informants from a remnant population. Because of this, there are more gaps in our understanding of early historic period aboriginal life on the Lower Columbia than elsewhere on the Northwest Coast—gaps which archaeological data can potentially help close.

\section{Social Inequality on the Northwest Coast}

As Ames and Maschner state, social inequality was a "permanent and pervasive" part of life on the Northwest Coast (1999:177). Northwest Coast societies contained a hierarchy of prestige positions, divided along the line of class into free and slave and containing further divisions within the free class. There has been considerable debate over whether the divisions among the free comprised separate classes or rather a continuous gradation of rank (Ames 1995; Donald 1985; Drucker 1939; Hajda 1984; Ray 1938). Regardless of where they fall in this debate, most scholars distinguish two groups, even if they are not explicitly labeled as classes: chiefs and other elites and commoners.

Northwest Coast society is generally considered to have been ranked within the free class and stratified along the line of free and slave (Ames 1995, Ames 2007, Ames and Maschner 1999, Donald 1985, Fried 1967, Hajda 1984). In his treatise on pre-state 
political organization, Fried (1967) outlines the defining characteristics of ranked versus stratified societies. Unlike egalitarian societies, both ranked and stratified societies are marked by permanent inequalities, but these inequalities take different forms. In ranked societies, there is differential access to positions of valued status, with fewer positions of high prestige than people with the talent to fill them. While positions of high prestige are limited, access to basic resources is equal, as generally are standards of living. Stratified societies also contain a hierarchy of prestigious positions, but additionally "members of the same sex and equivalent age status do not have equal access to the basic resources that sustain life" (Fried 1967:186). Fried specifically delineates slavery as a form of stratification.

This difference in access to basic resources for a ranked versus stratified society can be tied closely to the type of power available to those in positions of high prestige. In ranked societies, leaders have the authority to give commands, but these commands may not necessarily be obeyed; that is, "leaders can lead, but followers may not follow" (Fried 1967:133). Ames $(1995,2007)$ discusses this type of power as "social power," where leaders have the "power to" organize and wield sway. He contrasts this with "tactical/structural power," where leaders have power over subordinates through coercion. Within a stratified society, tactical/structural power is enjoyed by a small group of individuals, while leaders in a ranked society generally do not have this type of power over others.

Northwest Coast chiefs exercised power over slaves and could deprive them of access to basic resources (Ames 1995; Donald 1985). In contrast to the power of chiefs over slaves, chiefs appear to have had little power over free individuals (Ames 1995; 
Ames and Maschner 1999). They could exert influence, but free people could also choose to ignore them. As Ames states, they "had the power to wage war, to conduct trade, to permit outsiders to use resources belonging to the House's estate, to declare the fishing or hunting season open, and to display the House's privileges" (Ames 1995:171), but there is little evidence that they could exercise further power. The power of chiefs came primarily from their estates' resources, as they commanded the production of their households. Owning fertile resources attracted more people to a household, increasing the productive power of the household (Ames 1995; Donald and Mitchell 1975).

Matson (1985) argues that ownership or control of important resources, by creating differential access to those resources, is what led to differences in ascribed (inherited) status and thus was the basis for the development of ranked society on the Northwest Coast. Matson notes that for these inequalities to have been maintained, there must have been continued differential access to controlled resources. Accordingly, we see that the prestige of free individuals on the Northwest Coast — their estimation and standing in the eyes of others (Ames 2007; Henrich and Gil-White 2001) —was dependent on both inherited position and wealth (Ames 1995; Drucker 1939; Ray 1937, 1938). While chief was a hereditary position, the relative prestige of a chief was closely tied to his/her wealth and therefore may have depended at least partially on the richness of the resources within his/her (or his/her household's/kin group's) estate. It was a chief's wealth that made it possible for him/her to exert influence and participate in local and regional exchange systems (Ames 1995; Ames and Maschner 1999; Donald and Mitchell 1975; Drucker 1939; Hajda 1984; Silverstein 1990; Sobel 2004, 2006). 
Chiefs and their close relatives made up the highest stratum of the elite, while below them but still classed among the elite were those more distant relatives of the chief (referred to by Drucker 1939 as the middle class), along with prominent shamans, warriors, and traders (Ames 1995; Ray 1938). Relatively little has been written about commoners in the ethnohistoric literature. Commoners were free people, but they were poor, held no rights within a household, and were dependent on the rich. They were remoter relatives of the household chief, unconnected poor people, and the descendants of favored slaves (Ames and Maschner 1999; Hajda 1984).

Slaves were obtained primarily through trade, raiding, and gambling wagers, and they were held in particularly high numbers among the Chinookans, averaging up to a quarter of village populations along the Lower Columbia (Ames 2008; Hajda 1984; Ray 1938). While they generally were reported to have been well treated, living and working alongside their owners, they were still property and as such could be bought, sold, and killed. As slaves were property and thus a form of wealth, slave ownership was tied to prestige. Slaves made important contributions to the household production, with the most burdensome tasks often falling to them (Ames 2008; Ames and Sobel 2013; Hajda 1984; Ray 1938; Silverstein 1990; Suttles 1974).

Several lines of evidence have been used to recognize social inequality in the archaeological record, including energy invested in burials, nutritional markers on skeletal remains, house size and other architectural patterns, diversity of artifact assemblages, and the presence/absence of recognized status markers (prestige goods) (Ames 2007). For the Northwest Coast, ethnohistoric data and archaeological studies indicate that house size is a good predictor of household prestige (Ames 1996; Ames and 
Maschner 1999; Coupland 2006; Sobel 2006). This is due to several factors connecting houses and the households that inhabited them and the important link between prestige and wealth on the Northwest Coast. Construction of plankhouses was expensive, both in terms of the labor and the supplies required to build them (Ames 2008; Gahr 2006;

Shepard 2014), so greater wealth was required to build a larger house. Larger houses could hold more individuals, meaning more labor with which to harvest resources and produce wealth, and access to more productive resources would also attract more individuals to a household. Finally, larger houses allowed households to host large social and ritual gatherings, which were a means of enhancing prestige.

The layout of houses within a village also can reflect prestige. For example, on the northern Northwest Coast, the highest ranked households were usually located in the middle of the house row and in the front if there was more than one row (Ames and Maschner 1999; Coupland 2006). Likewise, the interior arrangements of plankhouses could reflect prestige differences of household members. In Chinookan plankhouses with open interiors, ethnographic accounts suggest a gradient of higher rank in the back of the house to lower rank in the front (Sobel 2004).

In addition to house size and arrangement, house contents have been important in recognizing prestige differences between and within houses on the Northwest Coast. Researchers have used the presence of rare and exotic non-utilitarian prestige goods such as labrets and dentalia shells to identify the residences of the elite class (Ames 1994; Ames and Maschner 1999; Coupland 2006; Gahr et al. 2006; Grier 2003, 2006). While such indicators can be of value, one limitation to this line of evidence is that their rarity can contribute to sampling problems (Ames 2007). Artifacts need not be rare or 
fundamentally "prestige goods" to be useful in identifying distinctions in prestige. For example, Sobel (2004, 2006), in her study of the Cathlapotle and Clahclellah Chinookan village sites, utilizes obsidian artifacts, which are exotic but also utilitarian and present in households of high and low prestige alike. She argues for a link between greater access to obsidian sources and higher prestige because of the importance of wealth and prestige in creating and maintaining larger exchange networks. Faunal remains are similarly far more abundant than prestige goods and thus less susceptible to issues with sampling error. Moreover, because faunal remains have a shorter use-life than crafted, exotic goods, they are more likely to reflect a finer-grain view of cultural behavior. The value of faunal remains to the study of social prestige has been demonstrated in multiple prehistoric and historic contexts throughout the world (Ashby 2002; Crabtree 1990; Curet and Pestle 2010; Emery 2003; Jackson and Scott 2003; Kirch and O’Day 2003; Peres et al. 2010; Schulz and Gust 1983), including the Northwest Coast (Coupland 2006; Coupland et al. 2003; Gardner-O’Kearney 2010; Huelsbeck 1994; Matson 2003; Moss 1993; Speller et al. 2005; Wessen 1988, 1994). Faunal remains may be particularly relevant to furthering our understanding of prestige dynamics on the Northwest Coast where prestige may have been closely tied to ownership and control of food resources.

\section{Resource Ownership and Control of Resource Distribution}

Resource ownership was a key aspect of Northwest Coast society throughout the region, but this ownership is characterized by considerable variation along the coast, particularly in the resources that were owned, the entity that owned them, and how stated ownership was understood and translated into resource use (Ames 1994, 1995; 
Richardson 1982). As a concept, resource ownership on the Northwest Coast differed from ownership of disposable property such as trade goods or slaves, and resource owners might better be described as resource managers. Functioning more like usufruct rights, resource ownership provided the owning entity with the right to control access to resources (Hajda 1984; Silverstein 1990). Access to a resource can only be controlled successfully if the resource is somehow limited, i.e. geographically and/or temporally, and exercising control is only worthwhile if the resource is abundant and reliable (Matson 1985; Richardson 1982).

In his review of resource ownership along the Northwest Coast, Richardson (1982) notes that it was generally the important resource patches or procurement sites themselves that were owned. Specific fishing sites or fishing streams, especially those for taking salmon (Oncorhynchus spp.), were particularly important and most often subject to ownership. Land-based ownership also occurred, especially in the northern subarea along the coasts of British Columbia and southeastern Alaska, but what such ownership meant in practice varied. Gottesfeld (1994) found that among Tsimshian and Athabaskan peoples in northwestern Canada, land was divided into territories, usually centered around a watershed, and permission from a chief had to be sought by those wishing to pass through or use another household's territory. However, ownership of territories did not always translate into such wide-reaching restrictions on use. Among the Tlingit, for example, all land and water was divided into territories that were owned by kin groups, but non-owners were only excluded from certain resources (Richardson 1982). Whether seated in entire territories or specific procurement sites, ownership of important, productive resources may have been tied closely to prestige. For example, 
Donald and Mitchell (1975) found that among the Kwakwaka'wakw the size of salmon runs within a local group's territory was one of the top predictors of that local group's prestige rank, though Coupland et al. (2001) did not find this to be true among the Tsimshian.

Resource ownership was most frequently vested in households or kin/local groups, but individual- and village-based ownership also existed, and there appears to be a geographic patterning of the owning entity along the coast. Richardson (1982) argues that in the southern subarea, among the Chinookans and Southern Coast Salish of northwest Oregon and western Washington, village communities owned a few key resources, fishing sites in particular. In the central subarea, among the Central Coast Salish of northwest Washington and southwest British Columbia, kin group and community ownership were found in conjunction with one another. For example, Suttles (1974) describes family ownership of clam beds and something more akin to community ownership of deer-net locations and fish weirs. Farther north, ownership was primarily kin group-based.

Individual ownership has been reported in various locations along the coast, but caution should be taken in interpreting the meaning of such stated ownership (Ames 1995; Drucker 1939; Richardson 1982). Individual ownership often translated to ownership in title only, with chiefs owning resources on behalf of their kin groups. In such cases, ownership did not give the individual exclusive use rights, but instead the power to direct the exploitation of the resource. For example, among the Central Coast Salish, ownership of reef net locations was attributed to particular individuals, but these individuals permitted their relatives to fish there (Suttles 1974). According to Richardson 
(1982), true individual ownership was only important in northwestern California, where individual men or a few close relatives often owned specific resource sites such as oak groves and salmon eddies.

From this geographic patterning in resource ownership, Richardson (1982) proposes a gradient of increasing control moving from the south to the north. Relatively loose community-level control prevailed in southern areas (i.e. among the Southern Coast Salish and the Chinookans) and tighter kin group control became progressively more important moving north. Richardson ties this gradient of control to latitudinal variation in the resource base. Moving northward along the coast, terrestrial resource abundance decreases, resources become more clumped and less diverse, and local and seasonal variation increase (Schalk 1977, 1981; Suttles 1974). The connection between latitudinal variation in the resource base and differences in the type/degree of control over the resource base is well illustrated by anadromous fish resources, long acknowledged as particularly important to Northwest Coast groups (Schalk 1977). In the north, especially the far north, anadromous fish species diversity is lower, greater year-to-year fluctuations in their abundances occur, and migrations are more temporally compressed. This temporal compression in particular puts more pressure on increasing the efficiency with which subsistence activities are performed. Schalk argues that this resulted in, among other things, less fluidity of group structure and increased centralization of authority in the group leader. In contrast, the greater stability, diversity, and abundance of anadromous fish resources in the south may have resulted in groups there placing less emphasis on restricting access to resources. 
Richardson's model provides a good starting point for understanding resource ownership on the Northwest Coast, but its weakness is that, in emphasizing broad patterns, it ignores or marginalizes variability within subareas. As Hajda (1984) points out, Richardson's assessment of the southern subarea relies primarily on data from the Southern Coast Salish. Data on ownership patterns among the Chinookans are particularly limited. Hajda convincingly argues that, while village-level ownership of key resources along the Lower Columbia was likely, household and individual control in this region cannot be ruled out. It is also problematic that the picture of resource availability that has been painted pits the abundance of the south against the scarcity of the north. Despite overall greater resource abundance and reliability in the southern subarea, food shortages were still a threat there, indicated by references in the ethnohistoric literature to a lack of food and even starvation among the Chinookans in late winter and early spring (Boyd and Hajda 1987; Ellis 2013; Ray 1938; Saleeby 1983; Suttles 1968; Vibert 1997). It follows, then, that the greater centralization of authority and restriction of access to resources provided by individual or household ownership still may have been relevant in the south.

Ownership of the resource base was not the only method by which access to certain resources could have been controlled or limited. Households were the basic economic unit on the Northwest Coast, and, as such, food harvested and processed by household members was expected to be shared within the household. However, foods may not have been shared equally amongst all household members (Ames 1995; Ray 1938; Suttles 1974). To understand how the distribution of shared food might be directed, I must return to the earlier discussion of power. Chiefs and other household heads had 
the most power when it came to their slaves. While the products of slave labor contributed to the general household pool, slave owners had the power to seize resources produced by their slaves for themselves (Ames 1995). Slave labor made significant contributions to household economies among the Chinookans, with slaves averaging up to a quarter of native village populations along the Lower Columbia (Ames 2008; Hajda 1984). Slave owners thus potentially had direct control over a large portion of their households' food resources.

The power that Northwest Coast chiefs had over the free members of their households and the resources they produced is more ambiguous. As discussed above, chiefs generally only had power to direct the labor of their households, as opposed to being able to coerce free individuals. However, one source (Ray 1938, noted by Ames 1995) does report chiefs exercising coercive power over free individuals and their resources. Citing examples from two Chinookan groups, the Chinook and the Clatsop, Ray argues that Chinookan chiefs were more powerful than chiefs elsewhere along the coast. Ray's informants “repeatedly emphasized [chiefs'] power to appropriate the property of others for personal purposes without regard of the owner" (1938:56). For example, one informant recounts witnessing a chief seizing several sturgeon caught by a lone fisherman, providing no payment in return. This power to appropriate food meant that chiefs and other members of the elite apparently never suffered from famine, as they took food from the lower classes when shortages occurred. Chiefs also did not necessarily need to exercise power over others directly to influence the distribution of food within their households. Ray reports that commoners regularly presented gifts of food to Chinook chiefs, which the chiefs then likely redistributed among the elite. Thus, 
Chinook chiefs (and perhaps Chinookan chiefs more generally) may have had considerable control over the distribution of resources produced by both slaves and free individuals.

\section{Social Prestige-Based Faunal Studies in the Pacific Northwest}

Faunal studies have great potential for providing information about social inequality because members of different social groups often have differential access to food resources. The ubiquity of faunal remains overcomes the sampling problem associated with prestige goods, and beyond this, the importance of food in everyday life means that faunal studies can provide more detailed or nuanced information about the differences between socioeconomic groups. Faunal studies of prestige and social inequality have been undertaken for prehistoric and historic sites throughout the world but most frequently for historic-era North American and European sites (Ashby 2002; Crabtree 1990; Curet and Pestle 2010; Emery 2003; Jackson and Scott 2003; Kirch and O’Day 2003; Peres et al. 2010; Schulz and Gust 1983). Researchers usually take an economic approach relating cost and status. They tend to rely on historic records to know how different animals or meat cuts were valued. Other approaches include taking high species diversity as an indicator of high socioeconomic status and using age profiles of domesticated animals to identify where people had the economic means to raise livestock solely for meat.

Several archaeologists have utilized faunal evidence as indicators of prestige at aboriginal village sites in the Pacific Northwest (Table 1). Three important themes run through these studies. First, researchers have applied prestige designations either to a 
limited number of taxa or to relatively broad taxonomic groups, second, they have most frequently drawn on ethnohistoric accounts to rank taxa, and, third, their arguments about the relative value of taxa are frequently ad hoc (e.g., Coupland 2006; Coupland et al. 2003; Huelsbeck 1994; Matson 2003). While ethnohistoric accounts have the potential to provide useful information for ranking taxa, they suffer from several shortcomings that account for why researchers have only discussed taxa as broad groups or in limited numbers, which I will discuss further below. Researchers who have made ad hoc assertions about prestige analyze the faunal remains first and then search for explanations for how they fit in with other prestige data. This sort of approach is problematic because it is particularly susceptible to circular arguments, and it allows for cherry-picking of the most useful data to support the observed patterns.

Table 1. Synthesis of prestige-based faunal studies in the Pacific Northwest

\begin{tabular}{|c|c|c|c|}
\hline Site & Prey Rank Designations & Support for Designations & References \\
\hline $\begin{array}{l}\text { McNichol } \\
\text { Creek, Prince } \\
\text { Rupert } \\
\text { Harbour, B.C. }\end{array}$ & $\begin{array}{l}\text { Mammals high rank, fish low } \\
\text { rank. Coast deer, dog, and } \\
\text { marine mammals are } \\
\text { identified as feast foods. }\end{array}$ & $\begin{array}{l}\text { Ethnographic accounts of } \\
\text { hunting as an activity for high } \\
\text { rank individuals, of marine } \\
\text { mammals as a prestige food, } \\
\text { and of dog as a ritual food. } \\
\text { Archaeological data connect } \\
\text { high proportions of mammal } \\
\text { with indicators of feasting. }\end{array}$ & $\begin{array}{l}\text { Coupland 2006; } \\
\text { Coupland et al. } 2003\end{array}$ \\
\hline $\begin{array}{l}\text { Shingle Point, } \\
\text { B.C. }\end{array}$ & Green sea urchin high rank. & $\begin{array}{l}\text { Green sea urchin described as } \\
\text { "highly valued," (pg. 96, 100) } \\
\text { but the reason for this } \\
\text { designation is not well } \\
\text { specified, possibly that it is not } \\
\text { available on site and may have } \\
\text { required outside community } \\
\text { connections for access. }\end{array}$ & Matson 2003 \\
\hline $\begin{array}{l}\text { Keatley Creek, } \\
\text { B.C. }\end{array}$ & $\begin{array}{l}\text { Chinook and sockeye salmon } \\
\text { higher ranked than chum and } \\
\text { pink salmon; chinook higher } \\
\text { ranked than sockeye. }\end{array}$ & $\begin{array}{l}\text { Ethnographic accounts of } \\
\text { preference based on taste and } \\
\text { oil content; researcher } \\
\text { intuition based on size, } \\
\text { nutritional benefits, restriction } \\
\text { of access. }\end{array}$ & Speller et al. 2005 \\
\hline
\end{tabular}




\begin{tabular}{|c|c|c|c|}
\hline Site & Prey Rank Designations & Support for Designations & References \\
\hline $\begin{array}{l}8 \text { coastal } \\
\text { Tlingit sites } \\
\text { near Angoon, } \\
\text { AK }\end{array}$ & $\begin{array}{l}\text { Shellfish associated with } \\
\text { poverty, low prestige, and } \\
\text { women by Tlingit and } \\
\text { devalued ethnographically, yet } \\
\text { economically important. }\end{array}$ & $\begin{array}{l}\text { Ethnographic and } \\
\text { ethnohistoric accounts, oral } \\
\text { traditions. Archaeological } \\
\text { data indicate economic } \\
\text { importance of shellfish. }\end{array}$ & Moss 1993 \\
\hline $\begin{array}{l}\text { Meier, OR and } \\
\text { Cathlapotle, } \\
\text { WA }\end{array}$ & $\begin{array}{l}\text { Greater species diversity } \\
\text { (driven by rare species) } \\
\text { associated with high rank. }\end{array}$ & $\begin{array}{l}\text { Ethnographic and } \\
\text { archaeological data. }\end{array}$ & $\begin{array}{l}\text { Gardner-O'Kearney } \\
2010\end{array}$ \\
\hline \multirow[t]{3}{*}{ Ozette, WA } & \multirow{2}{*}{$\begin{array}{l}\text { 1) Easily obtained resources } \\
\text { such as small land mammals } \\
\text { described as low status } \\
\text { relative to large land } \\
\text { mammals and sea mammals. } \\
\text { Halibut associated with high } \\
\text { status household, tied to } \\
\text { ownership of richer resource } \\
\text { area. }\end{array}$} & $\begin{array}{l}\text { 1) None specified regarding } \\
\text { small land mammals. } \\
\text { Ethnographic records indicate } \\
\text { good halibut fishing areas } \\
\text { were owned. }\end{array}$ & $\begin{array}{l}\text { 1) Huelsbeck } 1994 \\
\text { 2) Wessen } 1988 \text {, } \\
\text { 1994 }\end{array}$ \\
\hline & & \multirow[t]{2}{*}{$\begin{array}{l}\text { 2) Ethnographic and historic } \\
\text { records of shellfish as low } \\
\text { prestige food. }\end{array}$} & \\
\hline & $\begin{array}{l}\text { 2) High quantities and species } \\
\text { diversity of shellfish } \\
\text { associated with low rank, } \\
\text { reflecting wider and more } \\
\text { systematic exploitation. }\end{array}$ & & \\
\hline $\begin{array}{l}\text { Dionisio Point, } \\
\text { B.C. }\end{array}$ & $\begin{array}{l}\text { Abundances of extralocal } \\
\text { salmon indicate relatively } \\
\text { large distribution networks } \\
\text { and thus large, high ranked } \\
\text { households. }\end{array}$ & $\begin{array}{l}\text { Ethnographic and historic } \\
\text { records of regional movements } \\
\text { and interactions in the Gulf of } \\
\text { Georgia. }\end{array}$ & Grier 2003 \\
\hline $\begin{array}{l}\text { Bridge River, } \\
\text { B.C. }\end{array}$ & $\begin{array}{l}\text { Mammals high rank, fish low } \\
\text { rank. Ungulates, particularly } \\
\text { deer, and sometimes dogs } \\
\text { noted as favored. }\end{array}$ & $\begin{array}{l}\text { Ethnographic records of } \\
\text { mammals being sought as } \\
\text { relief for the "monotony of } \\
\text { dried fish" (pg. 553). }\end{array}$ & Prentiss et al. 2012 \\
\hline $\begin{array}{l}5 \text { village sites } \\
\text { near Lillooet, } \\
\text { B.C. }\end{array}$ & $\begin{array}{l}\text { Mammals and greater dietary } \\
\text { diversity linked to higher } \\
\text { household status. }\end{array}$ & $\begin{array}{l}\text { Taken from models developed } \\
\text { by Prentiss and Hayden. }\end{array}$ & Harris 2012 \\
\hline \multirow{2}{*}{$\begin{array}{l}\text { Tebenkof Bay, } \\
\text { southeast AK }\end{array}$} & Sockeye salmon high rank* & \multirow{2}{*}{$\begin{array}{l}\text { Ethnohistoric data linking } \\
\text { sockeye salmon stream } \\
\text { ownership to high rank }\end{array}$} & \multirow[t]{2}{*}{ Maschner 1992} \\
\hline & $\begin{array}{l}\text { *Discussion of ranking, but no } \\
\text { sockeye identified in study. }\end{array}$ & & \\
\hline
\end{tabular}

\section{Coupland's analysis of two houses at the Tsimshian McNichol Creek site}

provides a good example for why taking an ad hoc approach to prestige designations is

problematic (Coupland 2006; Coupland et al. 2003). His study draws on multiple lines of

evidence to argue that House $\mathrm{O}$ was a chief's house, particularly focusing on house size,

house location, and evidence of feasting, which would have been the prerogative of the 
elite. In House $\mathrm{O}$, a large majority of the faunal material is mammal, with fish making up the remainder. In the lower ranked House $\mathrm{D}$, this pattern is reversed. House $\mathrm{O}$ also contains the only identified marine mammal bones at the site. A high proportion of mammal bones in House $\mathrm{O}$ was found in association with a large hearth, which Coupland argues was a feasting hearth. He states that "the large hearth in House O, the high proportion of mammal remains in the hearth and in this house, and the high rate of burning of these remains all indicate special preparation, consumption, and discard consistent with the practice of feasting. The main feast foods appear to have been mammals, especially deer [Odocoileus sp.] and dog [Canis sp.], and, more rarely, marine mammals" (2006:91). Here, Coupland is offering the presence of mammals in the hearth as evidence that it was a feasting hearth at the same time that he takes their presence in the hearth as a way to identify them as feast foods.

Coupland does, after associating mammals with feasting through their presence in the hearth, draw on outside ethnographic evidence to support the argument that mammals were associated with the elite. Marine mammals and perhaps dogs were identified ethnographically as prestige foods, while hunting in general was noted as an activity for high status people. This ethnographic evidence helps relieve some of the circularity in Coupland's argument, but his use of it as an ad hoc explanation is still problematic. Instead of starting with expectations for how high prestige might be expressed in the faunal remains, Coupland finds ethnographic data to explain how the observed faunal remains support the hypothesis that House $\mathrm{O}$ was the chief's house. This allows him to select the ethnographic data that suit. For example, Coupland chooses not to explore ethnographic data on fish even though salmon, which itself has been identified in other 
contexts as an important food tied to prestige (Donald and Mitchell 1975, 1994), make up the majority of fish in House D.

This points to one problem inherent in using ethnohistoric data to develop relative rankings of taxa, which is the qualitative nature of the data. These accounts might tell us that a certain food was considered prestigious, but they are less likely to provide information on exactly how prestigious compared to another valued food. Speller et al. (2005) encounter this problem when attempting to determine the relative prestige of multiple salmon species for their aDNA study of salmon vertebrae from Keatley Creek. They first establish that, ethnographically, chinook (O. tshawytscha) and sockeye $(O$. nerka) were preferred over pink (O. gorbuscha) and chum (O. keta) because of their high oil content and rich taste. (Note that throughout this paper, the uncapitalized "chinook" refers to the salmon species, and the capitalized "Chinook" or "Chinookan" refers to the native peoples.) However, this information is irrelevant to the prestige comparisons that the authors wish to make because pink and chum turn out to be absent from their sample. The ethnographic information on preference appears to be less helpful for comparing within the already high-ranked species, so the authors are forced to improvise new arguments to rank chinook above sockeye, drawing on, for example, their own intuition that ease of access would be a determinant of the relative prestige associated with the species.

If we wanted to expand this sort of finer-scale comparison used by Speller et al. to even more taxa, the development of relative prestige rankings based on ethnographic accounts of preference becomes even more complicated. In Coupland's study, were the salmon in House D really less prestigious than all of the mammals in House O? 
Huelsbeck (1994) ranks small land mammals as low prestige relative to large land mammals and sea mammals. Where might salmon fit within these different categories of mammals? Huelsbeck also ranks halibut (Hippoglossus stenolepis) as a high prestige food, yet he does not consider how they might measure up against the different groups of mammals. Furthermore, where would the green sea urchin (Strongylocentrotus droebachiensis), which Matson (2003) associates with high prestige, fall within these other high prestige foods? Making such comparisons of numerous taxa using the type of prestige information available in the ethnohistoric literature would be a convoluted undertaking at best. Instead of attempting it, Pacific Northwest faunal analysts have chosen to side-step the issue by limiting their discussions of prestige to only a few taxa or ignoring finer distinctions and keeping their discussions to broad taxonomic groupings that could be based on overgeneralizations of the ethnographic data.

Another reason that ethnographically-derived prestige rankings either have been applied to just a few taxa or overgeneralized to large groups is that this sort of information is available for only a limited subset of utilized resources. The degree to which certain taxa were discussed in the ethnohistoric record, and the nature of this discussion, may have been influenced by the biases of the Westerners keeping the records (e.g., see Vibert 1997) as well as the biases of native peoples themselves. The use of shellfish among the Tlingit provides a good illustration of the strong influence biases can have on the reporting of subsistence practices. The ethnographic record is sparse in its discussion of Tlingit shellfish utilization, while the abundant shellfish deposits found in the archaeological record reveal a clearer picture of its dietary importance. Moss (1993) argues that the Tlingit's negative attitudes towards shellfish, which influenced their own 
self-reporting, as well as the gender biases of the anthropologists, who viewed women's economic contributions as relatively unimportant, together led to shellfish use being underreported and economically devalued in the ethnographic record.

The $19^{\text {th }}$-century records of fisheries on the Lower Columbia provide a salient example of how underreporting can be problematic for applying prestige designations to archaeological assemblages. These records focus primarily on anadromous salmon, sturgeon (Acipenser spp.), and eulachon (Thaleichthys pacificus) despite archaeological evidence that the Chinookans had an "extraordinarily rich and complex fishery" (Butler and Martin 2013:105, also see Boyd and Hajda 1987; Martin 2006; Ray 1938; Saleeby 1983). Resident freshwater fishes such as minnows and suckers (Cypriniformes) are nearly absent from the historic literature, yet these taxa rank first in abundance among fishes in many archaeological assemblages in the region (Butler 1992; Butler and Martin 2013; Frederick 2007). The personal preferences and concerns of the early explorers and fur traders help account for the disproportionate attention paid to the anadromous fish species in the literature, as these were the trade foods that were important to the Euroamericans who were keeping the written records. Because the information on minnows and suckers available in historic accounts is limited, determining their relative prestige based only on these records would necessitate making the potentially problematic conjecture that a lack of coverage in the literature is equivalent to a lack of prestige. Furthermore, caution should be taken in extending the values placed on certain taxa in these historic accounts back through time, as the impact that Euroamericans had on trade resulted in new economic parameters for value (Grier 2007) and might have influenced the preferences of the native groups themselves. 
Despite it being the primary source of ranking data for Pacific Northwest archaeologists who have examined prestige through faunal remains, the ethnohistoric record is a problematic source of data if we wish to apply prestige designations to the entire suite of taxa encountered in an archaeological assemblage. Any archaeologist relying on ethnohistoric data to build an argument must grapple with the problems I have touched on here regarding biases in the record and relevance through time (Ames 1991; Ford 1989; Grier 2007). Yet even if we are able to accept the data as accurate and relevant, we are met with further impediments to using these data to apply prestige designations, as the qualitative accounts are not well suited to the task of ranking a variety of taxa, and accounts likely will not be available for all of the taxa in question.

\section{Optimal Foraging Theory}

As an alternative to relying on ethnohistoric accounts and ad hoc arguments, optimal foraging theory provides an independent, quantitative, and universal analytical tool for determining which prey should be preferred and ranking prey based on this preference. Optimal foraging theory was developed within the framework of behavioral ecology, which examines the fitness-related behavioral choices that organisms make as adaptations to particular environments (Bird and O'Connell 2006; Smith and Winterhalder 1992). To behavioral ecologists, organisms are marked by behavioral flexibility, and the localized environment is central to determining individual behavior. Human behavioral ecology in particular posits that humans have been shaped by biological evolution just like any other organism, so natural selection and ecological adaptation should be central to understanding much of human behavior (Smith and 
Winterhalder 1992; Winterhalder and Smith 1992). Optimal foraging theory, which considers foraging decisions in the context of biological evolution and adaptation, was originally developed in the context of non-human organisms. Applications to human hunter-gatherers first appeared in the early 1980s, and the theory has since been applied extensively in both ethnographic (Bird et al. 2009; Hawkes et al. 1982; Hill et al. 1987; Kaplan and Hill 1985; Smith 1991; Winterhalder 1981a) and archaeological (Broughton 1994, 2002; Butler 2000; Butler and Campbell 2004; Cannon 2000; Etnier 2007; Lyman 2003; Nagaoka 2002a, 2002b, 2005) studies.

The basic tenet of optimal foraging theory is that, sustenance being essential to an organism's survival, natural selection should favor those organisms that optimize their foraging behavior (Smith and Winterhalder 1992; Winterhalder 1981b). Optimization of food returns is tied to fitness, or the maximization of survival and reproduction (Durham 1981; Smith and Winterhalder 1992). Natural selection acts on the phenotype, which is shaped by a variety of factors in addition to genes, but there must be some sort of underlying heritable component that is passed from parent to offspring for natural selection to favor a trait such as optimization; that is, for differential reproductive success to lead to the spread of optimization in a population (Pierce and Ollason 1987). In order to account for the behavioral flexibility associated with optimization, Bird and O'Connell (2006) describe the heritable genetic difference as variation in the capacity to optimize, thus avoiding the label of genetic determinism and the need to tie specific behaviors to genes. Furthermore, Pyke (1984) notes that the heritable component need not necessarily be genetic; if an organism learns its foraging responses from its parent, the spread of 
those foraging patterns would still be tied to reproductive fitness even if the trait has no genetic basis.

Optimal foraging theory has taken as implicit a direct connection between optimization of foraging and enhanced reproductive fitness based on the common-sense observation that caloric intake should predict reproductive fitness (Bamforth 2002). This assumption has been called into question because the ethnographic data on foraging in modern hunter-gatherers show that there is no connection between hunting optimization, measured as the amount of meat hunters are able to acquire, and the amount of meat hunters and their immediate family members actually consume (Kaplan and Hill 1985; Smith 2004). However, a direct link between optimization and fitness in the present is not necessary for natural selection to have favored optimization in the past. Indeed, given the complexity of human social learning and cultural transmission processes that no longer confine transmission to parent to offspring, it is more likely that a tendency towards optimization was shaped in the past through a connection between reproductive fitness and foraging choices, while cultural transmission processes are responsible for its continued occurrence, with the optimal choices becoming the culturally preferred choices (Richerson and Boyd 2005).

What in particular is optimized during foraging, referred to as the currency, is a crucial question that must be addressed because different currencies can lead to different foraging decisions. Ethnographic studies of modern hunter-gatherers are instructive here because they allow the currency to be measured directly and thus evaluated in terms of how well foragers actually optimize that currency (Bird et al. 2009; Hawkes et al. 1982; Hill et al. 1987; Kaplan and Hill 1985; Smith 1991; Winterhalder 1981a). The currency 
of choice for most optimal foraging studies is energetic efficiency, or caloric returns relative to the amount of time invested (Broughton 1994; Nagaoka 2002a, 2002b; Smith 1983). Energetic efficiency is thought to be the crucial currency because time spent foraging is time that cannot be allocated to other activities that may be important to survival and reproduction (Smith 1991). Other possible currencies, such as specific nutrients (Hill et al. 1987; Pyke 1984) and risk minimization (Bird et al. 2009; Winterhalder 1981b), have been considered in optimal foraging studies but to a much lesser degree, perhaps because they are thought to be less crucial or simply are more difficult to measure. Ethnographic studies do confirm that, while not necessarily the sole currency driving foraging decisions, there is indeed a general trend towards optimization of energetic efficiency.

Modeling Optimal Foraging Decisions

Optimal foraging theory uses models to predict which prey items should be selected from the environment (Charnov 1976; Winterhalder 2001). The prey choice model, also referred to as the diet breadth model, creates predictions about whether or not a forager will pursue a prey item when it is encountered (Bird and O'Connell 2006; Broughton 1994; Smith 1983). Foragers are assumed to rank prey types based on postencounter return rates of the currency. When energetic efficiency is the currency under consideration, as it is most frequently, post-encounter return rates are measured as energy gain per unit handling time, with handling time being the post-encounter pursuit plus processing times. While actual energetic returns can be measured directly in ethnographic studies of foraging behavior, this direct measurement is not possible in zooarchaeological studies. Therefore, researchers often use prey size as a proxy for 
energetic efficiency, with the largest-bodied prey being ranked the highest (Broughton 1994; Broughton et al. 2011; Griffiths 1975; Schoener 1979). I will consider the degree to which prey size is a useful proxy measure further below. Prey rankings say nothing about the quantitative importance of items in the diet, as high-ranked items may be rarely encountered and thus represent a small proportion of the diet; rankings only determine if a prey item will be taken on encounter and what order prey items are likely to enter and leave the diet (Hawkes et al. 1982).

The prey choice model predicts that the highest-ranked prey item is always taken on encounter, while whether or not a lower-ranked prey item is taken is dependent not on its own abundance but on the abundances of higher-ranked prey (Bird and O'Connell 2006; Broughton 1994; Nagaoka 2002a, 2002b). Search costs decrease as prey types are added to the diet in order of descending rank because encounter rates with prey within the diet increase. At the same time, the addition of lower-ranked prey items leads to an increase in handling costs, and the point of intersection between decreasing pursuit costs and increasing handling costs is the hypothesized optimal diet (Smith 1983). One prediction of a diet based on optimized return rates is that any prey item that takes more time to catch or collect and process than it would take to continue foraging and find another prey item with higher post-encounter return rates should be passed up (Hill et al. 1987; Smith 1991). However, it is important when considering the optimal diet to remember that this is an ideal only, and in practice optimization is not absolute. Optimization must be considered within the contextual constraints of both the intrinsic abilities and requirements of the individual and the external natural or social environment 
(Lupo 2007). For example, resource ownership on the Northwest Coast could have acted as an external control, limiting who had access to high-ranked prey.

One important stipulation of the prey choice model is the fine-grained search assumption, which is that the spatial distribution of prey types are assumed to be homogenous, and the chance of encountering any one prey type is independent of the chance of encountering any other (Broughton 1994; Butler and Campbell 2004; Nagaoka 2002a, 2002b; Smith 1983). It is unlikely that this assumption holds in practice, as humans tend to forage for clumped resources in heterogeneous environments. If people encounter multiple patches during foraging, prey choice may be determined by patch-use decisions, not just prey rank (Bird and O'Connell 2006; Charnov 1976). To get around this problem, prey taxa may be separated into resource patches, and foraging efficiency is analyzed within each patch separately (e.g., Bird et al. 2009; Broughton 2002; Butler 2000; Butler and Campbell 2004; Nagaoka 2002a, 2002b, 2005; Smith 1991). Patches may themselves be ranked for foraging efficiency, based on the prey found within them and/or their distance from the home base. It may be difficult to define distinct patches because many taxa crosscut environmental zones. Therefore, researchers have tended to define patches broadly and create patches based on human hunting behavior or characteristics of prey. For example, Nagaoka (2002a, 2002b, 2005) examines inland, coastal, and offshore patches, while Broughton (2002) creates separate patches for terrestrial mammals, estuarine fishes, and waterfowl.

Resource Depression and Resource Management

Because optimal foraging theory predicts that, either within the context of discrete patches or not, high-ranked prey are always taken on encounter, these high-ranked prey 
are particularly susceptible to depletion. Applications of optimal foraging theory in archaeological studies have centered around testing for this phenomenon, known as resource depression, as they provide the time-depth necessary to examine changes in resource abundance. Resource depression occurs when the activities of a predator, such as humans, lead to reduced abundance or availability of prey species. Resource depression is usually the result of overharvesting, also termed exploitation depression, but it is also possible that reduced availability may result from microhabitat relocation or behavioral changes in the prey species as it adopts more cryptic behavior to avoid predation (Charnov et al. 1976; Nagaoka 2002a, 2002b). Optimal foraging theory predicts that, given high enough population pressure and adequate harvesting technology, depression of high-ranked prey species should occur.

Relative abundance indices are ubiquitous in archaeological studies utilizing optimal foraging theory as a means of testing for and measuring resource depression (Broughton 1994, 2002; Butler 2000; Butler and Campbell 2004; Nagaoka 2002a, 2002b, 2005). These indices take the form of the number of identified specimens (NISP) of high-ranked prey/NISP of high-ranked + NISP of low-ranked prey, with values ranging from 0 to 1 . Results close to 1 indicate predominance of high-ranked prey in the assemblage, while smaller numbers indicate more low-ranked prey. Lower-ranked prey should increase in importance in the diet only if higher-ranked prey decline in abundance, so a decrease in the abundance index over time could indicate human-induced resource depression. However, a variety of factors other than resource depression could also explain such a change. Factors that could lead to a decrease in abundance indices in the absence of resource depression include technological changes that make the capture of 
low-ranked prey more efficient, environmental changes that affect resource abundance, and changes in foraging and land-use strategies that operate independently of resource abundance, such as a switch to a less mobile settlement pattern that involves utilizing fewer prey species more intensively (Broughton 1994, 2002; Butler and Campbell 2004; Grayson and Cannon 1999; Nagaoka 2002b).

Most archaeologists testing for human-induced resource depression have indeed found evidence of the depression of high-ranked prey as predicted by optimal foraging theory (Broughton 1994, 2002; Butler 2000; Cannon 2000; Nagaoka 2002a, 2002b, 2005). Exceptions to this rule (e.g., Butler and Campbell 2004; Etnier 2007; Lyman 2003) provide interesting opportunities for examining what particular conditions are responsible for expectations not being met. For example, in their review of faunal data from 63 archaeological sites in the Pacific Northwest spanning over 7,500 years, Butler and Campbell (2004) find no evidence for resource depression despite high population densities and effective harvesting technology. Instead, the data indicate long-term stability. Butler and Campbell divide the study area into two regions, the coastal zone of the south-central Northwest Coast and the arid interior Northern Columbia Plateau. On the coast, fish dominate the assemblage. Salmon are the high-ranked fish taxa, and the salmonid index comparing salmonid NISP to the NISP of all other fish taxa does not suggest depression of salmon. Salmon abundance varies across sites within particular time periods but shows relative stability across time, while cervids, representing the largest-bodied mammal family in the terrestrial patch, actually increase in abundance through time relative to smaller mammals. On the plateau, both salmon abundance relative to other fish and artiodactyl abundance (including cervids) relative to smaller 
mammals likewise increase through time. Thus, the data indicate that people throughout the Pacific Northwest were utilizing high-ranked prey over thousands of years with no indication of resource depression, even in the face of population increase.

Management, tied to resource ownership, may have been of primary importance in preventing the depression of the high-ranked prey (Butler and Campbell 2004; Campbell and Butler 2010a, 2010b). In the terrestrial patch, anthropogenic burning maintained and expanded cervid habitat, while elimination of competing predators would have allowed humans to increase their take without increasing overall pressure on artiodactyl populations (Butler and Campbell 2004). For the fish, Campbell and Butler (2010a) explore a variety of factors that could have contributed to the non-depression of salmon. While a flexible, broad-based diet likely helped, they argue that social institutions and beliefs were of primary importance in the sustainable use of salmon over thousands of years in the face of high population densities, heavy reliance on salmon, and effective harvesting technology capable of wiping out natural resources. In support of this, ethnographic and oral tradition literature contain numerous examples of harvest regulations, beliefs, and ritual practices that put constraints on salmon harvesting and would have contributed to resource conservation (e.g., Haggan et al. 2006; Johnsen 2001; Jones 2002; Trosper 2002). Ownership of salmon capture locations would have limited fishing access, while harvest timing and intensity were moderated by a central decisionmaking process, turning an open-access resource potentially susceptible to overexploitation into a managed, common-pool resource.

Salmon make a good candidate for a common-pool resource because they are temporally and spatially bounded, making it possible for an individual or group to control 
access to salmon runs and limit their harvest. As I discussed previously, the ethnohistoric data indicate that valuable fishing sites were indeed subject to ownership, and the owners could choose to exclude others from using these sites (Haggan et al. 2006; Richardson 1982; Trosper 2002). Reports of Nuu-Chal-Nulth groups removing chiefs when salmon runs failed indicate that, at least among some groups, continued ownership may have been contingent on proper management (Trosper 2002). Ownership of salmon procurement sites and the management systems tied to this ownership are an example of an external constraint on foraging optimization that limited the degree to which this highranked prey could be harvested.

\section{Using Prey Size to Rank Prey}

As mentioned above, energetic returns cannot be measured directly in archaeological studies, so zooarchaeologists have used body size as a proxy for energetic returns, with the largest prey being assigned the highest ranks (Broughton 1994; Butler 2000; Nagaoka 2002a, 2002b). A link between size and prey rank is apparent in many of the prestige-based faunal studies discussed above (Table 1). For example, Speller et al. (2005) rank chinook salmon above the smaller chum, pink, and sockeye; Huelsbeck (1994) ranks large land mammals above small land mammals; and multiple researchers (Coupland 2006; Coupland et al. 2003; Prentiss et al. 2012) rank mammals above fish, which are generally — though not always — smaller than mammals. However, this incorporation of size into ranking is never explicitly tied to optimal foraging theory in these studies.

Broughton (1994) describes the conceptual link between prey size and energetic returns as follows: the largest prey provide the most total calories, and the added pursuit 
and processing time linked to larger size are only high enough to counter the added calories for extremely large prey. Broughton et al. (2011) found that this proposed correlation between body size and energetic returns is supported in a majority of ethnographic studies. However, there are particular circumstances under which this correlation may not hold. For example, Bird et al. (2009) found size to have no predictive value for energetic returns because larger prey tended to be highly mobile and thus had higher pursuit times.

Clumped resources are another case in which the positive correlation between prey size and energetic returns may not hold. The prey choice model assumes that the chance of encountering any one prey item is independent of the chance of encountering any other, but this assumption does not hold when individuals of a single prey type are clumped. Post-encounter return rates are generally thought to be independent of prey abundance, but when prey are clumped and can be taken en masse, post-encounter return rates may actually be highly density-dependent (Madsen and Schmitt 1998). If postencounter return rates are indeed density-dependent, then the decision about whether or not to take a clumped low-ranked prey may be based on the abundance of that prey, and not just the abundance of higher-ranked prey as the prey choice model posits.

In their study of Late Holocene occupations in Utah, Madsen and Schmitt (1998) found evidence that grasshoppers, a small and supposedly low-ranked prey, were taken preferentially over larger prey such as artiodactyls at times when they became available in dense patches that accumulated on beaches. They convincingly argue that when clumped resources can be taken en masse, the mass of prey should be considered a single prey item and prey rank should be recalculated accordingly. Hawkes et al. (1982) 
likewise believe that foraging decisions made by the Ache regarding small species found in clumps, such as oranges and palm larvae, are better understood when their return rates are calculated for the resource clump as a single entity.

It should be kept in mind, though, that the presence of clumped prey may not necessarily result in an increase in post-encounter return rates if the cost of technology needed to procure the prey en masse is high. Ugan et al. (2003) show that the amount of time needed to create net technology in order to mass-harvest fish would increase handling time so much that a threshold of amount harvested using a particular net must be reached before mass harvesting becomes efficient. Thus, the amount of time invested in harvesting technology may reduce the energetic benefit of resource clumping, but if nets can be reused and repaired through many uses, the amount of time invested in making the net relative to the volume of fish harvested could become negligible.

While energetic returns are primarily determined by prey size, other factors can affect the energetic efficiency of resource harvesting. Because of this, energetic return rates should be examined carefully on a case-by-case basis. When determining the prey ranks of fish resources found at Cathlapotle, prey size will be the primary factor, but I will need to consider resource clumping and harvesting technology as well.

\section{Site Description}

The Cathlapotle archaeological site (45CL1) is located on the grounds of the Ridgefield National Wildlife Refuge in southwest Washington State approximately $1 \mathrm{~km}$ south of the confluence of the Lower Columbia and Lewis Rivers (Figure 1). Cathlapotle was a large, multi-plankhouse Chinookan village with a low-end population estimate of 
666 people (Ames 2008). The village was occupied continuously, probably year-round for roughly 400 years, from ca. 1450 C.E. into the 1830s C.E. (Ames and Sobel 2009). It was first observed by members of the Vancouver expedition in 1792 and described in some detail by Lewis and Clark on their 1805-1806 expedition (Boyd 2011; Hajda 1984). Attempts by archaeologists to relocate the site of the historically-documented village began in the 1940s, but site 45CL1 was not confirmed as the location of Cathlapotle until the 1990s. Anan Raymond of the U.S. Fish and Wildlife Service instigated this latter search for the village site, which was led by Dr. Kenneth M. Ames in 1991. In cooperation with the U.S. Fish and Wildlife and local tribes, the site was excavated under the direction of Dr. Ames by the Portland State University field school between 1992 and 1996.

Six plankhouses were identified during excavation, as well as several middens and debris fields. Houses 1 and 4 were the most extensively excavated houses and are the focus of my thesis (see Table 2 for excavated areas and volumes within Houses 1 and 4). House 1 is the largest, measuring $63 \mathrm{~m} \mathrm{x} 10 \mathrm{~m}$, and is divided into four subdepressions by low ridges running perpendicular to its long axis. These ridges were walls separating the house into compartments, labeled Compartments H1a through H1d. Figure 2 shows the locations of the houses, compartments, and excavation units. Only Compartments H1b, H1c, and H1d were excavated. House 1 excavations were focused primarily on Compartment H1d, and excavations in Compartment H1b were particularly minimal (Table 2). House 4 is considerably smaller than House 1, measuring $13 \mathrm{~m}$ x $8 \mathrm{~m}$, and consists of a single compartment. Large subfloor pit complexes used primarily for food storage were identified within both houses (Ames 2008). Strata have been identified 
as pre- or post-contact based on the presence/absence of Euroamerican trade goods in the deposits, and strata within the houses are primarily post-contact, likely due to cleaning practices that moved deposits from within the houses to outside middens (Ames and Sobel 2009; Ames personal communication).

Table 2. Surface Area $\left(\mathrm{m}^{2}\right)$ and Volume $\left(\mathrm{m}^{3}\right)$ Excavated from each House/Compartment.

\begin{tabular}{ccc}
\hline House Unit & $\begin{array}{c}\text { Surface Area } \\
\text { Excavated }\end{array}$ & $\begin{array}{c}\text { Volume } \\
\text { Excavated }\end{array}$ \\
\hline House 1 & 88 & 87.97 \\
H1b & 8 & 6.68 \\
H1c & 16 & 12.6 \\
H1d & 64 & 68.69 \\
House 4 & 40 & 43.31 \\
\hline
\end{tabular}




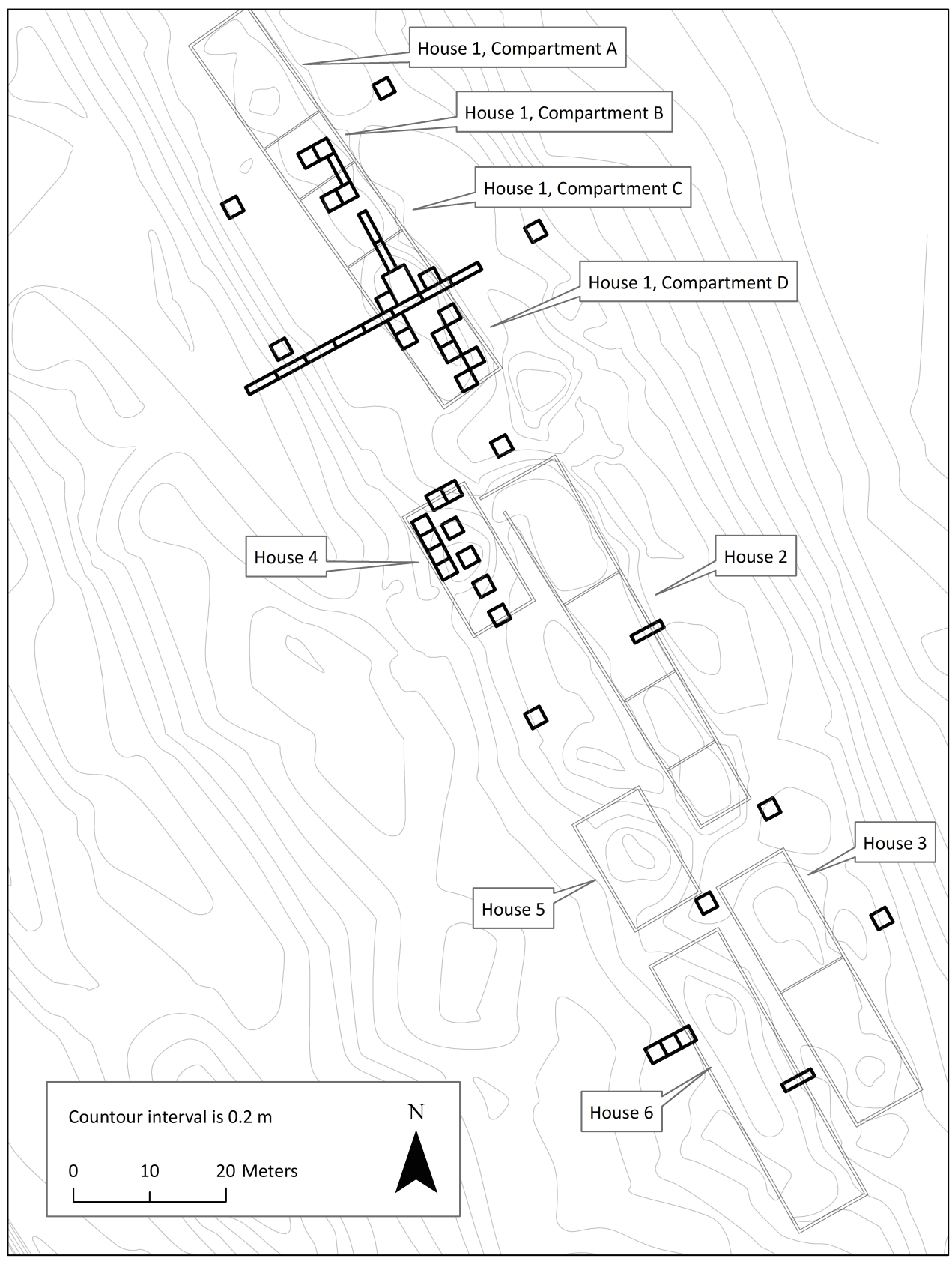

Figure 2. Plan view of Cathlapotle showing locations of houses, compartments, and excavation units. Map by Emily Shepard.

\section{Relative Prestige at Cathlapotle}

In this study, I consider relative prestige at two levels: between Houses 1 and 4 and between the compartments within House 1. Several independent measures have been 
used previously to assign prestige designations (Sobel 2004, 2006; Ames and Sobel 2009). House 1 is considerably larger than House 4, and, as discussed above, ethnohistoric data and archaeological studies indicate that house size is a good predictor of household prestige on the Northwest Coast. House 4 is also located at a lower elevation in a more flood-vulnerable area of the village, and this inferior position makes it unlikely that elites occupied this house. In addition, prestige goods (including two iron knives and stone beads) were found within Compartment H1d, while few prestige goods were recovered from House 4 (Ames and Sobel 2009). The presence of these prestige goods in House 1, along with its larger size, indicate that elites likely lived in this house. Thus, House 1 has a higher prestige designation than House 4.

In comparing between compartments within House 1, size is again a useful measure of prestige (Sobel 2004, 2006). Compartment H1d, measuring $18.7 \mathrm{~m}$ x $10.0 \mathrm{~m}$, is much larger than any of the other House 1 compartments. Compartment H1b measures $6.6 \mathrm{~m} \times 10.0 \mathrm{~m}$, and Compartment H1c measures $11.3 \mathrm{~m} \times 10.0 \mathrm{~m}$. While the cache of prestige goods mentioned above was found in Compartment H1d, prestige goods were absent from the other compartments within House 1. Because of the presence of these prestige goods in Compartment H1d, Ames (personal communication) believes that this compartment is the likely residence of the village chief, along with other elite members of the chief's household. Compartments H1b and H1c likely were occupied by household members of lower rank. Thus, Compartment H1d has a higher prestige designation than Compartments H1b and H1c. 


\section{Project Goals and Expectations}

The goal of my project is to use fish remains from Cathlapotle to examine the possible connection between prestige and resource control. Mammal remains from the site have been studied previously, in both a general analysis (Lyman 2002) and an examination of prestige (Gardner-O'Kearney 2010). Gardner-O'Kearney examined mammal remains associated with hearths at Cathlapotle and used taxonomic diversity as an indicator of prestige. Given this criterion, he did not find any prestige-related patterning in the distribution of mammal remains. However, this does not rule out the possibility of prestige-based resource control for the fish. The fish remains from Cathlapotle are well-suited to my purpose because they represent a dominant fraction of the animal bones excavated at the site, and fish (especially salmon and other anadromous taxa) have been widely discussed as a particularly important food resource on the Northwest Coast, subject to ownership and possibly connected to prestige (Donald and Mitchell 1975, 1994; Haggan et al. 2006; Richardson 1982; Ray 1938; Schalk 1977; Trosper 2002).

I have chosen to use optimal foraging theory to create prey rankings for the fish taxa at Cathlapotle because it provides a rule for determining prey preference that, free of the biases and limitations of the ethnohistoric record, can be applied to all of the fish identified at the site. It should be noted that this is not a means of identifying rare "prestige foods" associated exclusively or primarily with individuals of high prestige akin to rare and exotic non-utilitarian prestige goods. Costly signaling theory, which attempts to account for foraging decisions that do not optimize energetic returns, might be more appropriate for addressing such rare foods that are difficult to access or harvest (Bliege 
Bird et al. 2001; Hawkes and Bliege Bird 2002; Smith and Bliege Bird 2000). Instead, I am interested in determining the relative value of foods that are ubiquitous, consumed by most or all village residents but potentially in different proportions. Optimal foraging theory provides a rule for determining that relative value or preference. I want to determine if prestige affords its bearers greater access to the more highly valued, preferred prey. Differential access to preferred, high rank prey may have resulted either from differential access to harvesting sites, i.e., through ownership, or from individuals exercising power over how resources were allocated after harvesting. The prestige designations that have been hypothesized for the houses and compartments using independent measures allow me to take household and compartment prestige as a given and explore how access to fish might be tied to prestige.

As discussed above, the type of resource ownership operating on the Lower Columbia is uncertain. While Richardson (1982) argues that, on the southern coast, key resources were owned by villages, Hajda (1984) notes that data from the Lower Columbia are limited, and household and individual control in this region cannot be ruled out. The archaeological record at Cathlapotle may help clarify this question on level of resource ownership. If there are differences in the distribution of fish resources between the two plankhouses at Cathlapotle, this could indicate household-level ownership of resources. Given the possible connection between resource ownership and prestige (particularly of salmon; see Donald and Mitchell 1975, 1994), I would expect to see more preferred, highly-ranked fish that might be subject to ownership in the more highlyranked house, i.e., House 1, if there is indeed household-level ownership. 
The degree to which elites had power over the distribution of resources within their households is another question that the archaeological record could help answer. In general, chiefs only had power to direct the labor of the free members of their household, but, as discussed above, Chinook chiefs and perhaps Chinookan chiefs more generally may have had more power than elsewhere on the coast, seizing food without payment and redistributing gifts of food among the elite. I want to know if the archaeological record can confirm this relatively high degree of power that Ray (1938) argues for. Were chiefs actually directing the distribution of food to the extent that there were significant differences between the diets of elites and commoners? Within House 1, if there are differences in the distribution of fish resources between the higher-prestige Compartment H1d and the lower-prestige Compartments H1b and H1c, this could indicate chiefly or elite control over post-harvesting distribution of resources within the household. If the chief or other elite members of the household were indeed exercising power over resource distribution within the household, I would expect to see elite individuals taking more of the preferred, highly-ranked fish for themselves.

My specific goals for this project are as follows:

1. I will apply optimal foraging theory to create prey preference rankings for the fish taxa at Cathlapotle. Taking prey size as a general proxy for energetic returns, prey rankings will be primarily based on prey size while also taking into account prey clumping and harvesting technology. 
2. Given these rankings, I will determine if relative household and compartment prestige designations that have been hypothesized previously by independent measures are reflected in the fish remains.

3. I will attempt to answer the following questions about resource control:

a. Regarding resource ownership, was there any household-based ownership of

fish harvesting sites? Could one household restrict resource access of another household within the village?

b. Regarding post-harvesting control over resource distribution, did the chief or other elites exercise control over how fish were allocated within the household? 
Chapter III: Materials and Methods

\section{Sample and Analysis}

Cathlapotle was excavated in $2 \times 2$ and $1 \times 4$ meter units. The excavation protocol at the site changed through the field seasons. During all years, the entire excavated matrix was minimally screened through 1/4" $(6.4 \mathrm{~mm})$ mesh. During 1994 excavations, one quadrant of each excavation unit was additionally screened through $1 / 8$ " (3.2 mm) mesh, with select 1-liter bulk samples water-screened through 1/16" $(1.6 \mathrm{~mm})$ mesh. In subsequent years, bulk samples, usually 10-liters in volume, were taken from all features and one quadrant of each stratum in each unit and water-screened through nested $4 \mathrm{~mm}, 2 \mathrm{~mm}, 1 \mathrm{~mm}$, and $0.5 \mathrm{~mm}$ mesh screens. All constituents of these bulk samples were bagged, dried, and stored for future analysis. The fish remains from the $1 / 4 "$ and $1 / 8$ " mesh were sorted from the other faunal remains and stored at Portland State University. The bulk samples are currently held in curation at Fort Vancouver National Historic Site.

All fish remains recovered from the $1 / 4$ " mesh screens within Houses 1 and 4 were included in this analysis. Fish remains were recovered from all of the 30 excavation units within the houses. Butler (2002) had previously analyzed all or a portion of the $1 / 4$ " mesh fish bones from 16 units within the two houses, and I analyzed the remaining samples. See Appendix A for a breakdown of the units excavated within each house/compartment as well as the fish bone analyst(s) for each unit.

I used Butler's previous identifications as a reference for developing my identification protocol to ensure inter-observer consistency. Each fish specimen was 
assigned to the finest taxonomic category possible using materials available in Butler's reference collection at Portland State University. This reference collection includes multiple specimens from all historically documented fish in the Columbia River Basin (except some of the small Cottus species). Aside from sturgeon, specimens were only identified if the skeletal element could be identified. Sturgeon has a uniquely bumpy and/or woody texture that makes it readily identifiable as such even if the element is unknown.

All specimens were quantified using number of identifiable specimens (NISP). The presence or absence of a landmark was recorded for each specimen. A landmark is a pre-determined, often relatively robust non-repetitive portion of an element. For example, a vertebra has a landmark if at least half of the notochord opening is present. If less than half of the opening is present, the vertebra is recorded as a vertebral fragment. Recording landmark information provides one way of taking differential fragmentation into account.

The sturgeon specimens in the assemblage cover a wide range of sizes, particularly because very small specimens could be identified as sturgeon based on texture alone. To account for this, all sturgeon specimens from the $1 / 4 ", 4 \mathrm{~mm}$, and $2 \mathrm{~mm}$ mesh were weighed as an additional means of quantification, with weight standing as a proxy for size. These weights were measured to the nearest $0.01 \mathrm{~g}$. It was impractical to take weights of sturgeon specimens from smaller screen fractions due to their very small size and limitations of available equipment.

If specimens were clearly burned (charred black or calcine), this information was also recorded. All data were entered into SPSS (Statistical Package for the Social 
Sciences) for data management. SPSS version 22.0.0.0 was used for statistical analyses, and Microsoft Excel version 14.1.4 was used to create tables and figures.

\section{Species-Level Identification of Salmonid Vertebrae}

Salmon are the most ubiquitous fish in Pacific Northwest archaeological records (Campbell and Butler 2010a). Six of the seven species of Pacific salmon are known for the study area: chinook (Oncorhynchus tshawytscha), chum (O. keta), coho (O. kisutch), sockeye (O. nerka), steelhead (O. mykiss), and cutthroat (O. clarki) (Lee et al. 1980). These species are highly variable in body size. Chinook, the largest salmon species, is known to achieve weights over $60 \mathrm{~kg}(130 \mathrm{lbs}$.), while the maximum weights of the other species range from $8 \mathrm{~kg}$ to $25 \mathrm{~kg}$ (18-55 lbs.) (Froese and Pauly 2014; Martin 2006; Ray 1938). This variability raises the possibility that the different salmon species should not all be assigned the same prey rank.

Identification of salmonid remains generally can be made only to the genus level by traditional morphological analysis. In order to attain a finer resolution, researchers have begun exploring alternative methods of identifying salmon species, such as the use of ancient DNA (aDNA) (Cannon and Yang 2006; Grier et al. 2013; Moss et al. 2014; Speller et al. 2005). Despite the increased level of precision that aDNA studies have been able to provide in characterizing archaeological salmonid assemblages, aDNA analysis is destructive and expensive, making it practical for studying only a small proportion of an assemblage. As an alternative to this, Huber et al. (2011) created a model that uses morphometric analysis of salmonid vertebrae to classify archaeological 
specimens to the species or species group level. This method is fast and non-destructive and can be cheaply applied to a large number of specimens.

The model uses Type II and III salmon vertebrae, as defined by Butler (1990). These two types make up over $90 \%$ of a salmon's vertebral column. To develop their model, Huber et al. used vertebral measurements taken on a modern reference collection. They collected a minimum of ten adults of each of the seven species of Pacific Northwest anadromous salmon (this includes pink salmon, O. gorbuscha, in addition to the six species found in the Lower Columbia). The samples were all of spawning age and collected from various locations in Washington State. The authors based their taxonomic classifications on centrum length, centrum height, and the length/height ratio (see Huber et al. 2011 for measures). Several species showed considerable overlap in these measurements, so identifications using this model are more accurate when the following species groups are used: 1) chinook, 2) chum, coho, and steelhead, 3) cutthroat, and 4) sockeye and pink.

Moss et al. (2014) have recently questioned the accuracy of Huber et al.'s morphometric model, as they found identifications made by the model to be consistent with aDNA identifications only $57 \%$ of the time. However, the authors based this comparison on species level identifications, which we already know to be less accurate than identifications made to the groups listed above. In Moss et al.'s sample, the model most frequently misclassified pink as sockeye, which Huber et al. group together due to their similarities. Furthermore, the archaeological samples tested in this study are from the Coffman Cove site in Alaska, which is a considerable distance from the collection locations of Huber et al.'s modern reference material; it is possible that Huber et al.'s 
model is less applicable to these geographically distant salmon. Therefore, I believe that it is still sound to apply this model to the Cathlapotle assemblage, particularly to separate chinook from the other species, as chinook vertebrae are particularly distinctive in size and shape.

Portland State University graduate student Kathryn Mohlenhoff and I measured height and length on all type II and III salmon vertebrae recovered from the $1 / 4$ " mesh sample in Houses 1 and 4 that were sufficiently intact. Measurements were taken using electronic calipers to the nearest $0.01 \mathrm{~mm}$. I used the statistical program R version 2.9.2 to run Huber et al.'s model. Vertebrae were identified as either chinook or non-chinook.

\section{Estimating Representation of Fish in Bulk Samples}

Screen size is known to have a significant effect on fish bone recovery (Casteel 1972; Gordon 1993; Partlow 2006). While 1/4" screens are sufficient for sampling the larger fish taxa, smaller fishes are often too small to be caught by this mesh size and are thus likely to be underrepresented in the $1 / 4$ " sample. Therefore, including the bulk samples in my analysis is necessary to gain a more complete picture of fish resource use at Cathlapotle. This is particularly pertinent given that I am testing hypotheses related to fish size.

Sorting through the bulk matrix for very small fish specimens is a labor-intensive process, so only a small subset of bulk samples from Houses 1 and 4 could be examined for this study. I used a grab sample method to select the samples: I chose samples from excavation units/levels that had contained the highest numbers of fish bones in the $1 / 4$ " assemblage in order to maximize the sample size of identified fish per volume of bulk 
matrix searched. In total, I analyzed 18 bulk samples from the four house/compartment units, ranging in volume from 2 to 20 liters. See Appendix B for the location and volume of each analyzed bulk sample. I analyzed the $4 \mathrm{~mm}, 2 \mathrm{~mm}$, and $1 \mathrm{~mm}$ mesh fractions only, leaving the $0.5 \mathrm{~mm}$ mesh fractions unexamined.

I sorted through all of the $4 \mathrm{~mm}$ and $2 \mathrm{~mm}$ fractions of the selected samples. The $1 \mathrm{~mm}$ fractions contained most of the matrix volume and therefore required the majority of the labor. Two Portland State University undergraduate students, Emma Bailey and Nathan Jereb, assisted me in separating the fish remains from the $1 \mathrm{~mm}$ fraction matrix. For the $1 \mathrm{~mm}$ samples that had high matrix volumes, instead of sorting through all of the matrix from each sample, I only examined as much as was necessary to reach redundancy, using a "stopping rule" to determine the fraction size that must be analyzed to accurately estimate the total population of the sample. In this way, I was able to analyze a greater number of bulk samples in a given amount of time. One shortfall of sampling to redundancy is that it is less likely to provide accurate estimates of rare taxa. However, accurate representation of rare taxa is not of primary importance to me, as my reason for looking at the bulk samples is to estimate the representation of small fish prey types utilized at Cathlapotle and their contributions relative to medium and large taxa in each of the houses/compartments.

The sampling methodology that I utilized for the $1 \mathrm{~mm}$ fractions is described in detail by van der Veen and Fieller (1982) and was also used by Butler (2005) to sample fish bones from bulk samples. I used the following formula, which applies when the total number of specimens in the target population is of moderate size, as are the fish bones in a 10-liter sample of matrix: 


$$
n=\frac{N}{\left\{1+\frac{(N-1)}{P(1-P)}(d / Z \alpha)^{2}\right\}}
$$

where

$n=$ the required number of specimens in the subsample,

$N=$ the total number of specimens in the target population,

$P=$ the proportion of the particular taxon in the target population,

$d=$ the required accuracy or tolerance, and

$Z \alpha=$ the two-sided $\alpha$ percentage point of the normal distribution.

When the true proportion $P$ is unknown, as is the case here, $P$ should be set to $50 \%$, or 0.5 , which provides the upper bound on the sample size. With $P$ set to 0.5 , the formula reduces to the following:

$$
n=\frac{N}{\left\{1+4(N-1)(d / Z \alpha)^{2}\right\}}
$$

I chose a required accuracy of $d=0.05$; at this accuracy, the $Z$ score is 1.960 .

With these values set, I only required an estimate of $N$, the total number of specimens in the target population, in order to solve for $n$, the number of specimens in the subsample needed to accurately estimate the total population, i.e., the NISP at which redundancy is reached.

To obtain an estimate of $N$, I first analyzed a subsample of each $1 \mathrm{~mm}$ bulk sample. I used the following methodology for dividing each $1 \mathrm{~mm}$ bulk sample bag into 
subsamples of roughly equivalent size: I spread the contents of the bag out evenly on the work surface, ensuring that no size-sorting occurred when the bag was emptied. Depending on the volume of matrix, I then divided the sample, by eyeball, into either quarters or eights. I re-bagged three-quarters or six-eighths of these subsamples into separate bags and left the remaining one-quarter for immediate analysis.

After obtaining the NISP for this quarter subsample, I multiplied it by 4 to estimate the total number of specimens in the bag $(N)$, which I could plug into the formula to calculate $n$. If $n$ was larger than the number of specimens already identified in the first quarter of the sample, this meant that I needed to analyze additional subsamples to get a sufficiently accurate estimate of the taxonomic composition of the total population. I analyzed additional subsamples until my NISP was equal to or greater than $n$. I reached this stopping point prior to analyzing the entire $1 \mathrm{~mm}$ fraction for 9 of the 18 bulk samples analyzed. For these 9 samples, I then calculated estimated quantities of each taxon for the entire sample given the proportion of the sample that was actually analyzed. For example, if three-quarters of the sample had been analyzed, I would multiply the quantity of each taxon actually identified by four-thirds to get estimated quantities of each taxon. See Appendix $\mathrm{C}$ for a comparison of raw counts versus estimated quantities in these samples.

Table 3 summarizes the number of samples and total volume of bulk matrix analyzed from each house/compartment, along with the total raw and estimated quantities of fish identified. Unfortunately, these sample sizes are quite variable, and this could affect the validity of comparisons across the social units. 
Table 3. Sample Sizes of Bulk Samples.

\begin{tabular}{lcccc}
\hline & & & \multicolumn{2}{c}{ Frequency of Fish } \\
\cline { 4 - 5 } House Unit & N of Samples & Total Volume (L) & Raw NISP & Estimated NISP \\
\hline H1b & 5 & 61 & 366 & 404 \\
H1c & 6 & 63.85 & 2080 & 2735 \\
H1d & 4 & 52 & 952 & 1037 \\
H4 & 3 & 30 & 405 & 405 \\
\hline
\end{tabular}




\title{
Chapter IV: Results
}

Descriptive Summary of Fish Remains, 1/4” Mesh Screens

\begin{abstract}
A total of 4,566 fish specimens were identified from the $1 / 4$ " mesh sample. This includes 2,655 specimens identified by myself and 1,911 specimens identified by Butler (2002) in the previous analysis. A total of 3,356 were identified from House 1, including 1,939 from Compartment H1d, 1,360 from Compartment H1c, and 57 from Compartment H1b. 1,210 were identified from House 4 .
\end{abstract}

Class Osteichthyes - Bony Fishes

\section{Order Acipenseriformes}

Family Acipenseridae - sturgeons

$$
\text { Acipenser spp. - sturgeon }
$$

Materials: 24 branchiostegale, 16 ceratohyale, 16 claviculare, 11 cleithra, 29 dentale, 14 ectopterygoids, 8 entopterygoids, 1 frontale, 23 fulcra, 2 hyomanidbulare, 20 parasphenoids, 36 pectoral spines, 3 postorbitale, 1 posttemporale, 11 praemaxillomaxillare, 2 pterotics, 14 quadratojugale, 3 radii branchiostegii (interoperculum), 5 radii branchiostegii (suboperculum), 340 indeterminate scutes, 18 precaudal anal scutes, 17 precaudal dorsal scutes, 2 suboperculare, 1 suborbitale-infraorbitale, 5 supracleithrale, 1 supraorbitale, 2 supratemporale-intertemporale, 3 vomers, 2,025 unidentifiable elements: 2,653 specimens. 


\section{Remarks:}

Over 600 of the specimens were sufficiently intact to be identified to skeletal element. Sturgeon skeletal nomenclature used in this study is taken from Brinkhuizen (1986) and Findeis (1993) . Precaudal anal and dorsal scutes are distinctive and easily distinguished from other scute types. All other scutes were lumped together into an indeterminate scute category.

The vast majority of sturgeon specimens were either indistinguishable cranial elements or too fragmentary or eroded for the skeletal element to be identified. These specimens could be identified as sturgeon based on their texture. Broughton also utilized the unique texture of sturgeon bone to identify fragmentary specimens that were not identifiable to element (1995:119).

Two species of sturgeon are known for western North America, white sturgeon $(A$. transmontanus) and green sturgeon (A. medirostris). Both species of sturgeon are bottom feeders, feeding on a variety of invertebrates and fishes (Wydoski and Whitney 2003). The Columbia River is considered the most abundant white sturgeon habitat in North America. White sturgeon are anadromous and migrate upstream from the ocean to spawn between April and July, but some individuals live their whole lives in freshwater. Large resident populations were known historically for the Columbia, but numbers have since declined significantly (Martin 2006). White sturgeon were a major resource in the historic commercial fisheries (Butler and Martin 2013; Martin 2006). Local concentrations of white sturgeon occurred where they congregated to prey on spawning anadromous fish, including eulachon, salmon, and lamprey (Entosphenus tridentatus). Migrating eulachon drew particularly large numbers of white sturgeon. 
Little is known of the biology and behavior of green sturgeon. They are smaller than white sturgeon, quite rare, and primarily inhabit marine environments. Their preferred freshwater spawning habitats are smaller rivers such as the Rogue. In the Columbia, they are rarely found above the brackish waters of the estuary (Farr and Rein 2002; Martin 2006).

Broughton (1995) notes that it is unlikely that the two sturgeon species can be reliably distinguished from one another based on skeletal morphology, but Gobalet et al. (2004) call attention to interspecific differences in the morphology of the scute margins. However, between margin erosion and an incomplete green sturgeon reference collection, I was unable to take advantage of this distinction, and identifications were made to the genus level only. It is likely that a majority of the sturgeon specimens from the Cathlapotle collection are white sturgeon due to its historic dominance in the Lower Columbia.

\section{Order Salmoniformes}

Family Salmonidae - salmon, trout, and whitefish

Oncorhynchus spp. - salmon

Materials: 6 angular/articulars, 1 basioccipital, 6 basipterygia, 1 caudal bony plate, 4 ceratohyals, 2 coracoids, 1 dentary, 31 dorsal vertebral spines, 1 ectopterygoid, 2 epihyals, 1 exoccipital, 2 gillrakers, 2 hyomandibulae, 1 hypural, 7 maxillae, 1 mesocoracoid, 2 opercles, 2 palatines, 2 pectoral fin rays, 2 posttemorals, 5 preopercles, 1 prootic, 1 pterotic, 4 pterygiophores, 6 quadrates, 2 scapulae, 2 supracleithra, 1 urohyal, 5 type 1 
vertebrae, 291 type 2 vertebrae, 398 type 3 vertebrae, 22 type 4 vertebrae, 14

indeterminate vertebrae, 261 vertebral fragments: 1,090 specimens.

\section{Remarks:}

Salmonid cranial bones have a flaky, lightly built texture that does not preserve well. Their vertebrae are far more robust and represent the majority of identifiable salmonid specimens in the collection. The pectoral fin ray is a distinctive element that also preserves well due to high density (Butler and Chatters 1994). Vertebrae were assigned to one of four types based on morphology and location along the column, as described in Butler (1990:40). Vertebrae that were too fragmented to be identified to type but could be identified as salmonid due to the unique texture and morphology of salmonid vertebrae were designated as vertebral fragments.

Pacific salmon are anadromous, growing into adulthood in the ocean and returning to freshwater to spawn and, usually, die. Steelhead (aka rainbow trout) and cutthroat also have native resident stocks; the resident forms are much smaller than the migratory forms (Lee et al. 1980; Martin 2006). The relatively large size of salmonid remains recovered from Lower Columbia archaeological sites indicates that they are mainly from anadromous forms of Pacific salmon (Butler and Martin 2013), and this is true for this study as well. Pacific salmon enter the Columbia River to spawn in the main stem and its tributaries at various times. Table 4 shows the timings of these migrations and spawning as well as their presence in the Lewis River tributary, the mouth of which is located approximately $1 \mathrm{~km}$ north of Cathlapotle and $137 \mathrm{~km}$ above the mouth of the Columbia. Those species that entered the Lewis River to spawn would have been locally available for harvesting by the residents of Cathlapotle. 
Table 4. Timing of Salmon Runs in the Lower Columbia River and Presence in the Lewis River. (Table developed from Fulton 1968, 1970; Martin 2006; Saleeby 1983; and Wydoski and Whitney 2003.)

\begin{tabular}{llll}
\hline Species/Run & Time of Migration & Time of Spawning & $\begin{array}{l}\text { Enter Lewis River to } \\
\text { Spawn? }\end{array}$ \\
\hline $\begin{array}{llll}\text { Chinook } \\
\text { spring }\end{array}$ & Feb. to May & Late July to Sept. & Y \\
summer & June to Aug. & Aug. to Nov. & N \\
fall & Aug. to Oct. & Sept. to Dec. & Y \\
Coho & Late Aug. to Nov. & Sept. to Jan. & Y \\
Chum & Oct. to Dec. & Oct. to Dec. & Y \\
Steelhead & Year-round & Dec. to Mar. & Y \\
Cutthroat & No information & Dec. to Feb. & Y \\
& available & & \\
Sockeye & May to Aug. & Oct. & N \\
\hline
\end{tabular}

The Columbia River Basin was the most productive spawning habitat for chinook, which were particularly important in the historic commercial fisheries of the Columbia (Craig and Hacker 1940; Martin 2006). Chinook have an extended migration, which is divided into spring, summer, and fall runs. Spring and summer chinook are adapted to extended spawning migrations, while fall chinook are more mature, larger, and have reduced oils and fats, being closer to the completion of their life cycle when they enter the estuary. Chinook tend to swim in the deeper central portion of rivers, often making it necessary to capture them at river constrictions where rocks or fishing platforms extended out into the river (Speller et al. 2005). The two natural constrictions of Willamette Falls (for the spring run) and Cascades Rapids (for all runs) were known historically as important chinook fishing locations (Butler and Martin 2013; Figure 1). Fall chinook are also known to spawn in local streams such as the Lewis River in large numbers (Martin 2006), so they would have been available for harvesting in close proximity to Cathlapotle.

Chum and coho were known historically to be quite abundant in the study area as well, and chum in particular was important in the historic commercial fisheries of the 
Columbia, though it was a lower valued fish than chinook (Martin 2006). Both chum and coho spawn in the fall. Unlike other anadromous Oncorhynchus species, migratory steelhead and cutthroat do not necessarily die after spawning, with some returning to the sea and then migrating to freshwater to spawn again. Anadromous steelhead migrate year-round and primarily spawn in the spring. Anadromous cutthroat spawn primarily in late winter/early spring in the smallest headwater streams and tributaries of the Columbia. Their spawning densities are much lower than those of other Pacific salmon (Fulton 1970; Martin 2006; Wydoski and Whitney 2003). Sockeye would have been available in the mainstem of the Columbia, but they are not widely distributed in the Columbia Basin. They spawn along lake shorelines or in tributaries of lakes, and there is no sockeye spawning habitat near the study area (Martin 2006).

\section{Order Cypriniformes - minnows and suckers}

Seven native species of Cyprinidae (minnows) and 1 native species of Catostomidae (suckers) are known for the study area (Lee et al. 1980). The minnows include the large-bodied chiselmouth (Acrocheilus alutaceus), tui chub (Gila bicolor), peamouth (Mylocheilus caurinus), and northern pikeminnow (Ptychocheilus oregonensis) and the small-bodied longnose dace (Rhinichthys cataractae), speckled dace (Rhinichthys osculus), and redside shiner (Richardsonius balteatus). The only sucker species known for the study area is the largescale sucker (Catostomus macrocheilus). I have divided the minnow and sucker species into two groups based on a considerable gap in their sizes (Table 5). 
Table 5. Sizes of Minnow and Sucker Species at Cathlapotle. (Data from Lee et al. 1980.)

\begin{tabular}{ll}
\hline Taxon & Length (mm) \\
\hline Large-bodied minnow/sucker species & \\
Catostomus macrocheilus (largescale sucker) & $200-300$ \\
Ptychocheilus oregonensis (northern pikeminnow) & $210-300$ \\
Gila bicolor (tui chub) & $305-356$ (maximum size) \\
Mylocheilus caurinus (peamouth) & $160-205$ \\
Acrocheilus alutaceus (chiselmouth) & $150-200$ \\
Small-bodied minnow species & \\
Rhinichthys cataractae (longnose dace) & 75 \\
Richardsonius balteatus (redside shiner) & $55-80$ \\
Rhinichthys osculus (speckled dace) & $45-50$ \\
\hline
\end{tabular}

Lengths refer to standard length, which is the length of the fish from the end of the snout to the hypural.

Minnows and suckers vary in their feeding habits; minnows are generally more omnivorous, and suckers are more herbivorous. These resident freshwater fishes are found extensively in archaeological contexts in the region, but they are almost entirely ignored in ethnographic and $19^{\text {th }}$-century historic accounts (Butler and Martin 2013; Saleeby 1983). They would have been abundant in the seasonally flooded backwater wetland of the Columbia River floodplain, preferring relatively warm, slow-moving water. They spawn during late spring and early summer and would have been easiest to catch at this time, with adults congregating in the shallows of streams and lakes, as well as in late summer when the backwaters recede (Butler and Martin 2013).

Family Cyprinidae - minnows

Large-bodied minnow

Materials: 5 angular/articulars, 3 basioccipitals, 2 basipterygia, 18 ceratohyals, 15 cleithra, 3 coracoids, 2 dentaries, 1 ectopterygoid, 4 epihyals, 2 epiotics, 1 exoccipital, 4 frontals, 7 hyomandibulae, 4 interopercles, 11 mesopterygoid/endopterygoids, 8 
metapterygoids, 14 opercles, 4 parasphenoids, 3 pharyngeals, 1 premaxilla, 5 preopercles, 2 prootics, 1 pterosphenoid, 4 pterotics, 13 quadrates, 2 scapulae, 1 subopercle, 2

supraethmoids, 1 supraoccipital, 2 urohyals, $31^{\text {st }}$ vertebrae, $42^{\text {nd }}$ vertebrae, 1 vomer: 153 specimens.

Remarks:

All minnow specimens recovered from the $1 / 4$ " mesh that could be identified to species level were identified as one of the four large-bodied minnows (Table 5). No skeletal elements from the $1 / 4$ " mesh were identified as any of the small-bodied minnow species. Because of this and because the specimens from the $1 / 4$ " mesh were too large and robust as compared against the reference materials to be associated with the small-bodied minnows, all minnow specimens recovered from the $1 / 4$ " mesh that could not be assigned to particular minnow species were assigned to the general large-bodied minnow group.

Five elements were used to identify the large minnows to the species level: dentary, hyomandibula, maxilla, pharyngeal, and urohyal. P. oregonensis elements are most easily identified to species level based on their distinctive morphology and robusticity. Morphological differences between the other three species are more subtle but still often distinctive enough to make species-level identifications. The maxillae, urohyals, and pharyngeals are distinctive for all 4 species. The pharyngeals can be differentiated by bone shape, tooth shape, and tooth/tooth row number. The differences between the hyomandibulae of A. alutaceus, G. bicolor, and M. caurinus are subtle and not well preserved in eroded specimens. The dentaries of $P$. oregonensis and $A$. alutaceus are distinctive, while those of G. bicolor and M. caurinus cannot be differentiated from each other. 
Acrocheilus alutaceus - chiselmouth

Materials: 3 hyomandibula, 5 pharyngeals: 8 specimens.

\title{
Remarks:
}

A. alutaceus inhabits slow-flowing streams of all sizes and lakes. It specializes in scraping algae and diatoms from the bottom substrate (Lee et al. 1980).

\author{
Gila bicolor - tui chub
}

Materials: 1 urohyal.

\section{Remarks:}

G. bicolor schools in weedy lake shallows and quiet, slow-moving rivers. It is an opportunistic omnivore that concentrates on invertebrates (Lee et al. 1980). There is some question about the historic biogeography of the species. While it is commonly found in central and eastern Washington and Oregon and is rarely noted in fisheries biology reports as far west as the study area (Farr and Ward 1993; Wydoski and Whitney 2003), archaeological specimens of tui chub have been identified previously at archaeological sites along the Lower Columbia (Butler 1992, 2002; Frederick 2007).

$$
\text { Mylocheilus caurinus - peamouth }
$$

Materials: 1 hyomandibula, 25 pharyngeals: 26 specimens.

\section{Remarks:}

The pharyngeals of $M$. caurinus are particularly distinctive due to the unique molariform shape of the teeth. 
M. caurinus schools in lakes and slow-moving rivers and can also tolerate saltwater (Lee et al. 1980). It feeds on plankton and invertebrates and occasionally small fishes (Wydoski and Whitney 2003).

Ptychocheilus oregonensis - northern pikeminnow

Materials: 4 dentaries, 3 hyomandibulae, 4 maxillae, 3 urohyals, 12 pharyngeals: 26

specimens.

\section{Remarks:}

P. oregonensis inhabits lakes and slow- to moderate-moving rivers and streams. It is insectivorous when small and shifts to a piscivorous diet as it grows larger (Wydoski and Whitney 2003).

\section{Family Catostomidae - suckers \\ Catostomus macrocheilus - largescale sucker}

Materials: 4 angular/articulars, 1 basioccipital, 5 basipterygia, 24 ceratohyals, 16 cleithra, 18 coracoids, 34 dentaries, 10 epihyals, 8 epiotics, 5 exoccipitals, 6 frontals, 50 hyomandibulae, 30 interopercles, 29 maxillae, 16 mesopterygoid/endopterygoids, 22 metapterygoids, 32 opercles, 22 palatines, 11 parasphenoids, 4 parietals, 12 pharyngeals, 8 preopercles, 9 prootics, 8 pterotics, 73 quadrates, 4 scapulae, 4 sphenotics, 7 subopercles, 3 supraethmoids, 6 supraoccipitals, 12 urohyals, $11^{\text {st }}$ vertebra, $92^{\text {nd }}$ vertebrae, 3 vomers, 11 Weberian processes: 517 specimens. 


\section{Remarks:}

While the largescale sucker (C. macrocheilus) is the only species of sucker known from the study area, two other species of sucker are known from relatively nearby: the bridgelip sucker (C. columbianus) is found in upriver tributaries of the Columbia, and the mountain sucker (C. platyrhynchus) is found both in upriver tributaries of the Columbia and in the Willamette Basin. Four elements were used to identify Catostomus to the species level based on their distinctiveness in these three Catostomus species: the dentary, maxilla, palatine, and quadrate. After all such specimens that were sufficiently preserved to be identified to the species level were identified as C. macrocheilus, I likewise assigned all other Catostomus elements to C. macrocheilus.

C. macrocheilus prefers slower-moving portions of larger rivers and streams and also inhabits lakes. Its diet includes plant material and a variety of small invertebrates (Lee et al. 1980).

\section{Family Cyprinidae/Catostomidae - minnows and suckers \\ Large-bodied minnow/sucker}

Materials: 3 basipterygia, 1 cleithrum, 3 interopercles, 1 preopercle, 1 scapula, 2 subopercles, 52 abdominal vertebrae, 20 caudal vertebrae, 1 indeterminate vertebra, 7 vertebral fragments: 91 specimens.

\section{Remarks:}

Except for the first and second vertebrae of the column, Cyprinidae and Catostomidae vertebrae cannot be distinguished between the two families, so all such vertebrae were assigned to this joint family category. Any other specimens that were 
obviously from one of these two families but too eroded or fragmentary to be identified more precisely were also assigned to this joint family category. Based on size and robusticity, these specimens could not represent any of the small-bodied minnows.

\author{
Order Scorpaeniformes \\ Family Cottidae - sculpins \\ Cottus spp. - sculpins
}

Materials: 1 hyomandibula.

\title{
Remarks:
}

This hyomandibula was identified in Butler's earlier analysis. One other Cottus element was identified by Rosenberg in the bulk samples, listed below. Cottus species that may have been present in the study area include C. aleuticus, C. asper, C. beldingi, $C$. confusus, C. gulosus, C. perplexus, and C. rhotheus. These freshwater sculpins are relatively small-bodied fish, with adults averaging under $100 \mathrm{~mm}$ in length. These species were not all available in the comparative collection, so identification beyond the genus level was not possible.

\section{Descriptive Summary of Fish Remains, Bulk Samples}

A total of 3,803 fish specimens were identified from the $4 \mathrm{~mm}, 2 \mathrm{~mm}$, and $1 \mathrm{~mm}$ fractions of 18 bulk samples. Using the sampling methodology discussed above, approximately 4,581 specimens were estimated for these samples. While the estimated quantities will be utilized for the statistical analysis, the descriptive summary that follows refers to the raw data, or the specimens that were actually identified. See Appendix C for 
a complete breakdown of the taxa identified in each fraction of each bulk sample, including a comparison of raw data and estimated quantities for the $1 \mathrm{~mm}$ fractions.

\author{
Class Osteichthyes - Bony Fishes
}

Order Acipenseriformes

Family Acipenseridae - sturgeons

Acipenser spp. - sturgeon

Materials: 2 pectoral spines, 1 precaudal dorsal scute, 24 indeterminate scutes, 1,579 unidentifiable elements: 1,606 specimens.

\title{
Remarks:
}

A large number of very small sturgeon fragments make up the bulk of the sturgeon recovered from these samples.

\section{Order Salmoniformes}

Family Salmonidae - salmon, trout, and whitefish

Oncorhynchus spp. - salmon

Materials: 11 dorsal vertebra spines, 29 gillrakers, 2 type 3 vertebrae, 3 indeterminate vertebrae, 861 vertebral fragments: 906 specimens.

\section{Remarks:}

The gillraker is a small, relatively robust element that preserves well. The texture of salmonid vertebrae is highly distinctive, and even small fragments can be identified. 
These small fragments account for the majority of the identified salmon specimens in the bulk samples.

\author{
Order Osmeriformes \\ Family Osmeridae - smelts \\ Thaleichthys pacificus - eulachon
}

Materials: 6 angular/articulars, 10 ceratohyals, 3 cleithra, 5 dentaries, 3 hyomandibulae, 1 lingual plate, 6 opercles, 1 preopercle, 6 quadrates, 1 scapula, 509 indeterminate vertebrae, 174 vertebral fragments: 725 specimens.

\title{
Remarks:
}

Eulachon is an anadromous fish that enters the Columbia between December and February to spawn. It is an important primary prey of white sturgeon, which were known to congregate in the Columbia following the eulachon migrations. Eulachon was historically abundant and valuable to both the Chinookans and Euroamericans involved in the fur trade (Butler and Martin 2013; Martin 2006).

Eulachon were primarily identified from their vertebrae, which are distinctively simple with a large, hollow notochord opening. Different vertebrae types cannot be distinguished, so all vertebrae that were at least half complete were categorized as indeterminate vertebrae. Other elements are clearly distinguished from other small fishes by their unique morphology and lightly-built structure. 


\section{Order Cypriniformes \\ Family Cyprinidae - minnows \\ Large-bodied minnow}

Materials: 1 cleithrum, 5 epihyals, 1 opercle, 4 pharyngeals, 3 quadrates, 1 scapula, 1 supraoccipital, $101^{\text {st }}$ vertebrae: 26 specimens.

\section{Remarks:}

All elements listed here have been assigned to the large-bodied minnow group based on their size and robusticity as compared against reference materials of large and small minnows.

\section{Small-bodied minnow}

Materials: 1 basioccipital, 1 basisphenoid, 1 ceratohyal, $51^{\text {st }}$ vertebrae: 8 specimens.

\section{Remarks:}

These specimens were identified as minnow based on their morphology and have been assigned to the small-bodied category based on their size. They could represent one of the three small-bodied minnow species, but they could also represent juveniles of the large-bodied minnows (Table 5). Either way, these specimens came from small individuals.

Rhinichthys cataractae and $R$. osculus prefer cool, swift streams with gravel bottoms, but may also be found in lakes and warmer streams. $R$. cataractae feeds primarily on aquatic insect larvae, while $R$. osculus feeds on small invertebrates and plant material (Lee et al. 1980; Wydoski and Whitney 2003). Richardsonius balteatus is found 
in a variety of habitats, including lakes, rivers, streams, and sloughs, usually in slowmoving waters. It is an omnivore, feeding mainly on insects (Lee et al. 1980).

$$
\text { Mylocheilus caurinus - peamouth }
$$

Materials: 1 pharyngeal.

$$
\text { Ptychocheilus oregonensis - northern pikeminnow }
$$

Materials: 1 dentary.

$$
\text { Rhinichthys osculus - speckled dace }
$$

Remarks: 1 pharyngeal.

\section{Remarks:}

This is the only small-bodied minnow specimen identified to the species level. The pharyngeal of $R$. osculus is readily distinguished from the other two small-bodied minnow species by the number of teeth and tooth rows.

$$
\text { Family Catostomidae - suckers }
$$

Catostomus macrocheilus - largescale sucker

Materials: 3 angular/articulars, 3 dentaries, 2 epihyals, 2 hyomandibulae, 2 maxillae, 1 parasphenoid, 3 pharyngeals: 16 specimens. 
Family Cyprinidae/Catostomidae - minnows and suckers

Large-bodied minnow/sucker

Materials: 6 scapulae, $71^{\text {st }}$ vertebrae, 40 abdominal vertebrae, 40 caudal vertebrae, 40 vertebral fragments: 133 specimens.

\section{Remarks:}

While $1^{\text {st }}$ vertebrae can usually be distinguished between minnows and suckers, the $1^{\text {st }}$ vertebrae recorded here were too fragmented or eroded to be identified that specifically. Based on size, these specimens could not represent any of the small-bodied minnow species.

\section{Small-bodied minnow/sucker}

Materials: 1 maxilla, 2 scapulae, $11^{\text {st }}$ vertebra, 34 abdominal vertebrae, 41 caudal vertebrae, 3 indeterminate vertebrae, 5 vertebral fragments: 87 specimens.

\section{Remarks:}

These specimens were identified as minnow/sucker based on their morphology and have been assigned to the small-bodied category based on their size. They could represent one of the three small-bodied minnow species, but they could also represent juveniles of the large-bodied minnow and sucker species (Table 5). Either way, like the specimens assigned to the small-bodied minnow category, these specimens came from small individuals. 


\section{Order Gasterosteiformes}

\section{Family Gasterosteidae - sticklebacks \\ Gasterosteus aculeatus - threespine stickleback}

Materials: 98 basipterygia, 9 cleithra, 44 dorsal spine plates, 6 frontals, 2 hyomandibulae, 5 infracleithra, 16 opercles, 2 preopercles, 1 quadrate, 16 scales, 10 dorsal spines, 64 pelvic/pectoral spines, 4 indeterminate spines, 1 supraoccipital, 9 abdominal vertebrae, 5 caudal vertebrae: 292 specimens.

\section{Remarks:}

Species-level identification of the threespine stickleback is possible because it is the only stickleback species found in western North America. Stickleback elements are distinctive in both their morphology and texture, which is bumpy and robust. The dorsal and pelvic/pectoral spines along with the dorsal spine plates and basipterygia that the spines attach to are quite unique and preserve well. Unlike other fish species in this study, stickleback scales are distinctive and so were included in the analysis. Identification of the infracleithrum follows Mural (1973).

The threespine stickleback is widely distributed in marine and freshwater habitats in the northern hemisphere (Lee et al. 1980). It is a small fish found in a variety of habitats in the Columbia River Basin, ranging from shallow marine environments to freshwater lakes and slow-moving streams and rivers (Martin 2006). Their small body size, abundance, and slow swimming speed make them easy prey targets, but they have large dorsal, pelvic, and pectoral spines that may be a deterrent to predators. Despite this, they are found in the diets of a wide array of species. Among fish, predators of the threespine stickleback include salmonids (steelhead, cutthroat, and coho), minnows, and 
sculpins. A variety of bird species and mammals including river otter, mink, fur seal, and humans are also known to prey on them (Reimchen 1994).

Threespine stickleback is well represented in archaeological deposits, but it is unclear if this is because stickleback were targeted for harvesting or if they were part of the by-catch from backwater fishing. It is absent from Columbia River ethnohistoric documents, but it is known as a traditional food and source of dog food in the YukonKuskokwim Delta of southwest Alaska, and the Inupiat people of northwest Alaska apparently eat stickleback or use them as dog food in times of need (Butler and Martin 2013).

\author{
Order Scorpaeniformes \\ Family Cottidae - sculpins \\ Cottus spp. - sculpins
}

Materials: 1 abdominal vertebra.

\title{
Summary of Taxonomic Frequencies by Social Unit
}

As mentioned above, the majority of the deposits from within the houses are from the post-contact time period, and this includes the fish remains (Table 6). Due to the small number of pre-contact fish remains, I will be combining the pre- and post-contact deposits for my analyses in this study. Spatial patterns discussed below primarily reflect the post-contact time period, but the temporal distribution across the houses and compartments is not even, so spatial differences could be affected by this aggregation of time units. 
Table 7 summarizes the frequencies of fish taxa recovered from the 1/4" mesh screens by social unit (house/compartment). Sturgeon is the most common fish identified in the $1 / 4$ " mesh sample across all social units. Salmon ranks second throughout the houses except in Compartment H1c, where more sucker was recovered. Sucker is much more common than minnow throughout the houses, particularly in House 1. While relatively few minnow specimens could be identified to the species level $(\mathrm{N}=61)$, all four of the large-bodied minnow species present in the study area were identified at the site. Northern pikeminnow (P. oregonensis) and peamouth (M. caurinus) were the most heavily utilized minnow species.

The sample size of fish recovered from the $1 / 4$ " mesh screens from Compartment $\mathrm{H} 1 \mathrm{~b}$ is very small $(\mathrm{N}=57)$. This is expected given the limited amount of excavation that was carried out in this compartment, but because of this, the fish identified in H1b are likely not a representative sample of the compartment. To deal with the small sample size, I will be grouping the Compartment H1b samples together with those from Compartment H1c for all analyses. While this unfortunately increases the coarseness of comparisons by mixing potentially distinctive social units, it will still allow me to compare the fish from the lower-prestige Compartments H1b \& H1c to those from the higher-prestige Compartment H1d.

Table 6. NISP of Pre- versus Post-Contact Fish Remains Identified from $1 / 4$ ” Mesh Samples by Social Unit.

\begin{tabular}{|c|c|c|c|c|c|}
\hline \multirow[b]{2}{*}{ Taxon } & \multicolumn{3}{|c|}{ House 1} & \multirow[b]{2}{*}{ House 4} & \multirow[b]{2}{*}{ Total } \\
\hline & $\mathrm{H} 1 \mathrm{~b}$ & $\mathrm{H} 1 \mathrm{c}$ & H1d & & \\
\hline Pre-Contact & 34 & 21 & 475 & 421 & 951 \\
\hline Post-Contact & 23 & 1,337 & 1,462 & 789 & 3,611 \\
\hline Total & 57 & 1,358 & 1,937 & 1,210 & 4,562 \\
\hline
\end{tabular}


Table 7. NISP of Fish Taxa Identified from 1/4" Mesh Samples by Social Unit.

\begin{tabular}{|c|c|c|c|c|c|}
\hline \multirow[b]{2}{*}{ Taxon } & \multicolumn{3}{|c|}{ House 1} & \multirow[b]{2}{*}{ House 4} & \multirow[b]{2}{*}{ Total } \\
\hline & $\mathrm{H} 1 \mathrm{~b}$ & $\mathrm{H} 1 \mathrm{c}$ & H1d & & \\
\hline \multicolumn{6}{|l|}{ Acipenseridae } \\
\hline Acipenser spp.* & 45 & 804 & 992 & 812 & 2,653 \\
\hline \multicolumn{6}{|l|}{ Salmonidae } \\
\hline Oncorhynchus spp. & 6 & 185 & 617 & 282 & 1,090 \\
\hline \multicolumn{6}{|l|}{ Cyprinidae } \\
\hline Large-bodied minnow & 2 & 64 & 63 & 24 & 153 \\
\hline Acrocheilus alutaceus & 0 & 2 & 4 & 2 & 8 \\
\hline Gila bicolor & 0 & 1 & 0 & 0 & 1 \\
\hline Mylocheilus caurinus & 0 & 8 & 16 & 2 & 26 \\
\hline Ptychocheilus oregonensis & 2 & 8 & 15 & 1 & 26 \\
\hline \multicolumn{6}{|l|}{ Catostomidae } \\
\hline Catostomus macrocheilus & 0 & 262 & 203 & 52 & 517 \\
\hline \multicolumn{6}{|l|}{ Cyprinidae/Catostomidae } \\
\hline Large-bodied minnow/sucker & 2 & 26 & 28 & 35 & 91 \\
\hline \multicolumn{6}{|l|}{ Cottidae } \\
\hline Cottus spp. & 0 & 0 & 1 & 0 & 1 \\
\hline Total & 57 & 1,360 & 1,939 & 1,210 & 4,566 \\
\hline
\end{tabular}

*NISP for sturgeon includes specimens both identifiable and unidentifiable to element.

Table 8 summarizes the frequencies of fish taxa identified in the bulk samples by social unit. Frequencies shown in this table include quantities estimated for the $1 \mathrm{~mm}$ mesh fraction based on the sampling methodology discussed above; the estimated quantities will be utilized for all analyses presented below. Taxa identified in the bulk samples that were not recovered from the $1 / 4$ " mesh samples include eulachon $(T$. pacificus), threespine stickleback (G. aculeatus), and small-bodied minnow/sucker. High quantities of eulachon were identified throughout the houses, and stickleback is particularly abundant in Compartment H1d. Very few minnow specimens from the bulk samples could be identified to the species level $(\mathrm{N}=3)$, and only one of the three smallbodied minnow species present in the study area was identified at the site (speckled dace, 
R. osculus). Remarkably few sturgeon specimens were identified in the Compartment

H1d bulk samples.

Table 8. NISP of Fish Taxa from Bulk Samples by Social Unit (4 mm, $2 \mathrm{~mm}$, and $1 \mathrm{~mm}$ Fractions, with Number of Specimens Estimated for $1 \mathrm{~mm}$ Fraction).

\begin{tabular}{|c|c|c|c|c|c|}
\hline \multirow[b]{2}{*}{ Taxon } & \multicolumn{3}{|c|}{ House 1} & \multirow[b]{2}{*}{ House 4} & \multirow[b]{2}{*}{ Total } \\
\hline & $\mathrm{H} 1 \mathrm{~b}$ & $\mathrm{H} 1 \mathrm{c}$ & H1d & & \\
\hline \multicolumn{6}{|l|}{ Acipenseridae } \\
\hline Acipenser spp.* & 192 & 1,585 & 57 & 101 & 1935 \\
\hline \multicolumn{6}{|l|}{ Salmonidae } \\
\hline Oncorhynchus spp. & 153 & 532 & 264 & 122 & 1071 \\
\hline \multicolumn{6}{|l|}{ Osmeridae } \\
\hline Thaleichthys pacificus & 15 & 399 & 434 & 86 & 934 \\
\hline \multicolumn{6}{|l|}{ Cyprinidae } \\
\hline Large-bodied minnow & 7 & 20 & 4 & 0 & 31 \\
\hline Small-bodied minnow & 1 & 8 & 2 & 0 & 11 \\
\hline Mylocheilus caurinus & 0 & 1 & 0 & 0 & 1 \\
\hline Ptychocheilus oregonensis & 0 & 0 & 0 & 1 & 1 \\
\hline Rhinichthys osculus & 0 & 0 & 1 & 0 & 1 \\
\hline \multicolumn{6}{|l|}{ Catostomidae } \\
\hline Catostomus macrocheilus & 2 & 7 & 2 & 6 & 17 \\
\hline \multicolumn{6}{|l|}{ Cyprinidae/Catostomidae } \\
\hline Large-bodied minnow/sucker & 23 & 43 & 37 & 35 & 138 \\
\hline Small-bodied minnow/sucker & 6 & 69 & 20 & 16 & 111 \\
\hline Gasterosteidae & & & & & \\
\hline Gasterosteus aculeatus & 5 & 69 & 216 & 38 & 328 \\
\hline Cottidae & & & & & \\
\hline Cottus spp. & 0 & 0 & 1 & 0 & 1 \\
\hline Total & 404 & 2,733 & 1,038 & 405 & 4,580 \\
\hline
\end{tabular}

*NISP for sturgeon includes specimens both identifiable and unidentifiable to element.

Prey Ranks of Fish at Cathlapotle

I am using optimal foraging theory's prey choice model as a basis for developing taxonomic rankings of the fish at Cathlapotle and will be considering prey preference in terms of energetic returns. As body size is generally a good estimate of energetic returns, I am using body size as my primary criterion for assigning prey ranks, with larger prey 
being the higher-ranked, more preferred prey. Previously, Butler (2000) divided fish taxa from sites on the Columbia into two size classes. She designated sturgeon and salmon as the high-ranked, large fish group and all other taxa as the low-ranked, small fish group. In this study, I have further subdivided Butler's small fish group, separating out the larger-bodied minnow and sucker species from the very small fish and designating them as medium and small fish, respectively. Table 9 shows the fish species from Cathlapotle divided into three distinct size groups based on their average lengths. Except for 1 Cottus specimen, the small fish group is limited to taxa that were retrieved only from fine mesh screens with a gauge smaller than $1 / 4 "$. 
Table 9. Approximate Adult Body Size of Fish from the Lower Columbia Identified at Cathlapotle. (Data from Lee et al. 1980.)

\begin{tabular}{lc}
\hline Fish Taxon & Length (mm) \\
\hline Large Taxa & $8000-34000 \mathrm{FL}$ \\
Acipenser transmontanus (white sturgeon) & $13000 \mathrm{FL}$ \\
A. medirostris (green sturgeon) & $250-800$ \\
Oncorhynchus spp. (salmon) & $750-800$ \\
$\quad$ Oncorhynchus tshawytscha (chinook) & $610-711^{*} \mathrm{FL}$ \\
O. nerka (sockeye) & $480-800$ \\
O. keta (chum) & $450-610$ \\
O. kisutch (coho) & $250-750 \mathrm{TL}$ \\
O. mykiss (steelhead) & $300-485 \mathrm{TL}$ \\
O. clarki (cutthroat) & \\
Medium Taxa & $150-356$ \\
Large-bodied minnows & $305-356$ (maximum size) \\
$\quad$ Gila bicolor (tui chub) & $210-300$ \\
Ptychocheilus oregonensis (northern pikeminnow) & $160-205$ \\
Mylocheilus caurinus (peamouth) & $150-200$ \\
Acrocheilus alutaceus (chiselmouth) & $200-300$ \\
Catostomus macrocheilus (largescale sucker) & \\
Small Taxa & $125-170$ \\
Thaleichthys pacificus (eulachon) & $50-100$ \\
Cottus spp. (sculpins) & $45-80$ \\
Small-bodied minnows & 75 \\
Rhinichthys cataractae (longnose dace) & $55-80$ \\
Richardsonius balteatus (redside shiner) & $45-50$ \\
Rhinichthys osculus (speckled dace) & $30-75 \mathrm{TL}$ \\
Gasterosteus aculeatus (threespine stickleback) &
\end{tabular}

Unless otherwise noted, lengths refer to standard length, which is the length of the fish from the end of the snout to the caudal end of the hypural.

$\mathrm{FL}=$ fork length

$\mathrm{TL}=$ total length

*Fulton (1970) notes that the sockeye in the Columbia are among the smallest of this species.

These three size classes are a starting point for ranking fish prey. Accounts in ethnohistoric records are in agreement with the designations of salmon and sturgeon as the preferred, highest-ranked fish. Salmon was particularly important both to the Chinookans and in the commercial fish trade on the Lower Columbia (Martin 2006). Ray (1938) notes that the Chinook regarded chinook salmon, which was both the largest and most abundant salmon species in the Columbia, as the most valuable salmon species. 
The reverence that the Chinook had for chinook salmon is evident in their observance of the first salmon ceremony, performed for the first chinook catch of the season. The Chinook also held a similar rite for the first sturgeon of the season. Regarding the high value placed on sturgeon by the Chinook, Ray writes that sturgeon, "a much favored fish, was doubly important because a single catch provided a huge supply of food" (1938:107). Swan even wrote in his description of Chinook sturgeon fishing that "the Indians prefer them to salmon" (Swan 1972 (1857):246).

Eulachon, which fall at the larger end of the small fish group, are a unique case in terms of the relationship between body size and rank. They should not necessarily be considered a low-ranked prey item despite their small size because they congregate in particularly dense schools in the Columbia River. Eulachon were important in the historic commercial fisheries and were taken by Chinookans using mass harvesting fishing gear such as the eulachon rake and scoop net (Martin 2006). As an illustration of the large numbers of eulachon that could be quickly harvested, there are reports from the 1930s of individual commercial dip netters taking 1 to 2 tons of eulachon a day (Martin 2006:17). Furthermore, the time costs for making the gear to harvest eulachon were likely no greater than for larger fish, as net technology was used for harvesting a variety of fish species. For example, Martin (2006) notes that hoop nets were used to harvest salmon, and funnel nets were used for sturgeon. Eulachon are thus a case in which resource clumping appears to have had a significant effect on post-encounter return rates.

As an important primary prey of the white sturgeon, which were known to congregate in the Columbia following eulachon migrations, eulachon would have been encountered in the same resource patch, at the same time as sturgeon. Even with mass 
harvesting technology for taking eulachon, sturgeon are so big that, when encountered together, sturgeon should be chosen over eulachon as the more efficient prey choice. Therefore, eulachon is lower-ranked relative to sturgeon, but eulachon's rank relative to other fish species is less clear.

Aside from eulachon, I believe that it is appropriate to assign all other fish taxa to rank groups equivalent to their size groups. Thus, sturgeon and salmon are highranked prey, the four large-bodied minnow species and the largescale sucker are middle-ranked prey, and stickleback and the three small-bodied minnow species are low-ranked prey. Small minnow/sucker specimens that may represent juveniles of the large minnow and sucker species are also low-ranked prey.

As I have utilized Huber et al.'s (2011) model to identify chinook versus nonchinook salmon, it is relevant to further differentiate rankings within the salmon.

\section{Chinook are considerably larger and are therefore higher-ranked than the other} salmon species. This ranking is in agreement with ethnohistoric accounts, which single out chinook in particular as highly valued.

\section{Estimating Sturgeon Abundance:}

\section{Controlling for Identifiability and Fragmentation in the 1/4" Mesh Samples}

The unique nature of sturgeon bone makes quantifying it potentially problematic. Because very small fragments can be identified as sturgeon based on texture alone, the degree of fragmentation is potentially an important variable affecting the sturgeon NISP. Given this, two questions arise that must be answered before the relative contribution of sturgeon to the fish assemblage can be examined. First, should sturgeon specimens that 
cannot be identified to element be included in the analysis, and, second, is NISP a robust quantification measure for sturgeon?

I suggest that sturgeon specimens unidentifiable to element should indeed be included alongside identifiable skeletal elements in the sturgeon NISP. Sturgeon unidentifiable to element makes up a huge proportion of the total sturgeon in the $1 / 4$ " mesh sample. By number of specimens, it accounts for $73-83 \%$ of the total sturgeon (Tables $10-11$ ), and by weight it accounts for $48 \%-65 \%$ of the sturgeon (Tables $12-13$ ). Much information therefore would be lost if specimens unidentifiable to element were omitted from the analysis. There is also precedence for this decision, as Broughton (1995) includes these sturgeon specimens in his analysis.

Furthermore, removing the specimens unidentifiable to element from the analysis would not result in equivalent decreases in the contribution of sturgeon relative to other taxa across the site. In other words, sturgeon is not equally identifiable across the social units (i.e. House 1 vs. House 4 and Compartment H1d vs. Compartments H1b \& H1c). By both number of specimens (Table 10) and weight (Table 12), sturgeon specimens unidentifiable to element represent a significantly greater proportion of the sturgeon in House 4 than in House 1. Sturgeon specimens unidentifiable to element also represent a significantly greater proportion of sturgeon in Compartments H1b \& H1c than in Compartment H1d by weight (Table 13), though if number of specimens alone is considered, there is no statistical difference in the distribution of unidentifiable versus identifiable specimens within House 1 (Table 11). Thus, the effect of excluding the sturgeon specimens unidentifiable to element from the analysis varies both by social unit and by method of measurement. 
Table 10. Frequency of Sturgeon Specimens Unidentifiable Versus Identifiable to Element, Houses 1 and 4.

\begin{tabular}{lccc}
\hline House & $\begin{array}{c}\text { N Specimens } \\
\text { Unidentifiable to } \\
\text { Element }\end{array}$ & $\begin{array}{c}\text { N Specimens } \\
\text { Identifiable to } \\
\text { Element }\end{array}$ & $\begin{array}{c}\text { \% Specimens } \\
\text { Unidentifiable to } \\
\text { Element by N }\end{array}$ \\
\hline House 1 & 1351 & 490 & $73.38 \%$ \\
House 4 & 674 & 138 & $83.00 \%$ \\
\hline
\end{tabular}

Pearson Chi-Square $=28.866, \mathrm{df}=1, \mathrm{p}<0.001$

Table 11. Frequency of Sturgeon Specimens Unidentifiable Versus Identifiable to Element, House 1 Compartments.

\begin{tabular}{lccc}
\hline Compartment & $\begin{array}{c}\text { N Specimens } \\
\text { Unidentifiable to } \\
\text { Element }\end{array}$ & $\begin{array}{c}\text { N Specimens } \\
\text { Identifiable to } \\
\text { Element }\end{array}$ & $\begin{array}{c}\text { \% Specimens } \\
\text { Unidentifiable to } \\
\text { Element by N }\end{array}$ \\
\hline H1d & 731 & 261 & $73.69 \%$ \\
H1b \& H1c & 620 & 229 & $73.03 \%$ \\
\hline
\end{tabular}

Pearson Chi-Square $=0.103, \mathrm{df}=1, \mathrm{p}=0.749$

Table 12. Weight (g) of Sturgeon Specimens Unidentifiable Versus Identifiable to Element, Houses 1 and 4.

\begin{tabular}{lccc}
\hline House & $\begin{array}{c}\text { Weight of Specimens } \\
\text { Unidentifiable to } \\
\text { Element }\end{array}$ & $\begin{array}{c}\text { Weight of Specimens } \\
\text { Identifiable to } \\
\text { Element }\end{array}$ & $\begin{array}{c}\text { \% Specimens } \\
\text { Unidentifiable to } \\
\text { Element by Weight }\end{array}$ \\
\hline House 1 & 485 & 453 & $51.71 \%$ \\
House 4 & 240 & 151 & $61.38 \%$ \\
\hline
\end{tabular}

Pearson Chi-Square $=10.420, \mathrm{df}=1, \mathrm{P}=0.001$

Table 13. Weight (g) of Sturgeon Specimens Unidentifiable Versus Identifiable to Element, House 1 Compartments.

\begin{tabular}{lccc}
\hline Compartment & $\begin{array}{c}\text { Weight of Specimens } \\
\text { Unidentifiable to } \\
\text { Element }\end{array}$ & $\begin{array}{c}\text { Weight of Specimens } \\
\text { Identifiable to } \\
\text { Element }\end{array}$ & $\begin{array}{c}\text { \% Specimens } \\
\text { Unidentifiable to } \\
\text { Element by Weight }\end{array}$ \\
\hline H1d & 341 & 375 & $47.63 \%$ \\
H1b \& H1c & 144 & 78 & $64.86 \%$ \\
\hline
\end{tabular}

Pearson Chi-Square $=20.168, \mathrm{df}=1, \mathrm{p}<0.001$ 
Taking a look at the interaction between house unit, specimen identifiability, and weight allows us to better understand the complexity in the spatial distribution of sturgeon. In this analysis, house/compartment unit and specimen identifiability are independent variables, while weight of sturgeon sample is the dependent variable in a two-way ANOVA. Comparing Houses 1 and 4 (Table 14), specimens identifiable to element weigh significantly more than specimens unidentifiable to element $(p<0.001)$, but there is no statistical difference in the weights of sturgeon specimens between the two houses $(p=0.094)$. Looking at the compartments within House 1, the differences are more significant (Table 15). Specimens identifiable to element again are significantly larger than specimens unidentifiable to element $(\mathrm{p}<0.001)$, but additionally there is a significant difference in the weights of specimens between the two compartment groups. Compartment H1d has significantly larger specimens than Compartments H1b \& H1c. There is also a statistically significant interaction between the two dependent variables, meaning that the weights of identifiable versus unidentifiable elements vary based on whether the specimens were from Compartment H1d or Compartments H1b \& H1c. Because of the significant variability in the distribution of sturgeon specimens by weight, particularly when comparing between the House 1 compartments, number of specimens alone does not provide an accurate representation of sturgeon distribution across the social units. 
Table 14. Comparison of Weights (g) of Sturgeon Specimens Identifiable Versus Unidentifiable to Element, Houses 1 and 4.

\begin{tabular}{lcccc}
\hline House & $\begin{array}{c}\text { Specimen } \\
\text { Identifiable to } \\
\text { Element? }\end{array}$ & Mean Weight & Std. Deviation & $\mathrm{N}$ \\
\hline House 1 & Yes & 0.924 & 1.788 & 490 \\
House 4 & No & 0.360 & 0.426 & 1351 \\
& Yes & 1.093 & 1.536 & 138 \\
& No & 0.356 & 0.317 & 674 \\
\hline
\end{tabular}

2-Way ANOVA Results: Identifiability $\mathrm{F}=177.251$, $\mathrm{df}=1, \mathrm{p}<0.001$; House $\mathrm{F}=2.806$, $\mathrm{df}=1, \mathrm{p}=0.094$; Identifiability-House Interaction $\mathrm{F}=3.149, \mathrm{df}=1, \mathrm{p}=0.076$

Table 15. Comparison of Weights ( $\mathrm{g}$ ) of Sturgeon Specimens Identifiable Versus Unidentifiable to Element, House 1 Compartments.

\begin{tabular}{lcccc}
\hline & $\begin{array}{c}\text { Specimen } \\
\text { Identifiable to }\end{array}$ & & & \\
Compartment & Element? & Mean Weight & Std. Deviation & N \\
\hline H1d & Yes & 1.438 & 2.306 & 261 \\
& No & 0.466 & 0.504 & 731 \\
H1b \& H1c & Yes & 0.339 & 0.384 & 229 \\
& No & 0.235 & 0.261 & 620 \\
\hline
\end{tabular}

2-Way ANOVA Results: Identifiability $\mathrm{F}=115.593, \mathrm{df}=1, \mathrm{p}<0.001$; Compartment $\mathrm{F}=$ 176.990, df $=1, p<0.001$; Identifiability-Compartment Interaction $F=75.472$, df $=1, p$ $<0.001$

I have chosen to use all sturgeon specimens from the 1/4" mesh in my analyses regardless of identifiability, so it is useful to look at how sturgeon specimen weight varies across social units with sturgeon specimens both unidentifiable and identifiable to element combined (Tables 16 and 17). While the weights of sturgeon specimens are similar between Houses 1 and $4(t=0.743, p=0.457)$ (Table 16), the average sturgeon specimen in Compartment H1d weighs nearly 3 times as much as the average specimen in Compartments H1b \& H1c, which is a statistically significant difference $(t=9.844, p<$ 0.001) (Table 17). This is apparent in the fact that the amount of sturgeon excavated from the two compartment groups within House 1 appears to be similar by count $(\mathrm{H} 1 \mathrm{~d}$ : $\mathrm{N}$ 
$=992 ; \mathrm{H} 1 \mathrm{~b} \& \mathrm{H} 1 \mathrm{c}: \mathrm{N}=849)$, but the actual bulk of sturgeon excavated from H1d $(716 \mathrm{~g})$ is far greater than that excavated from H1b \& H1c (222 g). Therefore, if count alone were used in the analysis, the contribution of sturgeon relative to other fish would be inflated in $\mathrm{H} 1 \mathrm{~b} \& \mathrm{H} 1 \mathrm{c}$ due to the presence of many very small fragments of sturgeon in these compartments.

Table 16. Comparison of Sturgeon Specimen Weights (g) with Specimens Unidentifiable and Identifiable to Element Combined, Houses 1 and 4.

\begin{tabular}{lccc}
\hline House & Mean Weight & N All Sturgeon & Std. Deviation \\
\hline House 1 & 0.511 & 1841 & 1.022 \\
House 4 & 0.481 & 812 & 0.747 \\
\hline
\end{tabular}

T-Test: $\mathrm{t}=0.743, \mathrm{p}=0.457$

Table 17. Comparison of Sturgeon Specimen Weights (g) with Specimens Unidentifiable and Identifiable to Element Combined, House 1 Compartments.

\begin{tabular}{lccc}
\hline Compartment & $\begin{array}{c}\text { Mean Weight All } \\
\text { Sturgeon }\end{array}$ & N All Sturgeon & Std. Deviation \\
\hline H1d & 0.722 & 992 & 1.329 \\
H1b \& H1c & 0.263 & 849 & 0.302 \\
\hline
\end{tabular}

T-Test: $\mathrm{t}=9.844, \mathrm{p}<0.001$

It is possible that the observed differences in the sizes of sturgeon specimens, as measured by weight, could be due to the differences in the rates of burning of the specimens. Stiner et al. (1995) found that burned bone is more fragile and brittle and thus more susceptible to fragmentation than unburned bone. Just as there is no statistical difference in the weights of sturgeon specimens between the two houses, there is also no statistical difference in proportion of sturgeon specimens that are burned in House 1 versus House 4 (chi-square $=1.701, \mathrm{p}=0.192)$. The percentage of sturgeon specimens with evidence of burning ranges from $5.9 \%$ in House 4 to $7.3 \%$ in House 1 . Likewise, as the weights of sturgeon specimens in Compartment H1d are significantly greater than in 
Compartments $\mathrm{H} 1 \mathrm{~b} \& \mathrm{H} 1 \mathrm{c}$, the proportion of specimens that are burned is also significantly lower in H1d than in H1b \& H1c (chi-square $=154.900, p<0.001)$. The percentage of sturgeon specimens with evidence of burning in Compartment H1d is only $3.1 \%$, while the percentage with evidence of burning in Compartments H1b \& H1c is $20.8 \%$. It is likely that higher rates of burning in $\mathrm{H} 1 \mathrm{~b} \& \mathrm{H} 1 \mathrm{c}$ led to greater fragmentation and thus the smaller sizes of sturgeon specimens observed in these compartments.

Due to the large differences in the weights of sturgeon specimens, particularly between compartments in House 1, weight is a better measurement of sturgeon quantity than count. However, this means that I must address how to compare weight of sturgeon to NISP of all other fish taxa. To make these measures comparable, I performed a transformation on the weights of sturgeon specimens to create sturgeon counts that are standardized by weight. This involved dividing the weight of each sturgeon sample by the mean specimen weight for the entire analyzed $1 / 4$ " sturgeon assemblage, which is $0.501 \mathrm{~g}$. Performing this transformation means that the overall count of sturgeon in the analysis remains the same, but the counts are redistributed based on specimen weights, and very large pieces of sturgeon count for more than very small pieces. For example, if a particular unit/level contains 3 pieces of sturgeon weighing a total of $0.88 \mathrm{~g}$, these sturgeon specimens are smaller than average, so their count scaled for weight is only 1.76 $(0.88 / 0.501=1.76)$. Conversely, if a particular unit/level contains only 1 piece of sturgeon weighing $2.47 \mathrm{~g}$, this sturgeon piece is much larger than average, so its count scaled for weight is 4.93 .

The overall effect that adjusting the sturgeon counts by weight has on the analysis can be seen by comparing the two graphs in Figures 3 and 4 . Figure 3 compares fish taxa 
frequencies from the $1 / 4$ " mesh sample between House 1 compartments with sturgeon measured as raw count, unadjusted for weight. Figure 4 shows this same comparison with sturgeon measured as count scaled by weight. Because the sturgeon specimens weigh so much more in Compartment H1d than in Compartments H1b \& H1c, the sturgeon count dramatically increases for H1d and decreases for H1b \& H1c when sturgeon count is scaled by weight. The contributions of sturgeon relative to other fish also changes, with sturgeon becoming relatively more important in Compartment H1d and less important in Compartments H1b \& H1c. As Figure 4 takes sturgeon fragmentation into account, it should be a better representation of the actual contribution of sturgeon in the diet. Therefore, for the remainder of the $1 / 4$ " mesh analysis, I will only be utilizing sturgeon counts scaled by weight.

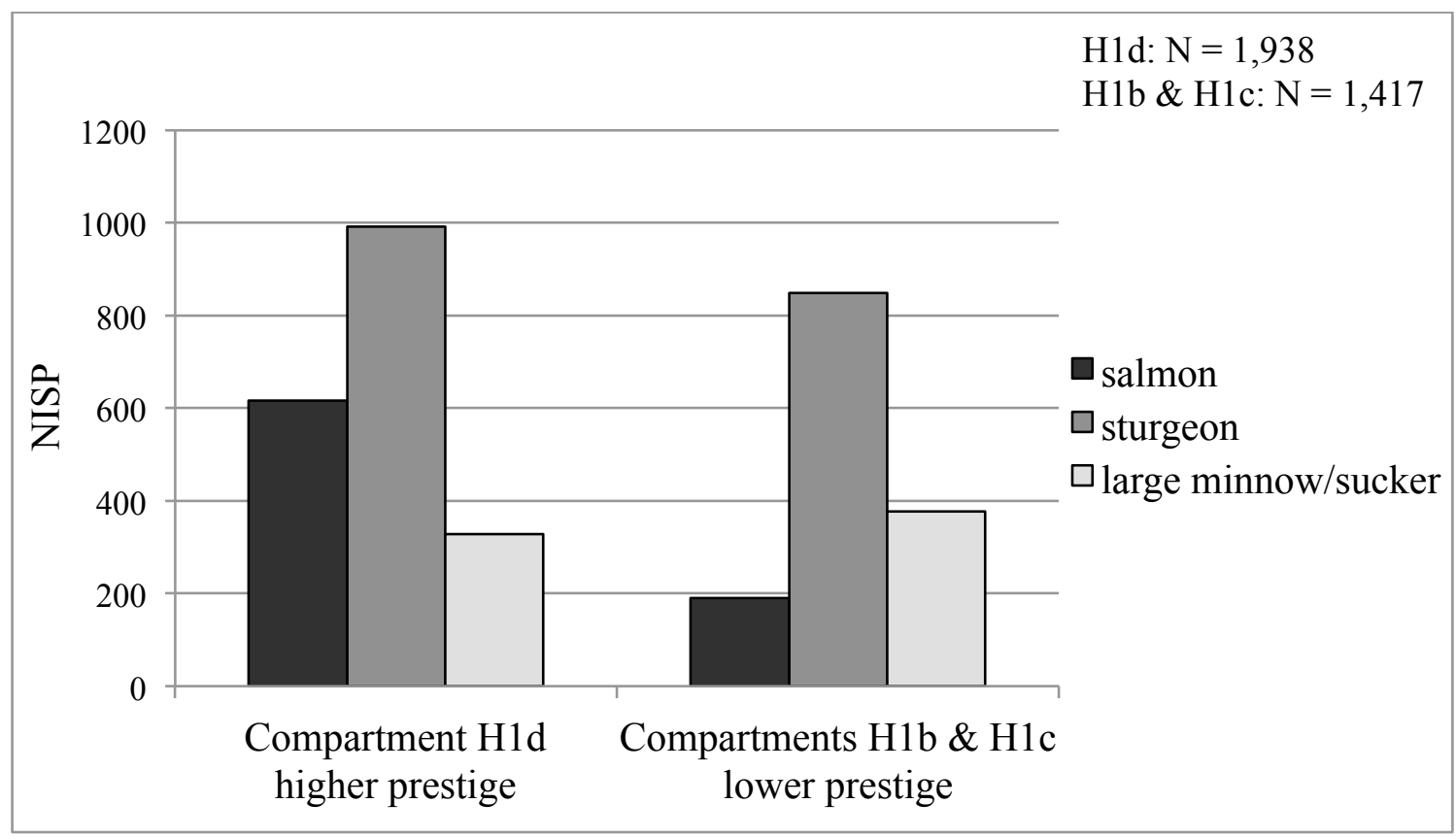

Figure 3. Frequencies of fish taxa ( $1 / 4$ " mesh screens) within House 1 compartments with raw sturgeon counts, unadjusted for weight. Single Cottus specimen from Compartment H1d excluded. 


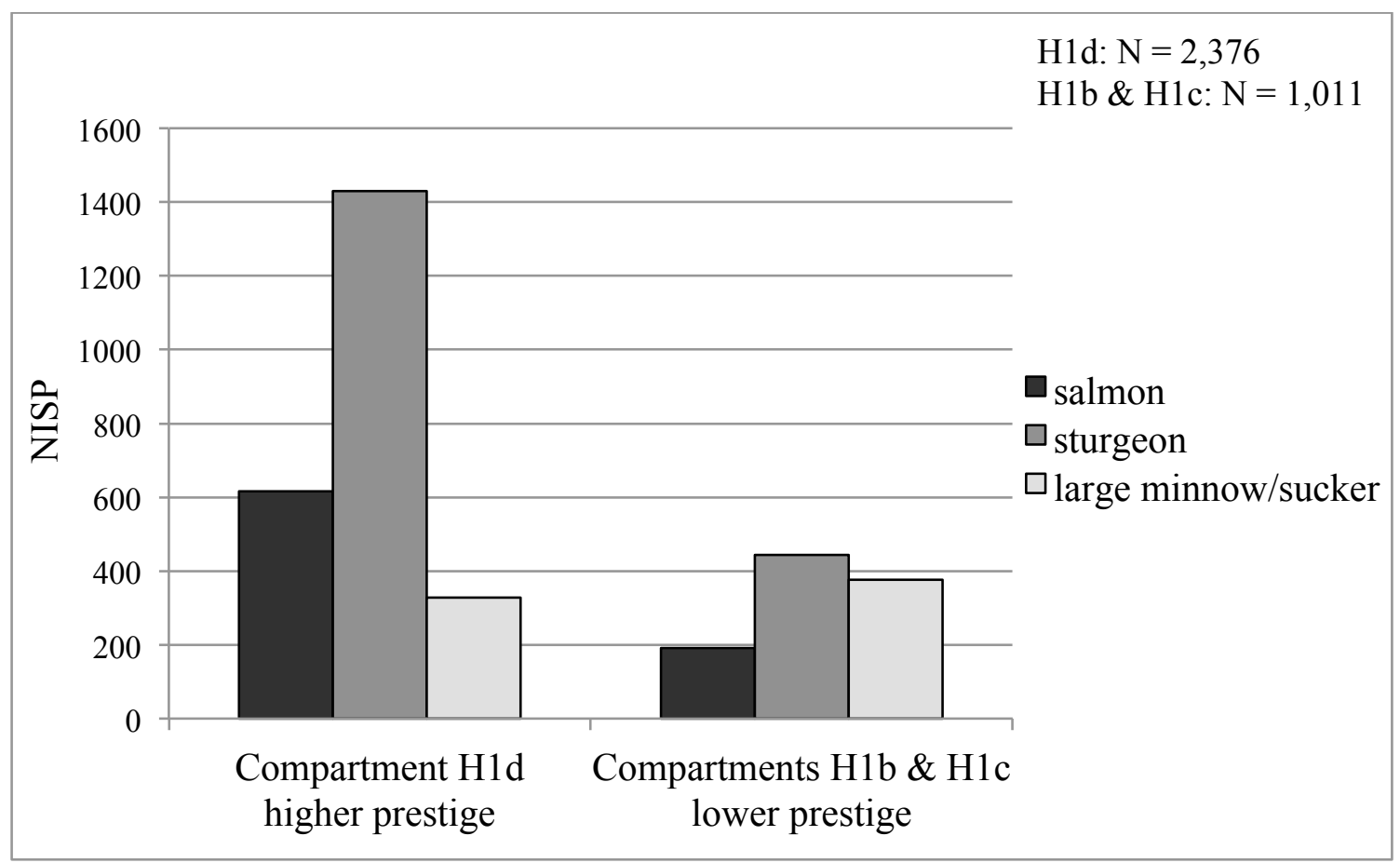

Figure 4. Frequencies of fish taxa ( $1 / 4$ " mesh screens) within House 1 compartments with sturgeon counts scaled by weight. Single Cottus specimen from H1d excluded.

\section{Evaluation of Expectations: 1/4" Mesh Samples}

Figure 5 summarizes the contributions of fish taxa recorded in the $1 / 4$ " mesh analysis for both houses combined. It is apparent from this that sturgeon was an important resource at Cathlapotle, making up nearly $60 \%$ of the fish assemblage. Comparing percent contributions of fish taxa within each house (Figure 6), the overall pattern appears to be fairly similar between the two houses, with sturgeon dominating and salmon ranking second in both houses, followed by large minnow/sucker. However, a Pearson Chi-Square test reveals that there are indeed significant differences in the relative contributions of fish taxa between the two houses (chi-square $=79.185, \mathrm{p}<0.001)$. Salmon is similarly represented, but House 1, which is the higher prestige house, has 
significantly more large-bodied minnow/sucker, while House 4 has significantly more sturgeon.

Comparing between compartments within House 1, Figure 7 shows the percent contributions of fish taxa within each compartment/compartment group. Overall, there are more differences between the compartments within House 1 than there are between the houses. Sturgeon dominates in Compartment H1d, which is the higher prestige compartment, but large minnow/sucker is almost as important as sturgeon in Compartments H1b \& H1c. A Pearson Chi-Square test shows that the differences between the compartments are significant $($ chi-square $=247.759, \mathrm{p}<0.001)$. Compartment H1d has significantly more salmon, more sturgeon, and less large minnow/sucker.

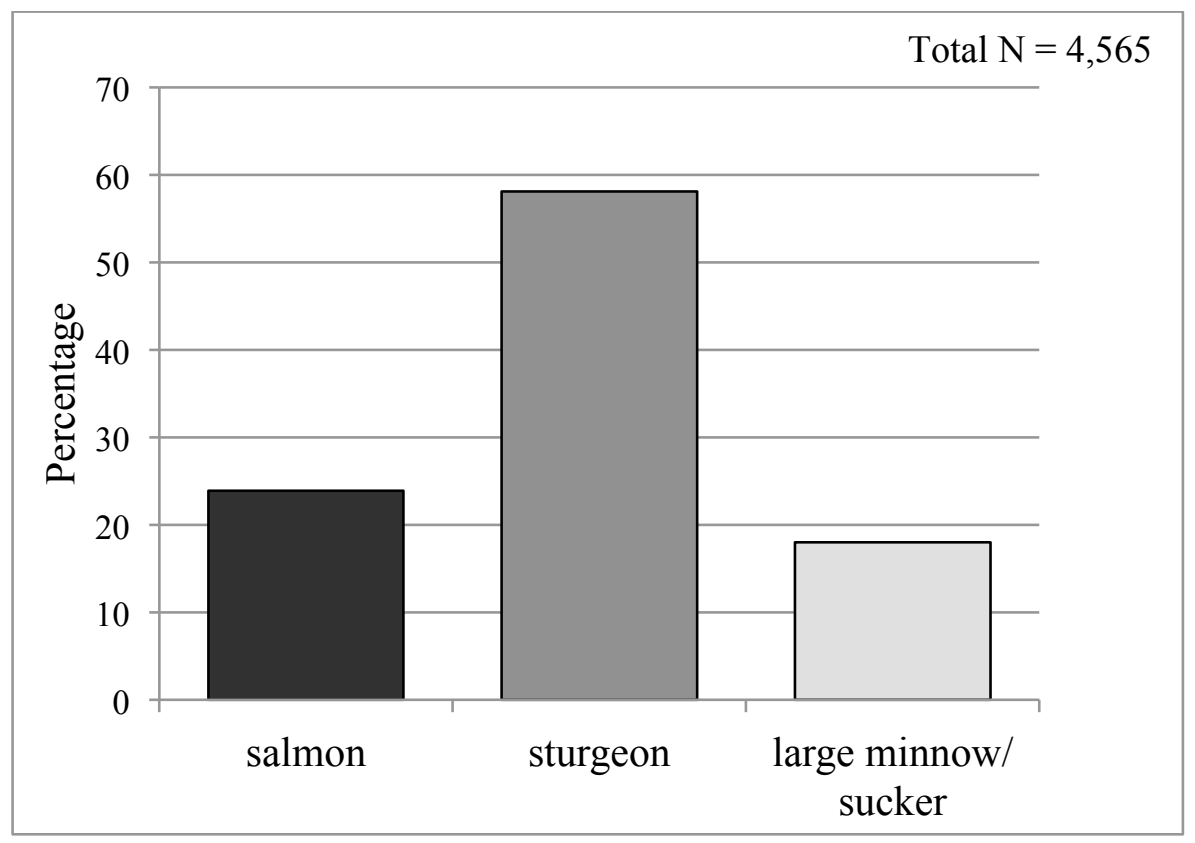

Figure 5. Proportion of fish taxa in Houses 1 and 4 (1/4" mesh screen). Single Cottus specimen from H1d excluded. 


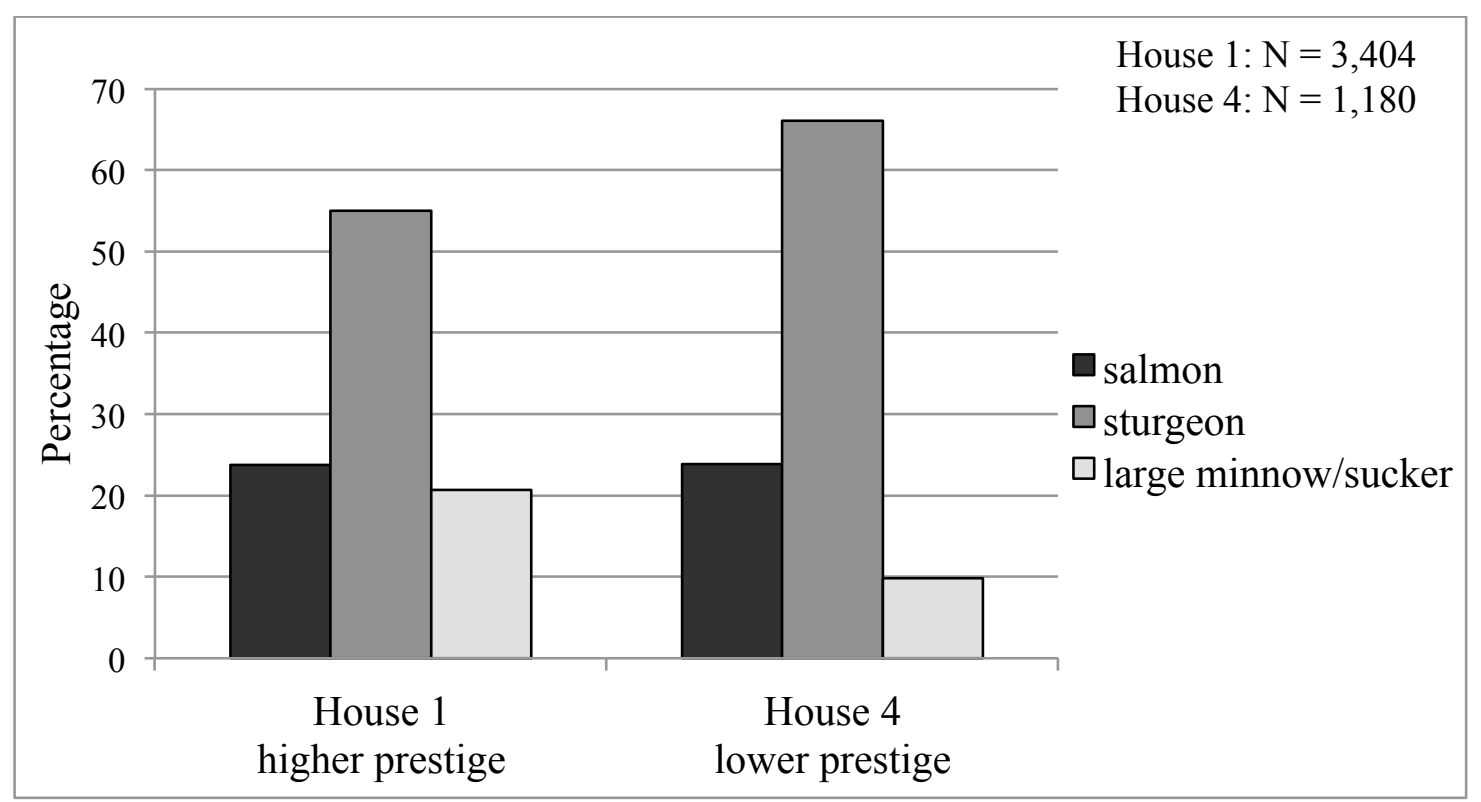

Figure 6. Percent contributions of each fish taxon to total fish assemblage within each house ( $1 / 4$ " mesh screens). Sturgeon percentages based on counts scaled by weight. Single Cottus specimen from H1d excluded.

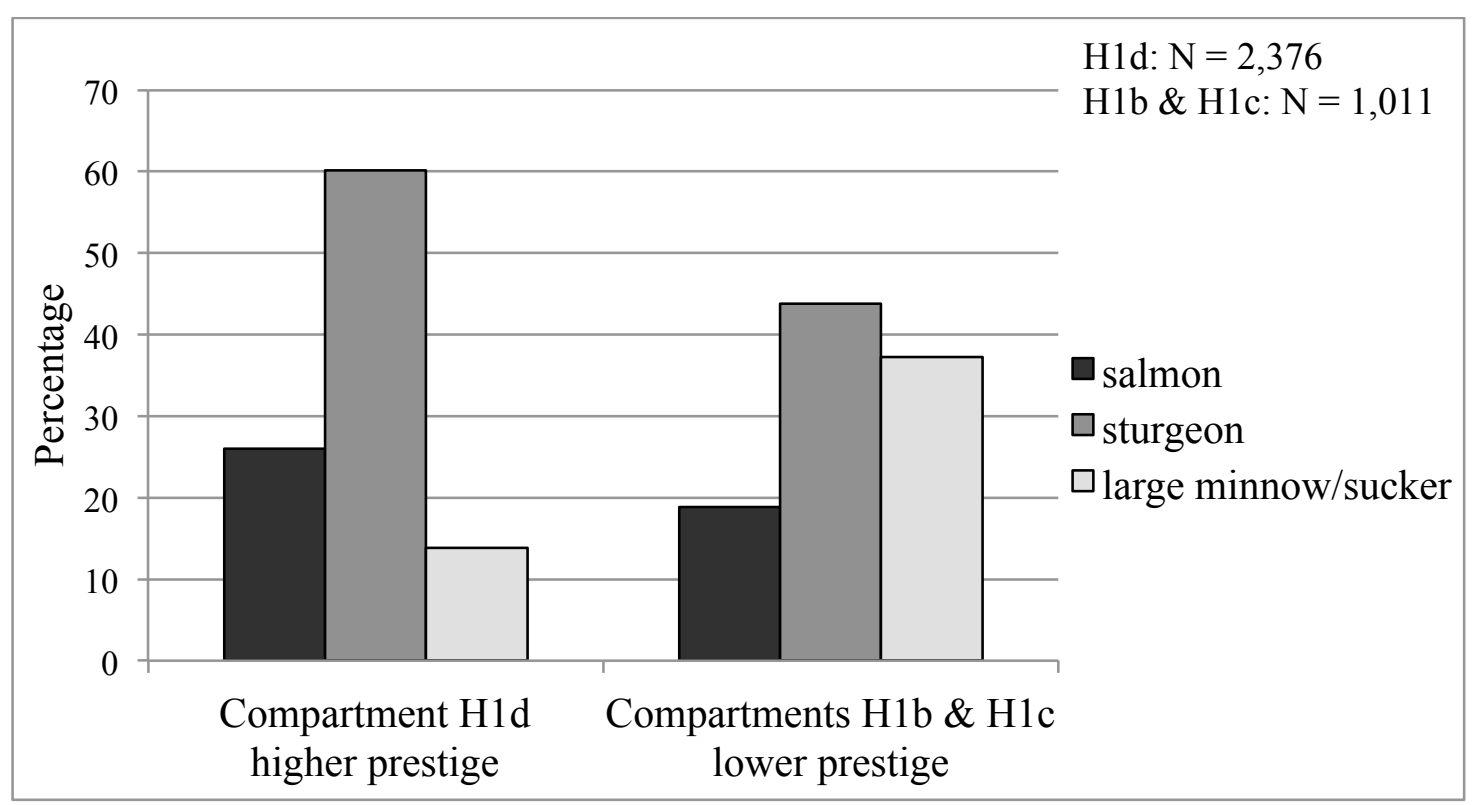

Figure 7. Percent contributions of each fish taxon to total fish assemblage within each compartment group in House 1 ( $1 / 4$ " mesh screens). Sturgeon percentages based on counts scaled by weight. Single Cottus specimen from H1d excluded. 


\section{Evaluation of Expectations for Salmon Species: 1/4" Mesh Samples}

For my analysis thus far, I have lumped all salmon species into a single category. As discussed previously, it is useful and feasible to separate out the larger, higher-ranked chinook salmon from the other salmon species using Huber et al.'s (2011) morphometric model. The total sample size for both houses of salmon vertebrae that could be measured is 338 vertebrae.

Figure 8 compares the proportion of chinook versus non-chinook salmon within each house. There is significantly more chinook in House 1 than House 4, with chinook accounting for $73 \%$ of the salmon in House 1 and only $38 \%$ of the salmon in House 4 (chi-square $=26.801, \mathrm{p}<0.001)$. Thus, even though Houses 1 and 4 have about the same proportion of salmon relative to other fish taxa, the salmon that the members of House 1 were eating were a larger and more highly ranked salmon species.

Figure 9 compares the proportion of chinook versus non-chinook salmon within each compartment group in House 1. There is significantly more chinook in Compartment H1d than in Compartments H1b \& H1c, with chinook accounting for $80 \%$ of the salmon in H1d and only $43 \%$ of the salmon in H1b \& H1c (chi-square $=29.174, p$ $<0.001$ ). Thus, not only were the members of Compartment H1d consuming proportionately more salmon than the members of Compartments H1b\&c, they were also consuming more of the larger, more highly-ranked salmon species. 


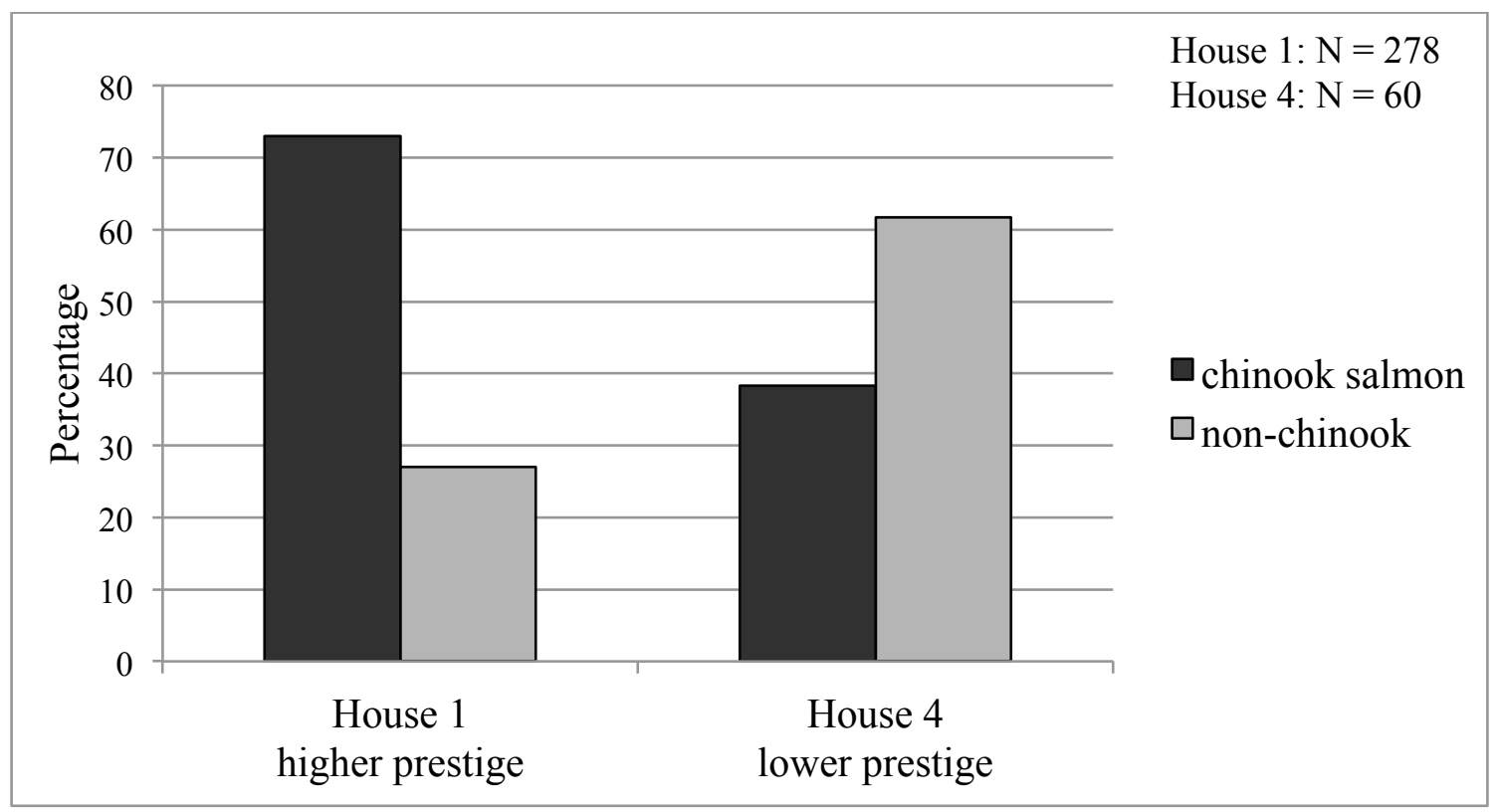

Figure 8. Percent contributions of chinook versus non-chinook salmon within each house.

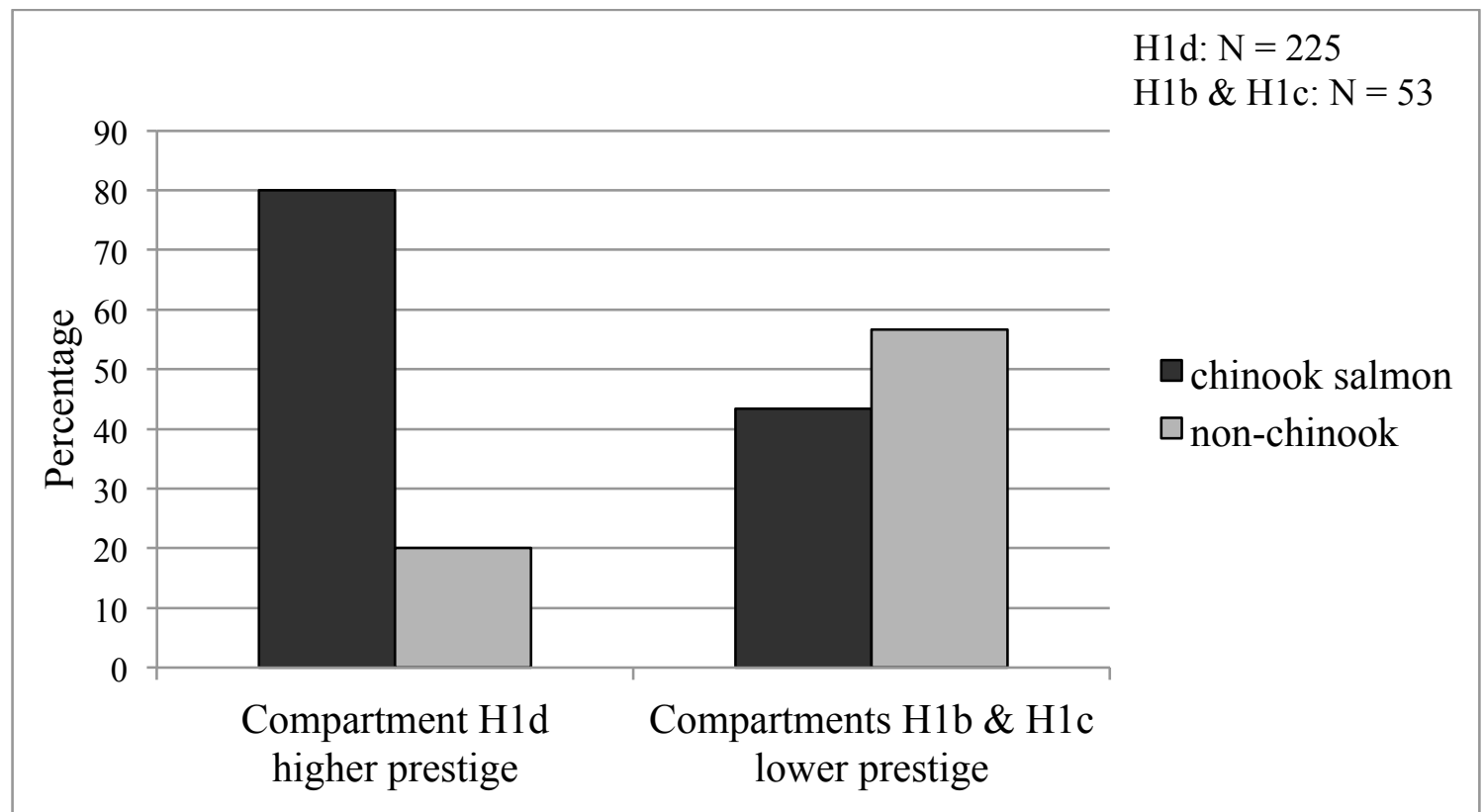

Figure 9. Percent contributions of chinook versus non-chinook salmon within each compartment group in House 1.

Evaluation of Expectations: Bulk Samples (4 mm, $2 \mathrm{~mm}$, and $1 \mathrm{~mm}$ Mesh Fractions)

Figure 10 summarizes the frequency of fish taxa recorded in the fine mesh analysis. The quantities of salmon and sturgeon shown here are particularly high given 
the relatively large sizes of these taxa and the relatively small volume of matrix these samples represent. These salmon and sturgeon counts likely are heavily inflated due to fragmentation and therefore are not the most representative portrayal of the relative salmon and sturgeon contributions to the fine mesh fish assemblage. As noted above, the unique texture of all sturgeon bone as well as salmon vertebrae means that even extremely small fragments can be identified. Because of this, large quantities of sturgeon specimens unidentifiable to element $(\mathrm{N}=903)$ and salmon vertebral fragments $(\mathrm{N}=724)$ were identified in the $1 \mathrm{~mm}$ mesh fraction. These quantities are therefore heavily affected by fragmentation, and any potential differences in quantities between proveniences could very well be primarily due to differences in fragmentation rates.

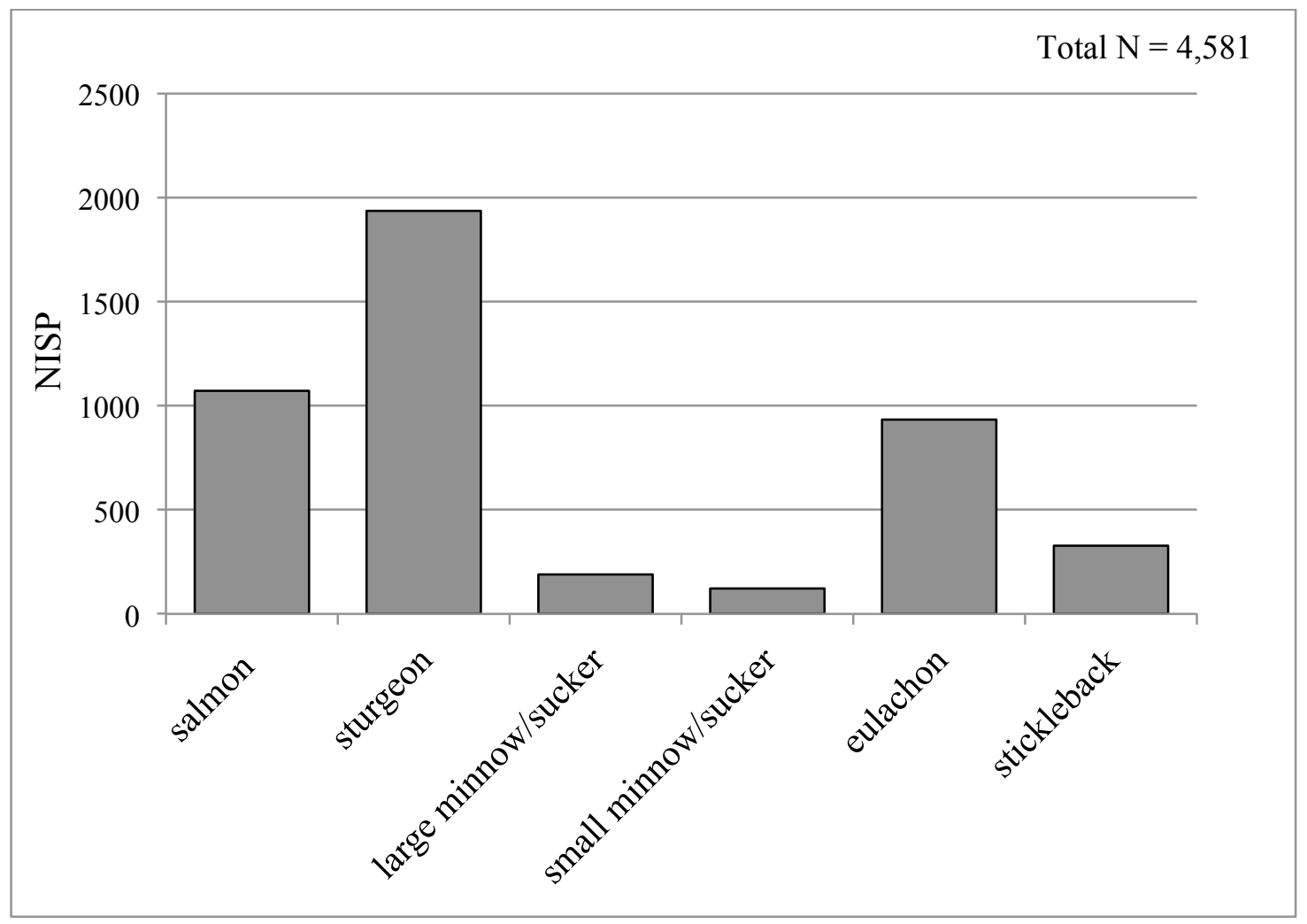

Figure 10. Frequency of fish taxa identified in all analyzed bulk samples $(4 \mathrm{~mm}, 2 \mathrm{~mm}$, and $1 \mathrm{~mm}$ fractions), including estimated values for the $1 \mathrm{~mm}$ fraction. Single Cottus specimen from H1d excluded. 
I accounted for differences in sturgeon fragmentation rates across social units in the $1 / 4 "$ mesh by scaling counts by weight. It was impractical to weigh the sturgeon fragments from the $1 \mathrm{~mm}$ mesh fractions, so instead I have chosen to exclude the $1 \mathrm{~mm}$ sturgeon specimens from my analysis, using only the $4 \mathrm{~mm}$ and $2 \mathrm{~mm}$ sturgeon specimens (including those that are unidentifiable as well as identifiable to element). In all of the following analyses, sturgeon specimens have been scaled by weight using the average weight of sturgeon specimens from the larger bulk fractions, $0.035 \mathrm{~g}$. In line with eliminating the smallest sturgeon fragments from the analysis to help account for differential fragmentation, I have chosen to do the same for the salmon, excluding from the analysis all salmon vertebral fragments recovered from the $1 \mathrm{~mm}$ mesh for all of the following analyses.

Eliminating these smallest salmon and sturgeon fragments should result in a more accurate understanding of the relative contributions of fish taxa in the bulk samples. Figure 11 shows the frequencies of all fish recorded in the fine mesh analysis, excluding the very small salmon and sturgeon fragments. From this, we see that sturgeon and eulachon dominate, with salmon and stickleback ranking next in importance. The proportion of large minnow/sucker relative to salmon and sturgeon is lower here than in the 1/4" assemblage (compare to Figure 5), and small minnow/sucker, likewise, represents a small proportion of the bulk assemblage. 


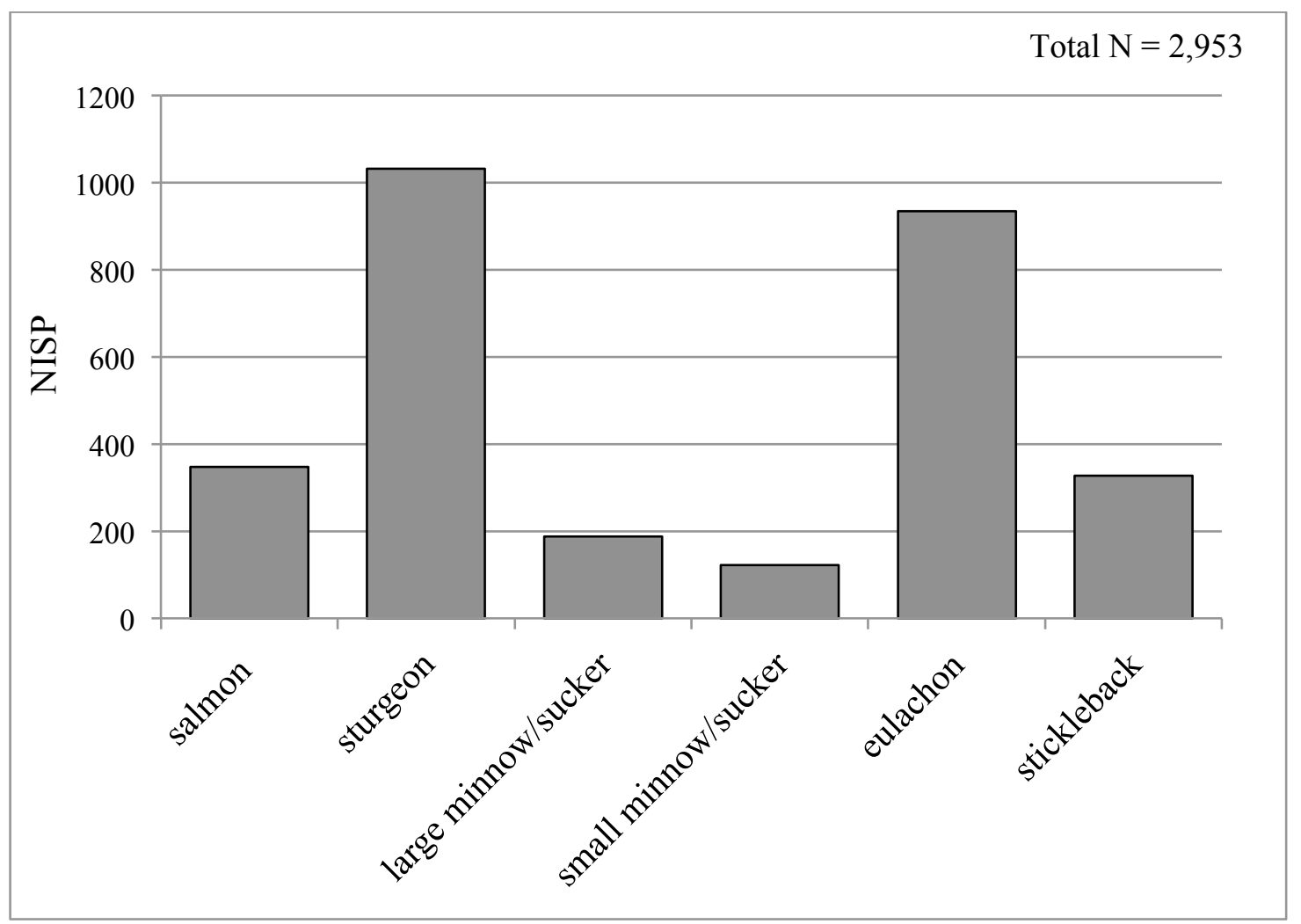

Figure 11. Frequency of fish taxa identified in all analyzed bulk samples $(4 \mathrm{~mm}, 2 \mathrm{~mm}$, and $1 \mathrm{~mm}$ fractions), excluding sturgeon fragments and salmon vertebral fragments from the $1 \mathrm{~mm}$ fraction, including estimated values for the $1 \mathrm{~mm}$ fraction. Single Cottus specimen from H1d excluded.

Looking now to comparisons between houses, Figure 12 shows the percent contributions of fish groups from the bulk samples within each house. While there are generally similar patterns, a Pearson Chi-Square test reveals that there are significant differences between the houses (chi-square $=48.945, \mathrm{p}<0.001)$. Based on adjusted residuals, there is significantly more eulachon in House 1 (the higher prestige house) than in House 4, while there is significantly more sturgeon and large minnow/sucker in House 4. Other differences in taxonomic frequencies between houses are not significant.

Figure 13 shows the percent contributions of fish groups from the bulk samples within each compartment group in House 1. A Pearson Chi-Square test shows that there 
are significant differences between the compartments (chi-square $=728.244, \mathrm{p}<0.001$ ). Based on adjusted residuals, there is significantly more salmon, eulachon, and stickleback in Compartment H1d (the higher prestige compartment) than in Compartments H1b \& $\mathrm{H} 1 \mathrm{c}$, where there is significantly more sturgeon and small minnow/sucker. 


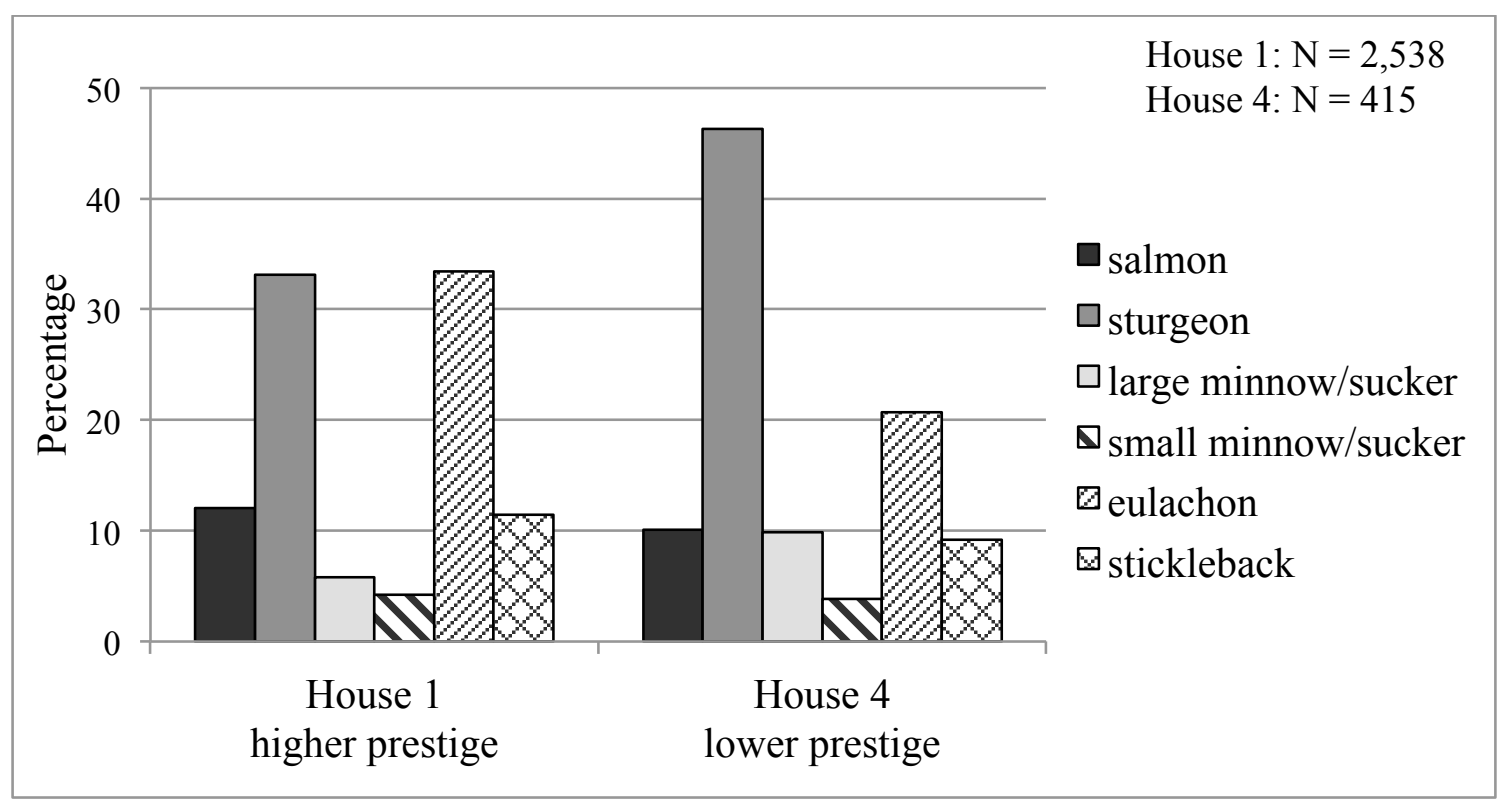

Figure 12. Percent contributions of each fish taxon to total fish assemblage within each house (bulk sample $4 \mathrm{~mm}, 2 \mathrm{~mm}$, and $1 \mathrm{~mm}$ fractions), excluding sturgeon fragments and salmon vertebral fragments from the $1 \mathrm{~mm}$ fraction, including estimated values for the 1 $\mathrm{mm}$ fraction. Sturgeon specimens have been scaled by weight. Single Cottus specimen from H1d excluded.

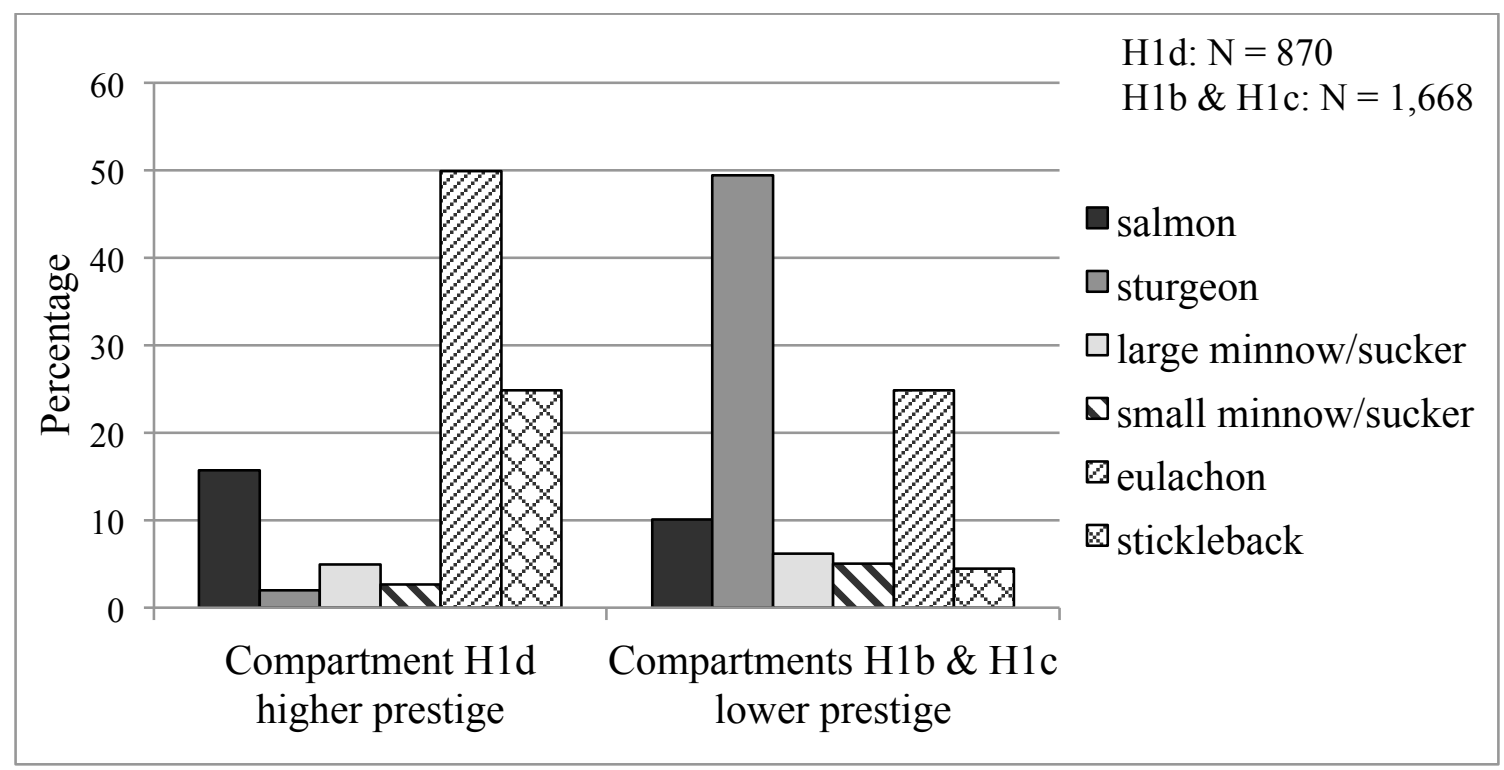

Figure 13. Percent contributions of each fish group to total fish assemblage within each compartment group in House 1 (bulk sample $4 \mathrm{~mm}, 2 \mathrm{~mm}$, and $1 \mathrm{~mm}$ fractions), excluding sturgeon fragments and salmon vertebral fragments from the $1 \mathrm{~mm}$ fraction, including estimated values for the $1 \mathrm{~mm}$ fraction. Sturgeon specimens have been scaled by weight. Single Cottus specimen from H1d excluded. 


\section{Analysis of Burning in Bulk Samples}

It is possible that differences in rates of burning can account for some of these differences in taxonomic representation across the site. As noted above, fragmentation in sturgeon was shown to be linked to burning in the $1 / 4$ " mesh samples. In the bulk samples, burning rates are far lower for the small fishes than the medium and large fishes (Figure 14). This is particularly true for eulachon and stickleback. Fewer than $1 \%$ of eulachon specimens have evidence of burning, as do fewer than $6 \%$ of stickleback specimens. A Pearson Chi-Square test confirms that burning rates differ significantly between fish groups $($ chi-square $=997.105, \mathrm{p}<0.001)$. Butler and Martin $(2013)$, who observed this pattern at several sites on the Lower Columbia, suggest that burned remains of eulachon and stickleback are more susceptible to disintegration than burned bones of larger fish. It was apparent during analysis that there were very few burned eulachon specimens given the overall rates of burning in the samples, and when I did come across burned eulachon vertebrae, they more than once disintegrated even with limited handling. While it is possible, as pointed out by Butler and Martin, that lower rates of burning of the small fishes could be due to differences in processing and disposal methods, it also cannot be ruled out that burning has led to differential preservation of small versus larger fishes. 


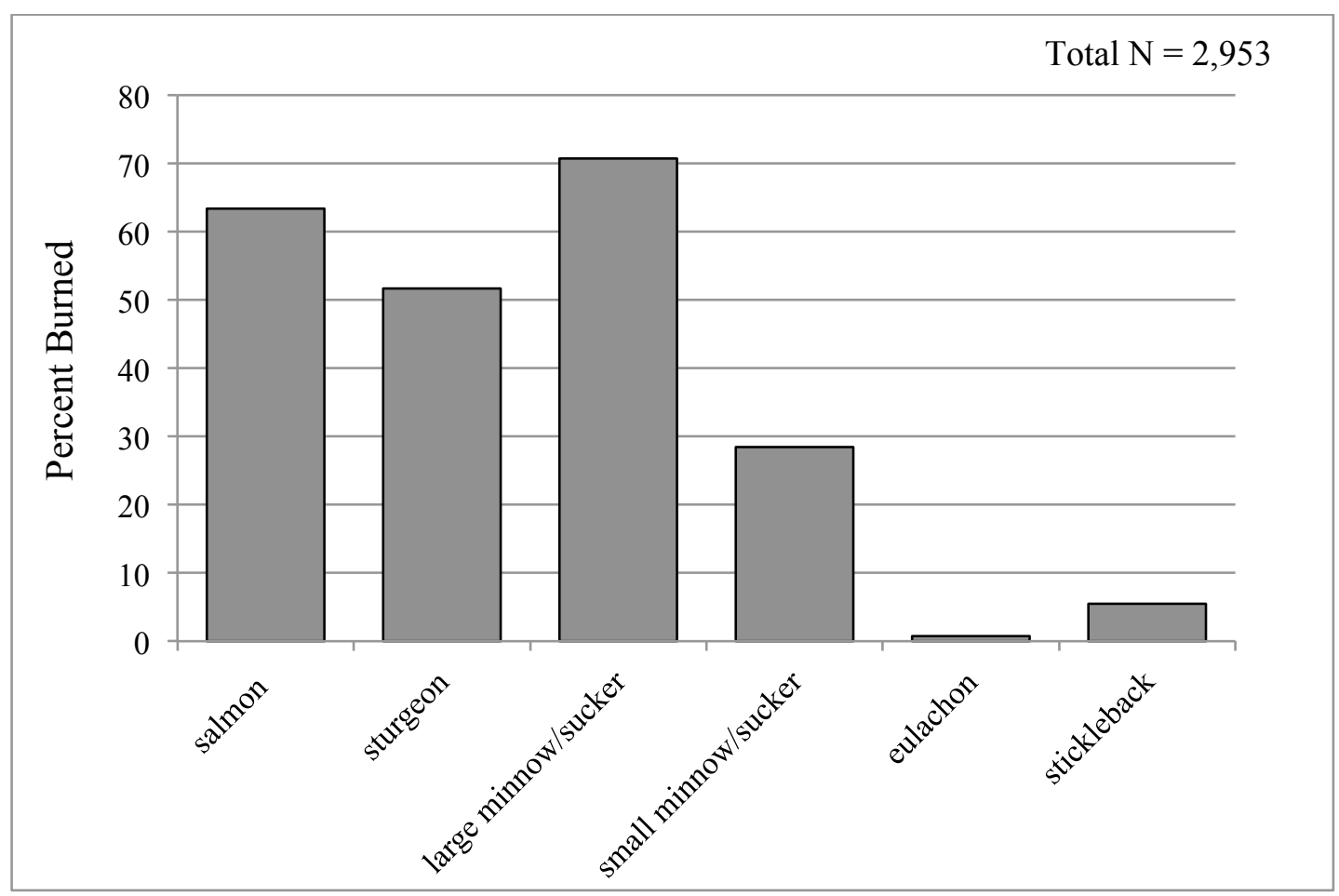

Figure 14. Percent of specimens from each fish group with evidence of burning (bulk sample $4 \mathrm{~mm}, 2 \mathrm{~mm}$, and $1 \mathrm{~mm}$ fractions), excluding sturgeon fragments and salmon vertebral fragments from the $1 \mathrm{~mm}$ fraction, including estimated values for the $1 \mathrm{~mm}$ fraction. Single Cottus specimen from H1d excluded.

Because it is possible that burning has differentially affected the preservation of taxa based on size, it is necessary to determine if rates of burning are equivalent across the site. If rates of burning vary between houses and compartments, it is possible that burning could be driving the observed differences in taxonomic representation between these areas. Pearson Chi-Square tests reveal that rates of burning do vary significantly both between Houses 1 and 4 (chi-square $=35.085, \mathrm{p}<0.001)$ and between compartments within House 1 (chi-square $=156.107, \mathrm{p}<0.001)$. Significantly more specimens are burned in House 1 than in House 4 (Figure 15), and significantly more specimens are burned in Compartments H1b \& H1c than in Compartment H1d (Figure 16). Indeed, close to half of the specimens in $\mathrm{H} 1 \mathrm{~b} \& \mathrm{H} 1 \mathrm{c}$ are burned. It is therefore 
possible that the much higher abundances of eulachon and stickleback in H1d relative to H1b \& H1c are more the result of differential preservation from burning than from differential rates of consumption of these fishes within these compartments. 


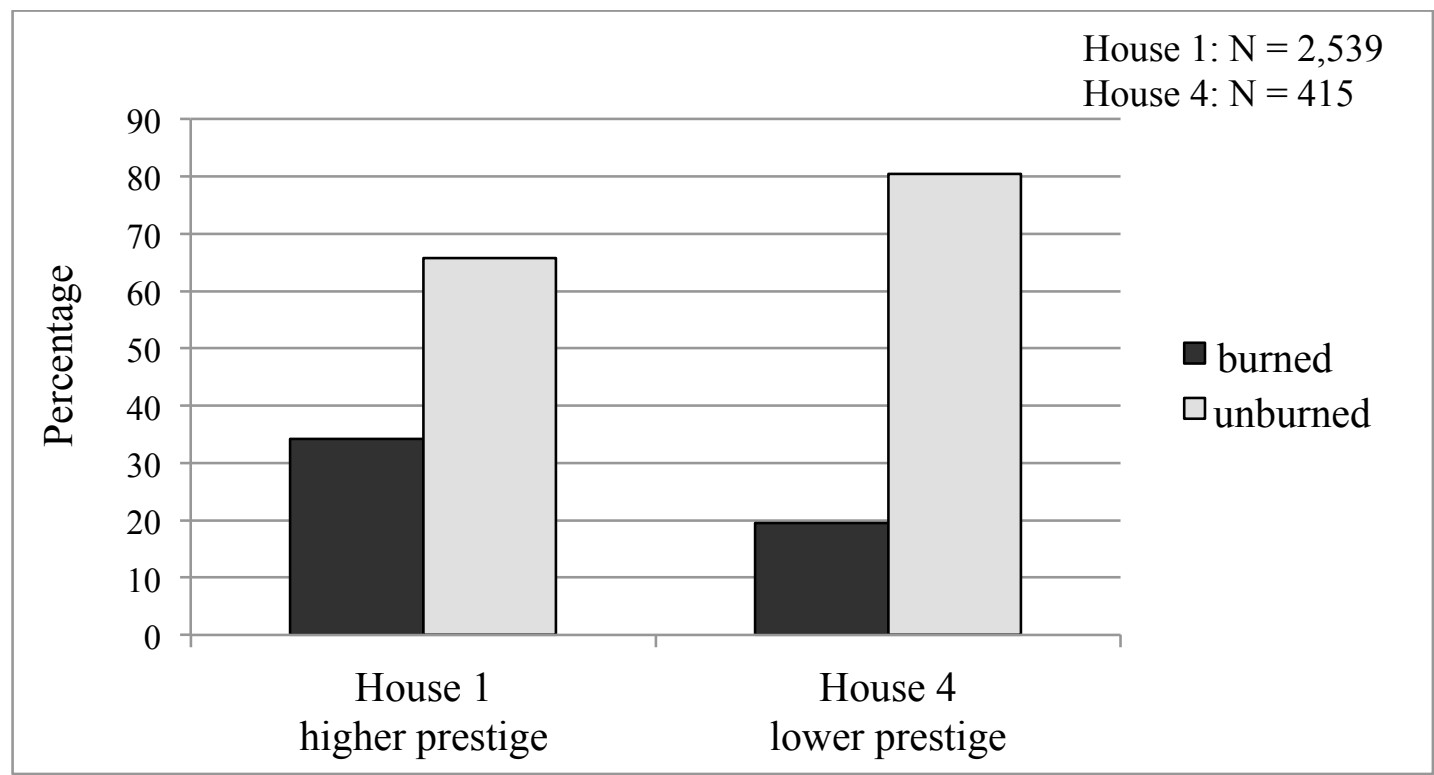

Figure 15. Percentage of burned versus unburned specimens within each house (bulk sample $4 \mathrm{~mm}, 2 \mathrm{~mm}$, and $1 \mathrm{~mm}$ fractions), excluding sturgeon fragments and salmon vertebral fragments from the $1 \mathrm{~mm}$ fraction, including estimated values for the $1 \mathrm{~mm}$ fraction.

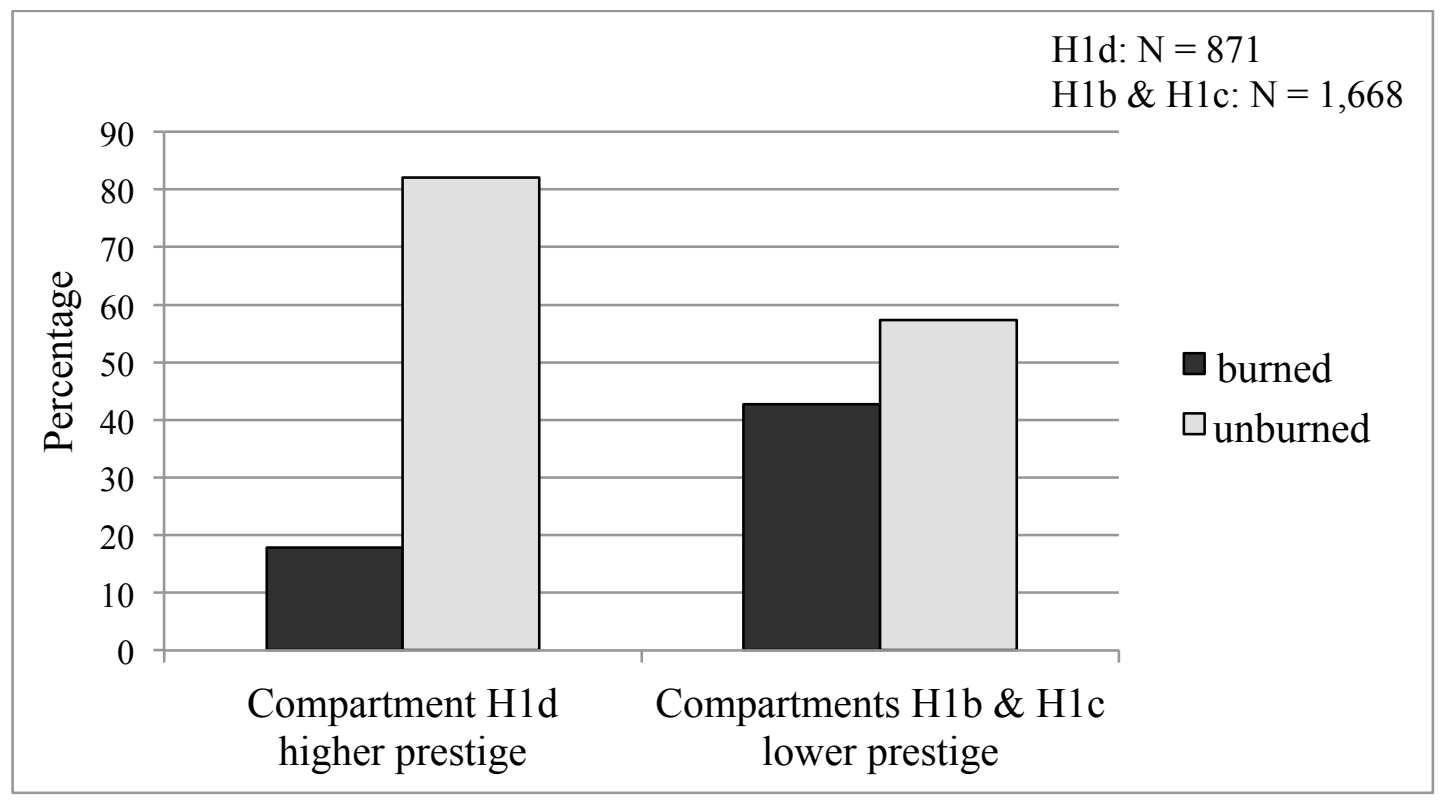

Figure 16. Percentage of burned versus unburned specimens within each compartment group in House 1 (bulk sample $4 \mathrm{~mm}, 2 \mathrm{~mm}$, and $1 \mathrm{~mm}$ fractions), excluding sturgeon fragments and salmon vertebral fragments from the $1 \mathrm{~mm}$ fraction, including estimated values for the $1 \mathrm{~mm}$ fraction. 


\section{Sturgeon-Eulachon Comparisons}

While the rank of eulachon relative to most species is ambiguous because of the effects of mass capture, it should still be lower ranked relative to sturgeon. Therefore, to understand the relationship between eulachon and prestige, it may be useful to look more closely at the relative contributions of sturgeon and eulachon across houses and compartments. When considering these, it must be kept in mind that burning has likely affected the eulachon quantities differentially across the units of analysis. Sturgeon and eulachon proportions in House 1 are similar to each other, while there is significantly more sturgeon and significantly less eulachon in House 4 than in House 1 (chi-square $=$ 35.673, $\mathrm{p}<0.001$ ) (Figure 17). The House 1 samples have been more affected by burning than the House 4 samples, so it is possible that eulachon is actually artificially underrepresented for House 1. Within House 1, Compartment H1d, with a very small sturgeon sample, has significantly more eulachon, while Compartments H1b \& H1c have significantly more sturgeon $($ chi-square $=581.576, \mathrm{p}<0.001)($ Figure 18$)$. However, the H1b \& H1c samples have been more affected by burning than the H1d samples, so it is possible that eulachon is actually artificially underrepresented for Compartments H1b \& H1c. 


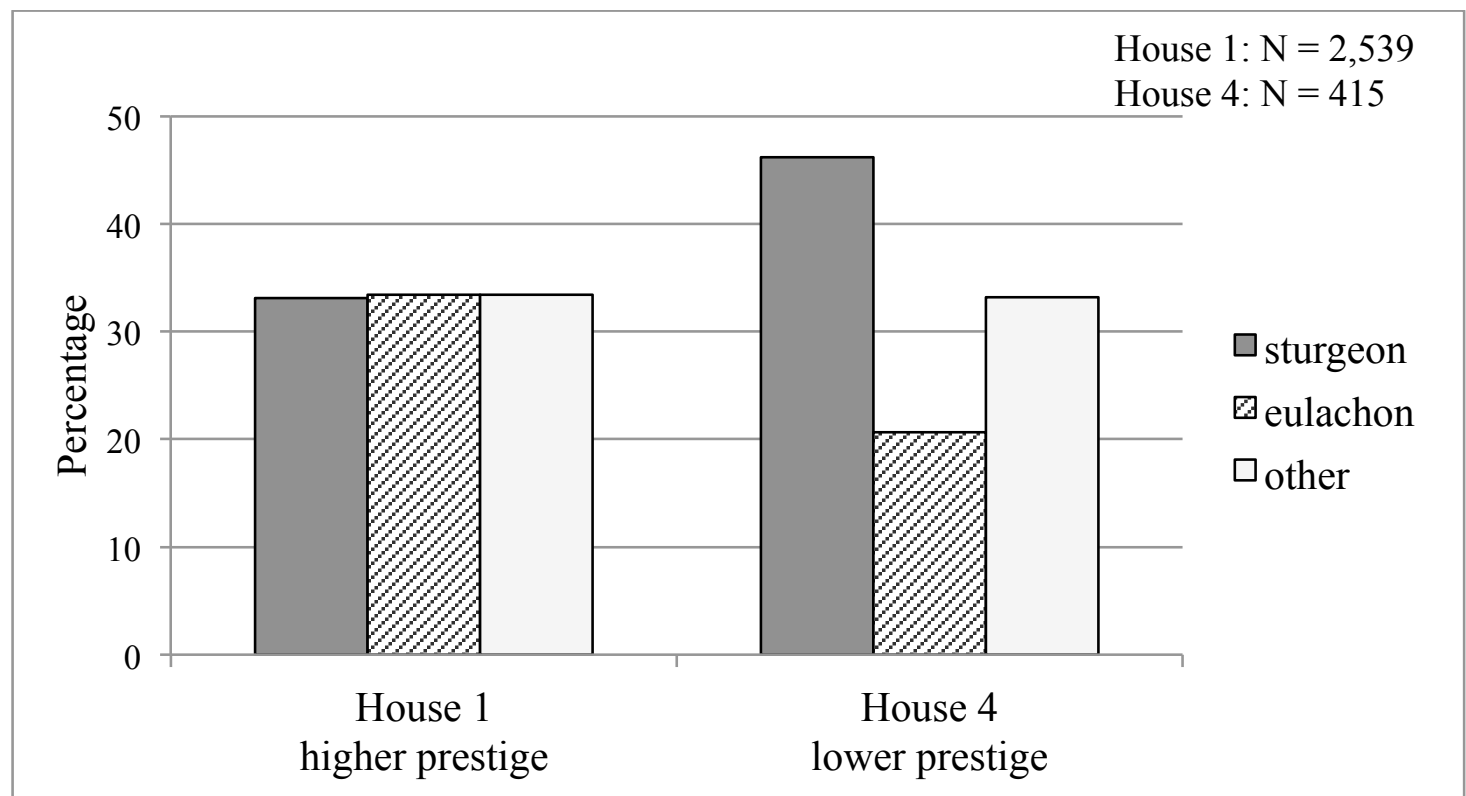

Figure 17. Comparison of sturgeon and eulachon contributions within each house (bulk sample $4 \mathrm{~mm}, 2 \mathrm{~mm}$, and $1 \mathrm{~mm}$ fractions), excluding sturgeon fragments and salmon vertebral fragments from the $1 \mathrm{~mm}$ fraction, including estimated values for the $1 \mathrm{~mm}$ fraction.

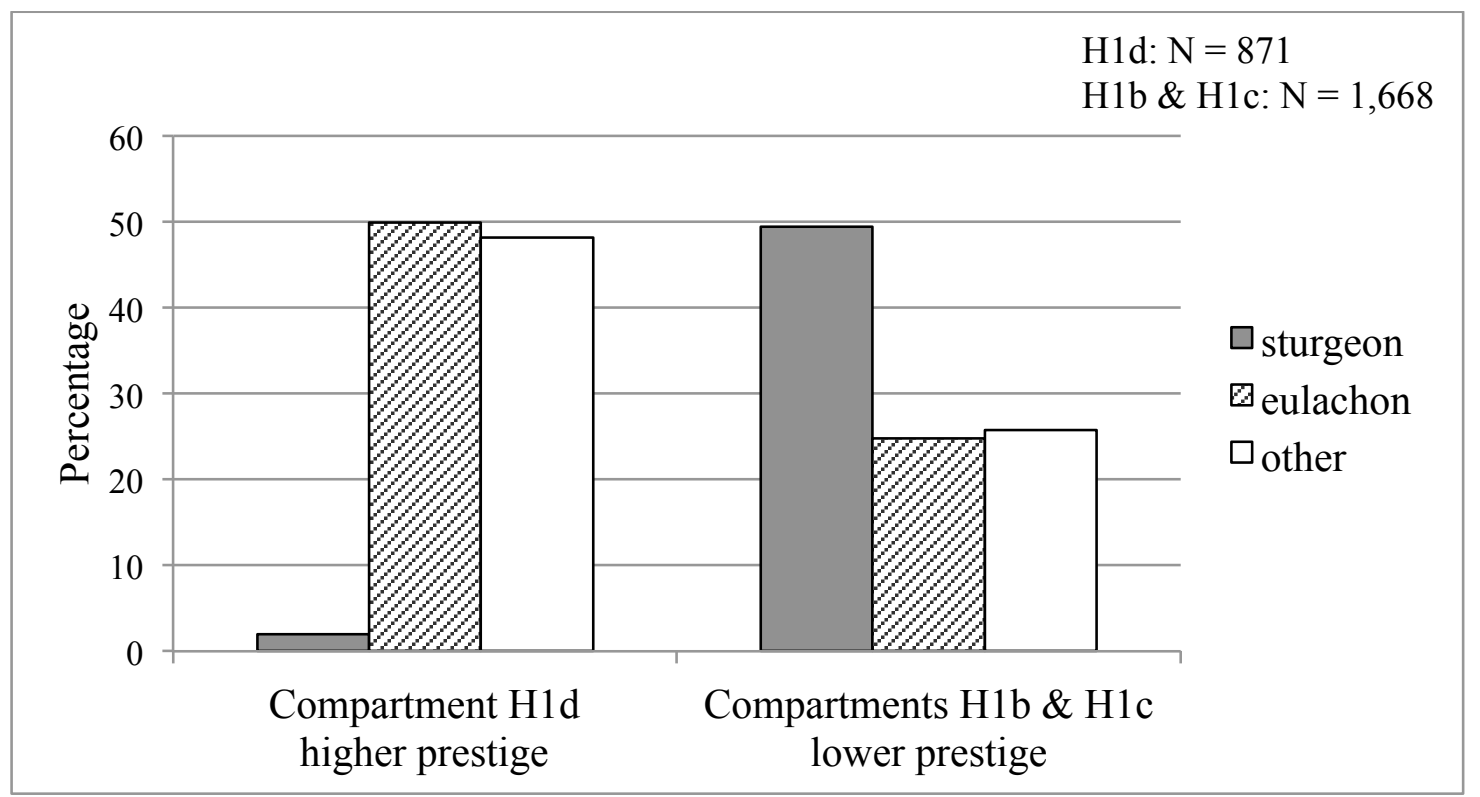

Figure 18. Comparison of sturgeon and eulachon contributions within each compartment group in House 1 (bulk sample $4 \mathrm{~mm}, 2 \mathrm{~mm}$, and $1 \mathrm{~mm}$ fractions), excluding sturgeon fragments and salmon vertebral fragments from the $1 \mathrm{~mm}$ fraction, including estimated values for the $1 \mathrm{~mm}$ fraction. 


\section{Chapter V: Discussion, Conclusions, and Future Work}

\section{Implications for Resource Control: 1/4” Mesh Samples}

The clearest relationships between prestige and fish ranks can be seen in the results from the $1 / 4$ " mesh sample. First, comparing between compartments in House 1, the differences in taxonomic representation match up well with prestige. The higher prestige H1d inhabitants appear to have been consuming more of the high-ranked sturgeon and salmon and less of the middle-ranked large minnow/sucker than the lower prestige H1b \& H1c inhabitants. In addition, the H1d inhabitants were consuming more of the higher-ranked chinook salmon relative to other salmon species. Not only were the members of Compartment H1d consuming proportionately more salmon than the members of Compartment H1b \& H1c, but they were also consuming more of the larger, more highly-ranked salmon species. It therefore appears that the chief and perhaps other elite members of the household were indeed exercising power over resource distribution within the household and taking more of the preferred, highly-ranked fish for themselves, leaving the lower prestige household members to eat a greater proportion of the less desirable fish. This fits well with Ray's (1938) account of Chinook and perhaps Chinookan chiefs being more powerful than chiefs elsewhere on the Northwest Coast, able to appropriate the property, particularly food, of free individuals, and redistribute it amongst the elite.

Comparing Houses 1 and 4 for the $1 / 4$ " mesh, a weaker connection between prestige and fish rank is apparent. Salmon is similarly represented in the two houses, but House 1, which is the higher prestige house, has significantly more large-bodied 
minnow/sucker, while House 4 has significantly more sturgeon. If there were ownership of fish resources or harvesting sites at the household level, I would expect to see this pattern reversed, with House 1 having more of the high-ranked sturgeon and House 4 having more of the middle-ranked large minnow/sucker. Thus, at this level of taxonomic analysis, the data do not support household-based ownership of fish resources at Cathlapotle, and it is likely that there were no household-based restrictions on the taking of sturgeon even though it was a preferred prey. Perhaps this is not surprising given the nature of sturgeon as a resource. The resources most frequently subject to access restrictions on the Northwest Coast were those that were predictable, abundant, and geographically limited or patchy (Matson 1985; Richardson 1982). While sturgeon were predictable and abundant, locations for taking sturgeon were not limited in the same way they were for salmon, so it would be difficult to restrict access to sturgeon through ownership of specific fishing locations. Instead, the most important limitations on taking sturgeon were likely access to the necessary equipment such as canoes and a work force capable of catching and processing such large animals.

While there is no support for household-based ownership at this broader taxonomic level of analysis, there may be evidence for household ownership of specific salmon resources. Looking at chinook versus other salmon species, House 1 has significantly more chinook than House 4 . This meets expectations given a scenario of household ownership of salmon resources, with the household of higher prestige having greater access to the more highly ranked salmon species. These differences in salmon resource use between the houses could be the result of House 1 owning particular salmon 
fishing locations or fishing platforms, giving House 1 greater access to chinook than House 4.

As larger individuals, chinook salmon tend to swim in the deeper central portion of rivers, often making it necessary to capture them at river constrictions, where rocks or fishing platforms extended out into the river (Speller et al. 2005). While fall chinook are known to spawn in local streams in large numbers and therefore could have been accessed more easily in the Lewis River, local access to other chinook runs would have been more limited, and summer chinook were not available at all in the Lewis. The constriction on the Columbia at Cascades Rapids was known historically as an important chinook fishing location, where platforms that extended out into the river were utilized along with hoop nets to harvest salmon (Martin 2006). There is evidence that other tribes in this region owned this sort of fishing resource at the individual or household level. Among the Quinault, a Southern Coast Salish group from western Washington, salmon weirs were owned by villages, but individual platforms for fishing at those weirs were owned by household heads as trustees for their households (Olson 1938 referenced in Hajda 1984). It is possible that fishing platforms at constriction sites on the Columbia such as Cascades Rapids were likewise owned at the household level. If House 1 had owned one or more fishing platforms on the Columbia, and House 4 had not, this would have given House 1 greater access to chinook and could explain the differences in the proportions of chinook recovered from the two houses.

On the other hand, instead of owning the fishing locations/platforms themselves, it could be that House 1 simply had greater ability to access these locations. If House 1 had owned more canoes, this would have made travel to these more remote fishing 
locations easier and allowed them to bring larger quantities of chinook back to the village. As House 1 is the more prestigious household, it is likely that this household would have owned more capital such as canoes than House 4. As a larger household, House 1 also would have had a larger work force. Speller et al. (2005) note that the high oil content of chinook, especially the early spring and summer runs, makes them more difficult to dry than other salmon, and because of this they would have required a greater labor force to process for preservation. House 1 may have had more chinook salmon because they had the ability to process them in greater quantities than House 4 .

It is also possible that the two households had equal access to and processing capabilities for chinook, and that the difference in chinook between the two houses has more to do with how the fish were distributed after they were harvested and processed. As mentioned above, unlike elsewhere on the Northwest Coast where chiefs were primarily household chiefs, Chinookan chiefs were village chiefs. This opens up the possibility that chiefs were able to exert power not only over members of their own households, but also over other village members. For example, Ray's (1938) account of a chief seizing several sturgeon from a fisherman provides no details about the relationship between the chief and this fisherman. If the Cathlapotle village chief did indeed live in Compartment H1d as hypothesized, the greater amount of chinook salmon in House 1 overall, and H1d in particular, could be the result of the chief taking preferred fish not only from members of his/her own household, but from members of households throughout the village. Ray also reports that commoners regularly presented chiefs with gifts of food, so the greater amount of chinook in House 1 could be the result of House 4 inhabitants gifting chinook to the chief. These scenarios would mean that House 4 
inhabitants were not necessarily excluded from accessing any particular fish resources, but instead were giving up, either by force or voluntarily, some of the more preferred resources after accessing them.

It also may be problematic to compare Houses 1 and 4 in this way at all because only three of the four compartments in House 1 were excavated, with large-scale excavations of only Compartment H1d. As the comparisons within House 1 indicate, fish remains were not evenly distributed across the House 1 compartments. Therefore, the fish assemblage excavated from House 1 may not be representative of the entire household's fish consumption and thus not a good indicator of the overall fish resource base that House 1 had access to relative to House 4. It could be that House 1 did not actually have greater access to chinook than House 4.

Finally, it should be kept in mind that deposits from the pre- and post-contact time periods have been combined for this analysis because most of the deposits within the houses are post-contact era. Unfortunately, this means that I was unable to track this important transition, which may have included significant changes in resource use.

\section{Implications for Resource Control: Bulk Samples}

The relationship between prestige and fish rankings is less clear for the bulk sample results. Comparing between compartments in House 1, the higher prestige Compartment H1d has significantly more of the high-ranked salmon but also significantly more of the low-ranked stickleback. The lower prestige Compartments H1b \& H1c have significantly more of the low-ranked small minnow/sucker but also significantly more of the high-ranked sturgeon. For the between-house comparisons, the 
lower prestige House 4 has significantly more of the middle-ranked large minnow/sucker but also significantly more of the high-ranked sturgeon than House 1 . Turning just to the sturgeon-eulachon comparison, both House 4 and Compartments H1b \& H1c have higher ratios of the high-ranked sturgeon to the lower-ranked eulachon when compared to House 1 and Compartment H1d, respectively. This is the reverse of the expected relationship between high prestige and high fish rank given either ownership or control over resource distribution. There is therefore no obvious pattern relating prestige to fish rank for the bulk samples looking either within House 1 or between Houses 1 and 4.

One partial explanation for these confusing results is the problem of burning. It is likely that burning has a substantial effect on the preservation of the small fishes, especially eulachon and stickleback. Because rates of burning are differentially distributed across the units of analysis, this makes comparisons of these small fishes less valid. For example, Compartments H1b \& H1c have a significantly higher rate of burning than Compartment H1d. This means that the relatively small amounts of eulachon and stickleback recovered from $\mathrm{H} 1 \mathrm{~b} \& \mathrm{H} 1 \mathrm{c}$ may have more to do with bones from these fishes being destroyed to a greater degree in these compartments than from the members of $\mathrm{H} 1 \mathrm{~b} \& \mathrm{H} 1 \mathrm{c}$ actually eating less of these fishes than other members of the household.

Aside from burning, another possible reason that the relationships between household/compartment prestige and fish ranks do not meet expectations for the bulk data is that not enough bulk samples were analyzed to get a representative sample. If the bulk samples chosen for this analysis were indeed representative, I would expect to see similar contributions amongst the larger taxa (i.e., sturgeon, salmon, and large minnow/sucker) in 
the bulk samples as in the $1 / 4$ " mesh samples, with perhaps slightly greater representation of the large minnow/sucker group in the bulk samples, as these taxa may not be as well sampled by the $1 / 4$ " mesh due to their smaller sizes. However, this is not the case. Overall, the proportion of large minnow/sucker relative to salmon and sturgeon is much lower in the bulk samples than in the $1 / 4$ " assemblage (compare Figures 5 and 11). Within House 1, sturgeon dominates relative to salmon and large minnow/sucker in the Compartment H1b \& H1c bulk samples (Figure 13) far more than in the 1/4" mesh samples (Figure 7). Looking at the Compartment H1d results in these graphs, the difference between the bulk and $1 / 4$ " samples is even more pronounced. The number of sturgeon specimens recovered from the H1d bulk samples is particularly small $(\mathrm{N}=17$ scaled by weight, excluding fragments from the $1 \mathrm{~mm}$ fraction), yet sturgeon account for $60 \%$ of the H1d $1 / 4$ " samples. Because of this, the sturgeon-eulachon comparisons between compartments are especially suspect. Furthermore, the number and volume of bulk samples studied from H1b \& H1c is much higher than from H1d, so the H1b \& H1c results have a disproportionate effect on the overall picture of House 1, making comparisons between the houses more problematic.

Because it is likely that an insufficient number of bulk samples was analyzed to achieve a representative sample, intrasite comparisons of the bulk data are not particularly useful or meaningful. Analysis of bulk samples, particularly the $1 \mathrm{~mm}$ mesh fractions, is extremely labor intensive, and projects that seek to understand spatial patterns need to invest more resources into this scale of analysis. It appears to be necessary to examine the $1 \mathrm{~mm}$ fractions in order to gain a full understanding of fish utilization at Cathlapotle (Table 18). Very few stickleback and no small minnow/sucker 
specimens were recovered from mesh sizes larger than $1 \mathrm{~mm}$. Of the small fishes, only eulachon was recovered from the $2 \mathrm{~mm}$ mesh in substantial quantities. It is possible that analyzing only the $4 \mathrm{~mm}$ and $2 \mathrm{~mm}$ fractions from a larger number of bulk samples selected more systematically than in this study would be sufficient to gain a good understanding of the relative use of eulachon across social units. Analyzing just these larger fractions would greatly reduce the amount of labor and time necessary to achieve a more representative sample and make spatial comparisons more valid.

Table 18. Frequencies of Fish Taxa Recovered from Bulk Samples by Screen Size.

\begin{tabular}{lccc}
\hline & \multicolumn{3}{c}{ Screen Size } \\
Taxon & $4 \mathrm{~mm}$ & $2 \mathrm{~mm}$ & $1 \mathrm{~mm}^{*}$ \\
\hline Salmon & 8 & 317 & 746 \\
Sturgeon & 158 & 875 & 903 \\
Large-bodied minnow/sucker & 17 & 119 & 52 \\
Small-bodied minnow/sucker & 0 & 0 & 123 \\
Eulachon & 0 & 145 & 789 \\
Stickleback & 1 & 4 & 323 \\
Sculpin & 0 & 1 & 0 \\
Total & 184 & 1461 & 2936 \\
\hline
\end{tabular}

*1 mm values include estimated number of specimens.

While they may not be sufficient for comparisons between social units, the results from the bulk samples are still useful when considering the site as a whole, as they greatly expand the picture of fish utilization at Cathlapotle. Large quantities of the small fishes, particularly eulachon and stickleback, were identified throughout the site, in higher and lower prestige areas alike, indicating that these smaller fishes were an important part of the subsistence strategy. The results from the bulk data taken together with the $1 / 4$ " data indicate that the inhabitants of Cathlapotle were exploiting a relatively broad fish subsistence base, taking fish from the seasonally flooded backwater wetlands 
as well as the main rivers and streams, and including many taxa in their diet, such as minnow, sucker, and stickleback, that are barely touched on in the ethnohistoric record.

\section{Conclusions}

1) Using Optimal Foraging Theory as a basis for ranking fish made it possible to apply rankings to the entire suite of taxa encountered at Cathlapotle. Rankings of fish based primarily on size are consistent with the available ethnohistoric accounts of preference, and this is a promising approach for future studies examining the relationship between prestige and food resources.

2) The $1 / 4 "$ sample results from within House 1 are consistent with expectations regarding the relationship between prestige and prey rank. The chief and possibly other elite members of House 1 appear to have had some control over the distribution of fish resources within their household. Higher prestige members of House 1 had greater access to the preferred fishes, including sturgeon and salmon, especially chinook salmon. 3) There is little evidence to support household-based ownership of resources. While House 1 may have owned fishing platforms, giving its members greater access to chinook salmon, other explanations are possible for the observed differences in the quantities of chinook between the houses. Alternative explanations for the greater abundance of chinook in House 1 include access to more canoes for travel to remote fishing locations, a larger workforce for processing the salmon, village-wide control over post-harvesting distribution of resources by the chief, and gifts of food being presented to the chief by members of other households. Observed differences may also be the result of disproportionate sampling of house compartments during excavation. 
4) Time and labor constraints limited the number of bulk samples that could be analyzed. Without a representative sample, it is difficult to draw any conclusions from intrasite comparisons of the bulk data. The bulk data do add to the overall picture of fish use at Cathlapotle. The inhabitants of Cathlapotle were exploiting a broad fish subsistence base including relatively large numbers of small fishes such as eulachon and stickleback.

\section{Future Work}

Sampling decisions made during both excavation and bulk sample analysis placed limitations on the degree to which social units could be compared in this study. Incorporating additional bulk samples selected more systematically could address some of these sampling limitations, but this would require a large investment of labor and time. As mentioned above, one possible solution is to analyze only the $4 \mathrm{~mm}$ and $2 \mathrm{~mm}$ mesh fractions of a larger number of bulk samples. Given the substantial quantities of eulachon recovered from the $2 \mathrm{~mm}$ mesh, this could be a useful compromise for future work that would allow for intrasite comparisons at least of eulachon relative to larger fish.

The results of the chinook salmon species identification using Huber et al.'s (2011) morphological model are intriguing, but the model is still relatively untested. It would be useful to test the results of the model against aDNA analysis for a sample of the salmon vertebrae from Cathlapotle to determine if the model can indeed reliably distinguish chinook from other the salmon species. Given concerns raised by Moss et al. (2014), more such tests on archaeological assemblages are warranted.

The universality of the system of prey ranking used here makes it easily transferrable to other sites. This model could be applied in other large river systems such 
as the Lower Fraser or Lower Sacramento where the fish resources are abundant and varied to examine similar questions about the interplay between social prestige and resource control. 


\section{References Cited}

Ames, Kenneth M.

1991 The Archaeology of the Longue Durée: Temporal and Spatial Scale in the

Evolution of Social Complexity on the Southern Northwest Coast. Antiquity 65:249.

1994 The Northwest Coast: Complex Hunter-Gatherers, Ecology, and Social

Evolution. Annual Review of Anthropology 23:209-229.

1995 Chiefly Power and Household Production on the Northwest Coast. In

Foundations of Social Inequality, edited by T. Douglas Price and Gary M.

Feinman, pp. 155-187. Plenum Press, New York, NY.

1996 Life in the Big House: Household Labor and Dwelling Size on the Northwest

Coast. In People Who Lived in Big Houses: Archaeological Perspectives on Large

Domestic Structures, edited by Gary G. Coupland and E. B. Banning, pp. 178-200.

Prehistory Press, Madison, WI.

2007 The Archaeology of Rank. In Handbook of Archaeological Theories, edited

by R. Alexander Bentley, Herbert D. G. Maschner, and Christopher Chippendale,

pp. 487-513. AltaMira Press, Lanham.

2008 Slavery, Household Production, and Demography on the Southern Northwest

Coast: Cables, Tacking, and Ropewalks. In Invisible Citizens: Captives and Their

Consequences, edited by Catherine M. Cameron, pp. 138-158. University of Utah

Press, Salt Lake City, UT.

Ames, Kenneth M. and Herbert D. G. Maschner

1999 Peoples of the Northwest Coast: Their Archaeology and Prehistory. Thames

and Hudson, New York, NY.

Ames, Kenneth M. and Elizabeth A. Sobel

2009 Finding and Dating Cathlapotle. Archaeology in Washington XV:5-32.

2013 Houses and Households. In Chinookan Peoples of the Lower Columbia, edited

by Robert T. Boyd, Kenneth M. Ames, and Tony A. Johnson, pp. 125-145.

University of Washington Press, Seattle, WA.

Ames, Kenneth M., Cameron M. Smith, William L. Cornett, Elizabeth A Sobel, Stephen

C. Hamilton, John Wolf, and Doria Raetz

1999 Archaeological Investigations at 45CL1 Cathlapotle (1991-1996), Ridgefield

National Wildlife Refuge Clark County, Washington A Preliminary Report.

Prepared for U.S. Fish and Wildlife Services by Portland State University. Report on file, Department of Anthropology, Portland State University, Portland, OR.

Ashby, Steven P.

2002 The Role of Zooarchaeology in the Interpretation of Socioeconomic Status: A

Discussion with Reference to Medieval Europe. Archaeological Review from

Cambridge 18:37-59.

Bamforth, Douglas B.

2002 Evidence and Metaphor in Evolutionary Archaeology. American Antiquity

67(3):435-452.

Bird, Douglas W., Rebecca Bliege Bird, and Brian F. Codding 
2009 In Pursuit of Mobile Prey: Martu Hunting Strategies and Archaeofaunal Interpretation. American Antiquity 74(1):3-29.

Bird, Douglas W. and James F. O'Connell

2006 Behavioral Ecology and Archaeology. Journal of Archaeological Research 14:143-188.

Bliege Bird, Rebecca, Eric Alden Smith, and Douglas W. Bird

2001 The Hunting Handicap: Costly Signaling in Human Foraging Strategies. Behavioral Ecology and Sociobiology 50:9-19.

Boyd, Robert T.

1999 The Coming of the Spirit of Pestilence: Introduced Infectious Diseases and Population Decline among Northwest Coast Indians, 1774-1874. University of Washington Press, Seattle, WA.

2011 Cathlapotle and its Inhabitants: 1792-1860. U.S. Fish and Wildlife Service, Portland, OR.

Boyd, Robert T. and Yvonne P. Hajda

1987 Seasonal Population Movement along the Lower Columbia River: The Social and Ecological Context. American Ethnologist 14(2):309-326.

Brinkhuizen, Dick C.

1986 Features Observed on the Skeletons of some Recent European Acipenseridae: Their Importance for the Study of Excavated Remains of Sturgeon. In Fish and Archaeology: Studies in Osteometry, Taphonomy, Seasonality and Fishing Methods, edited by Dick C. Brinkhuizen and A. T. Clason, pp. 18-33. BAR International Series 294, Oxford, UK.

Broughton, John (Jack) M.

1994 Declines in Mammalian Foraging Efficiency During the Late Holocene, San Francisco Bay, California. Journal of Anthropological Archaeology 13:371-401.

1995 Resource Depression and Intensification During the Late Holocene, San

Francisco Bay: Evidence from the Emeryville Shellmound Vertebrate Fauna.

$\mathrm{Ph} . \mathrm{D}$. dissertation, Department of Anthropology, University of Washington, Seattle, WA.

2002 Prey Spatial Structure and Behavior Affect Archaeological Tests of Optimal Foraging Models: Examples from the Emeryville Shellmound Vertebrate Fauna. World Archaeology 34(1):60-83.

Broughton, Jack M., Michael D. Cannon, Frank E. Bayham, and David A. Byers

2011 Prey Body Size and Ranking in Zooarchaeology: Theory, Empirical Evidence, and Applications from the Northern Great Basin. American Antiquity 76(3):403428.

Butler, Virginia L.

1990 Distinguishing Natural from Cultural Salmonid Deposits in Pacific Northwest North America. Ph.D. dissertation, Department of Anthropology, University of Washington, Seattle, WA.

1992 Fish Remains from the Meier Site. Data reporting results from excavation units S30-32/E30-32 and S12-14/E20-22. Report on file, Department of Anthropology, Portland State University, Portland, OR. 
2000 Resource Depression on the Northwest Coast of North America. Antiquity 74:649-661.

2002 Fish Remains from Cathlapotle: Preliminary Report. Report on file,

Department of Anthropology, Portland State University, Portland, OR.

2005 Fish Remains from the St. Johns Site (35MU44/46). In Archaeological

Excavations at the St. Johns Site (35MU44/46), Portland, Oregon, edited by

Richard Pettigrew, appendix H.1-H.30. Cascadia Archaeology, Seattle, WA.

Butler, Virginia L. and Sarah K. Campbell

2004 Resource Intensification and Resource Depression in the Pacific Northwest of

North America: A Zooarchaeological Review. Journal of World Prehistory

18(4):327-405.

Butler, Virginia L. and James C. Chatters

1994 The Role of Bone Density in Structuring Prehistoric Salmon Bone

Assemblages. Journal of Archaeological Science 21:413-424.

Butler, Virginia L. and Michael Martin

2013 Aboriginal Fisheries of the Lower Columbia River. In Chinookan Peoples of

the Lower Columbia, edited by Robert T. Boyd, Kenneth M. Ames, and Tony A.

Johnson, pp. 80-105. University of Washington Press, Seattle, WA.

Campbell, Sarah K. and Virginia L. Butler

2010a Archaeological Evidence for Resilience of Pacific Northwest Salmon

Populations and the Socioecological System Over the Last 7,500 Years. Ecology

and Society 15(1):17.

$2010 \mathrm{~b}$ Fishes and Loaves? Explaining Sustainable, Long-Term Animal Harvesting

on the Northwest Coast Using the "Plant Paradigm." In The Archaeology of

Anthropogenic Environments, edited by Rebecca M. Dean, pp. 175-203. Center

for Archaeological Investigations, Southern Illinois University, Carbondale, IL.

Cannon, Aubrey and Dongya Y. Yang

2006 Early Storage and Sedentism on the Pacific Northwest Coast: Ancient DNA

Analysis of Salmon Remains from Namu, British Columbia. American Antiquity

71(1):123-140.

Cannon, Michael D.

2000 Large Mammal Relative Abundance in Pithouse and Pueblo Period

Archaeofaunas from Southwestern New Mexico: Resource Depression among the

Mimbres-Mogollon? Journal of Anthropological Archaeology 19:317-347.

Casteel, Richard W.

1972 Some Biases in the Recovery of Archaeological Faunal Remains. Proceedings

of the Prehistoric Society 38:382-388.

Charnov, Eric L.

1976 Optimal Foraging, the Marginal Value Theorem. Theoretical Population

Biology 9(2):129-136.

Charnov, Eric L., Gordon H. Orians, and Kim Hyatt

Ecological Implications of Resource Depression. The American Naturalist 110:247-

259.

Coupland, Gary 
2006 A Chief's House Speaks: Communicating Power on the Northern Northwest Coast. In Household Archaeology on the Northwest Coast, edited by Elizabeth A. Sobel, D. Ann Trieu Gahr, and Kenneth M. Ames, pp. 80-96. International Monographs in Prehistory, Ann Arbor, MI.

Coupland, Gary, Roger H. Colten, and Rebecca Case

2003 Preliminary Analysis of Socioeconomic Organization at the McNichol Creek

Site, British Columbia. In Emerging from the Mist: Studies in Northwest Coast

Culture History, edited by R.G. Matson, Gary Coupland, and Quentin Mackie, pp. 152-169. UBC Press, Vancouver, B.C.

Coupland, Gary, Andrew R.C. Martindale, and Susan Marsden

2001 Does Resource Abundance Explain Local Group Rank Among the Coast

Tsimshian? In Perspectives on Northern Northwest Coast Prehistory, edited by

Jerome S. Cybulski, pp. 223-248. Mercury Series, Archaeological Survey of

Canada Paper 160, Canadian Museum of Civilization, Hull, Quebec.

Crabtree, Pam J.

1990 Zooarchaeology and Complex Societies: Some Uses of Faunal Analysis for the

Study of Trade, Social Status, and Ethnicity. Archaeological Method and Theory

2:155-205.

Craig, Joseph A. and Robert L. Hacker

1940 The History and Development of the Fisheries of the Columbia River. Bulletin of the Bureau of Fisheries, Volume XLIX, No. 32, Washington, D.C.

Curet, L. Antonio and William J. Pestle

2010 Identifying High-Status Foods in the Archeological Record. Journal of

Anthropological Archaeology 29(4):413-431.

Donald, Leland

1985 On the Possibility of Social Class in Societies Based on Extractive Subsistence.

In Status, Structure and Stratification: Current Archaeological Reconstructions, edited by Marc Thompson, Maria Teresa Garcia, and Francois J. Kense, pp. 237-

243. The University of Calgary Archaeological Association, Calgary, Alberta.

Donald, Leland and Donald H. Mitchell

1975 Some Correlates of Local Group Rank among the Southern Kwakiutl.

Ethnology 14(4):325-346.

1994 Nature and Culture on the Northwest Coast of North America: The Case of the Wakashan Salmon Resources. In Key Issues in Hunter-Gatherer Research, edited by Ernest S. Burch, Jr. and Linda J. Ellanna, pp. 95-117. Berg Publishers, Oxford, UK.

Drucker, Philip

1939 Rank, Wealth, and Kinship in Northwest Coast Society. American

Anthropologist, New Series 41(1):55-65.

Durham, William H.

1981 Overview: Optimal Foraging Analysis in Human Ecology. In Hunter-Gatherer

Foraging Strategies, edited by Bruce Winterhalder and Eric Alden Smith, pp.

218-231. The University of Chicago Press, Chicago, IL.

Ellis, David V. 
2013 Cultural Geography of the Lower Columbia. In Chinookan Peoples of the Lower Columbia, edited by Robert T. Boyd, Kenneth M. Ames, and Tony A. Johnson, pp. 42-62. University of Washington Press, Seattle, WA.

Emery, Kitty F.

2003 The Noble Beast: Status and Differential Access to Animals in the Maya World. World Archaeology 34(3):498-515.

Etnier, Michael A.

2007 Defining and Identifying Sustainable Harvests of Resources: Archaeological

Examples of Pinniped Harvests in the Eastern North Pacific. Journal for Nature Conservation 15:196-207.

Farr, Ruth A. and Thomas A Rien

2002 Green Sturgeon Population Characteristics in Oregon. Annual Progress

Report: Fish Research Project Oregon. Project Number F-178-R, 1 October 2001

- 30 September 2002. Oregon Department of Fish and Wildlife, Clackamas, OR.

Findeis, Eric K.

1993 Skeletal Anatomy of the North American Shovelnose Sturgeon Scaphirhynchus platorynchus (Rafinesque 1820) with Comparisons to other Acipenseriformes.

Ph.D. dissertation, Department of Biology, University of Massachusetts, Amherst, MA.

Ford, Pamela J.

1989 Archaeological and Ethnographic Correlates of Seasonality: Problems and

Solutions on the Northwest Coast. Canadian Journal of Archaeology 13:133-150.

Frederick, Gay

2007 Report on the Fish Faunal Remains from the Meier Site, 35CO5, Oregon,

U.S.A. Report on file, Department of Anthropology, Portland State University, Portland, OR.

Fried, Morton $\mathrm{H}$.

1967 The Evolution of Political Society: An Essay in Political Anthropology.

Random House, New York.

Froese, R and D. Pauly

2014 FishBase. Electronic document, www.fishbase.org, accessed February 18, 2015.

Fulton, Leonard A.

1968 Spawning Areas and Abundance of Chinook Salmon (Oncorhynchus

tshawytscha) in the Columbia River Basin-Past and Present. U.S. Fish and

Wildlife Service Special Scientific Report-Fisheries No. 571, Washington, D.C.

1970 Spawning Areas and Abundance of Steelhead Trout and Coho, Sockeye, and

Chum Salmon in the Columbia River Basin-Past and Present. National Marine

Fisheries Service Special Scientific Report-Fisheries No. 618, Washington, D.C.

Gahr, D. Ann Trieu

2006 From Architects to Ancestors: The Life Cycle of Plank Houses. In Household Archaeology on the Northwest Coast, edited by Elizabeth A. Sobel, D. Ann Trieu Gahr, and Kenneth M. Ames, pp. 57-79. International Monographs in Prehistory, Ann Arbor, MI.

Gahr, D. Ann Trieu, Elizabeth A. Sobel, and Kenneth M. Ames 
2006 Introduction. In Household Archaeology on the Northwest Coast, edited by Elizabeth A. Sobel, D. Ann Trieu Gahr, and Kenneth M. Ames, pp. 1-15.

International Monographs in Prehistory, Ann Arbor, MI.

Gardner-O'Kearney, William Clark

2010 Domestic Hearth Features at the Cathlapotle (45CL1) and Meier (35CO5)

Sites in the Wapato Valley of Oregon and Washington. M.A. thesis, Department of Anthropology, Portland State University, Portland, OR.

Gobalet, Kenneth W., Peter D. Schulz, Thomas A. Wake, and Nelson Siefkin

2004 Archaeological Perspectives on Native American Fisheries of California, with

Emphasis on Steelhead and Salmon. Transactions of the American Fisheries

Society 133(4):801-833.

Gordon, Elizabeth A.

1993 Screen Size and Differential Faunal Recovery: A Hawaiian Example. Journal of Field Archaeology 20(4):453-460.

Gottesfeld, Leslie M. Johnson

1994 Conservation, Territory, and Traditional Beliefs: An Analysis of Gitksan and Wet'suwet'en Subsistence, Northwest British Columbia, Canada. Human Ecology 22(4):443-465.

Grayson, Donald K. and Michael D. Cannon

1999 Human Paleoecology and Foraging Theory in the Great Basin. In Models for

the Millennium: Great Basin Anthropology Today, edited by Charlotte Beck, pp.

Grier, Colin

141-151. University of Utah Press, Salt Lake City, UT.

2003 Dimensions of Regional Interaction in the Prehistoric Gulf of Georgia. In

Emerging from the Mist: Studies in Northwest Coast Culture History, edited by R.

G. Matson, Gary Coupland, and Quentin Mackie, pp. 170-187. UBC Press, Vancouver, B.C.

2006 Temporality in Northwest Coast Households. In Household Archaeology on

the Northwest Coast, edited by Elizabeth A. Sobel, D. Ann Trieu Gahr, and

Kenneth M. Ames, pp. 97-119. International Monographs in Prehistory, Ann

Arbor, MI.

2007 Consuming the Recent for Constructing the Ancient: The Role of Ethnography

in Coast Salish Archaeological Interpretation. In Be of Goof Mind: Essays on the

Coast Salish, edited by Bruce Granville Miller, pp. 284-307. UBC Press,

Vancouver, B.C.

Grier, Colin, Kelli Flanigan, Misa Winters, Leah G. Jordan, Susan Lukowski, and Brian

M. Kemp

2013 Using Ancient DNA Identification and Osteometric Measures of

Archaeological Pacific Salmon Vertebrae for Reconstructing Salmon Fisheries

and Site Seasonality at Dionisio Point, British Columbia. Journal of

Archaeological Science 40(1):544-555.

Griffiths, David

1975 Prey Availability and the Food of Predators. Ecology 56(5):1209-1214. Haggan, Nigel, Nancy Turner, Jennifer Carpenter, James T. Jones, Quentin Mackie, and Charles Menzies 
2006 12,000+ Years of Change: Linking Traditional and Modern Ecosystem Science in the Pacific Northwest. Working Paper. Fisheries Centre, University of British Columbia. Electronic document, http://www.fisheries.ubc.ca/publications/working/index.php.

Hajda, Yvonne P.

1984 Regional Social Organization in the Greater Lower Columbia, 1792-1830.

$\mathrm{Ph} . \mathrm{D}$. dissertation, Department of Anthropology, University of Washington.

2013 Social and Political Organization. In Chinookan Peoples of the Lower

Columbia, edited by Robert T. Boyd, Kenneth M. Ames, and Tony A. Johnson,

pp. 146-162. University of Washington Press, Seattle, WA.

Harris, Lucille

2012 Heterarchy and Hierarchy in the Formation and Dissolution of Complex

Hunter-Gatherer Communities on the Northern Plateau of Northwestern North

America, ca. 2000-300 B.P. Ph.D. dissertation, Department of Anthropology,

University of Toronto, Toronto, Ontario.

Hawkes, Kristen and Rebecca Bliege Bird

2002 Showing Off, Handicap Signaling, and the Evolution of Men's Work.

Evolutionary Anthropology 11:58-67.

Hawkes, Kristen, Kim Hill, and James F. O'Connell

1982 Why Hunters Gather: Optimal Foraging and the Ache of Eastern Paraguay. American Ethnologist 9:379-398.

Hayden, Brian and Aubrey Cannon

1982 The Corporate Group as an Archaeological Unit. Journal of Anthropological Archaeology 1(2):132-158.

Henrich, Joseph and Francisco J. Gil-White

2001 The Evolution of Prestige: Freely Conferred Deference as a Mechanism for

Enhancing the Benefits of Cultural Transmission. Evolution and Human Behavior 22:165-196.

Hill, Kim, Hillard Kaplan, Kristen Hawkes, and A. Magdalena Hurtado

1987 Foraging Decisions Among Ache Hunter-Gatherers: New Data and Implications for Optimal Foraging Models. Ethology and Sociobiology 8:1-36.

Huber, Harriet R., Jeffrey C. Jorgensen, Virginia L. Butler, Greg Baker, and Rebecca

Stevens

2011 Can Salmonids (Oncorhynchus spp.) be Identified to Species Using Vertebral Morphometrics? Journal of Archaeological Science 38:136-146.

Huelsbeck, David R.

1994 Mammals and Fish in the Subsistence Economy of Ozette. In Ozette Archaeological Project Research Reports, Volume II: Fauna, edited by Stephan R.

Samuels, pp. 17-92. Washington State University Department of Anthropology, Pullman, WA.

Jackson, H. Edwin and Susan L. Scott

2003 Patterns of Elite Faunal Utilization at Moundville, Alabama. American

Antiquity 68(3):552-572.

Johnsen, D. Bruce 
2001 Customary Law, Scientific Knowledge, and Fisheries Management among

Northwest Coast Tribes. Environmental Law Journal 10(1):1-69.

Jones, James T.

2002 “We Looked After All the Salmon Streams.” Traditional Heiltsuk Cultural

Stewardship of Salmon and Salmon Streams: A Preliminary Assessment. M.A.

thesis, School of Environmental Studies, University of Victoria, Victoria, B.C.

Kaplan, Hillard and Kim Hill

1985 Hunting Ability and Reproductive Success Among Male Ache Foragers:

Preliminary Results. Current Anthropology 26(1):131-133.

Kirch, Patrick V. and Sharyn Jones O'Day

2003 New Archaeological Insights into Food and Status: A Case Study from PreContact Hawaii. World Archaeology 34(3):484-497.

Lee, David S., Carter R. Gilbert, Charles H. Hocutt, Robert E. Jenkins, Don E. McAllister, and Jay R. Stauffer, Jr.

1980 Atlas of North American Freshwater Fishes. Publication No. 1980-12, North

Carolina Biological Survey.

Lupo, Karen D.

2007 Evolutionary Foraging Models in Zooarchaeological Analysis: Recent

Applications and Future Challenges. Journal of Archaeological Research 15:143189.

Lyman, R. Lee

2002 The Mammalian Zooarchaeology of the Cathlapotle Site. Report on file,

Department of Anthropology, Portland State University, Portland, OR.

2003 Pinniped Behavior, Foraging Theory, and the Depression of Metapopulations and the Nondepression of a Local Population on the Southern Northwest Coast of North America. Journal of Anthropological Archaeology 22:376-388.

Madsen, David B. and Dave N. Schmitt

1998 Mass Collecting and the Diet Breadth Model: A Great Basin Example. Journal of Archaeological Science 25:445-455.

Martin, Michael A.

2006 The Fisheries of the Lower Columbia River, 1792-1850, Based on

Euroamerican Explorer and Fur Company Accounts. M.A. thesis, Department of Anthropology, Portland State University, Portland, OR.

Maschner, Herbert D. G.

1992 The Origins of Hunter and Gatherer Sedentism and Political Complexity: A

Case Study from the Northern Northwest Coast. Ph.D. dissertation, Department of Anthropology, University of California, Santa Barbara, CA.

Matson, R. G.

1985 The Relationship between Sedentism and Status Inequalities among Hunters and Gatherers. In Status, Structure and Stratification: Current Archaeological Reconstructions, edited by Marc Thompson, Maria Teresa Garcia, and Francois J. Kense, pp. 245-252. The Archaeological Association of the University of Calgary, Calgary, Alberta.

2003 The Coast Salish House: Lessons from Shingle Point, Valdes Island, British Columbia. In Emerging from the Mist: Studies in Northwest Coast Culture 
History, edited by R. G. Matson, Gary Coupland, and Quentin Mackie, pp. 76-104. UBC Press, Vancouver, B.C.

Mitchell, Donald and Leland Donald

1988 Archaeology and the Study of Northwest Coast Economies. In Prehistoric

Economies of the Northwest Coast, edited by Barry L. Isaac, pp. 293-351.

Research in Economic Anthropology, Supp. 3., JAI Press, Greenwich, CT.

Moss, Madonna

1993 Shellfish, Gender, and Status on the Northwest Coast: Reconciling

Archeological, Ethnographic, and Ethnohistorical Records of the Tlingit.

American Anthropologist, New Series 95(3):631-652.

Moss, Madonna L., Kathleen G. Judd, and Brian M. Kemp

2014 Can Salmonids (Oncorhynchus spp.) be Identified to Species using Vertebral

Morphometrics? A Test using Ancient DNA from Coffman Cove, Alaska.

Journal of Archaeological Science 41:879-889.

Mural, Richard J.

1973 The Pliocene Sticklebacks of Nevada with a Partial Osteology of the

Gasterosteidae. Copeia 4:721-735.

Nagaoka, Lisa

2002a The Effects of Resource Depression of Foraging Efficiency, Diet Breadth, and Patch Use in Southern New Zealand. Journal of Anthropological Archaeology 21:419-442.

2002b Explaining Subsistence Change in Southern New Zealand Using Foraging

Theory Models. World Archaeology 34(1):84-102.

2005 Declining Foraging Efficiency and Moa Carcass Exploitation in Southern New

Zealand. Journal of Archaeological Science 32:1328-1338.

Partlow, Megan A.

2006 Sampling Fish Bones: A Consideration of the Importance of Screen Size and

Disposal Context in the North Pacific. Arctic Anthropology 43(1):67-79.

Peres, Tanya M., Amber M. VanDerwarker, and Christopher A. Pool

2010 The Farmed and the Hunted: Integrating Floral and Faunal Data from Tres

Zapotes, Veracruz. In Integrating Zooarchaeology and Paleoethnobotany, edited

by Amber M VanDerwarker and Tanya M. Peres, pp. 281-308. Springer

Science+Business Media, New York, NY.

Pierce, G. J. and J. G. Ollason

1987 Eight Reasons Why Optimal Foraging Theory is a Complete Waste of Time.

Oikos 49(1):111-117.

Prentiss, Anna Marie, Thomas A. Foor, Guy Cross, Lucille E. Harris, and Michael

Wanzenried

2012 The Cultural Evolution of Material Wealth-Based Inequality at Bridge River,

British Columbia. American Antiquity 77(3):542-564.

Pyke, Graham

1984 Optimal Foraging Theory: A Critical Review. Annual Review of Ecology and Systematics 15:523-575.

Ray, Verne 
1937 The Historical Position of the Lower Chinook in the Native Culture of the Northwest. The Pacific Northwest Quarterly 28(4):363-372.

1938 Lower Chinook Ethnographic Notes. University of Washington Publications in Anthropology 7(2):29-165.

Reimchen, Thomas E.

1994 Predators and Morphological Evolution in Threespine Stickleback. In The

Evolutionary Biology of the Threespine Stickleback, edited by Michael A. Bell and Susan A Foster, pp. 240-276. Oxford University Press, New York, NY.

Richardson, Allan

1982 The Control of Productive Resources on the Northwest Coast of North

America. In Resource Managers: North American and Australian Hunter-

Gatherers, edited by Nancy M. Williams and Eugene. S. Hunn, pp. 93-112.

Westview Press, Boulder, CO.

Richerson, Peter J. and Robert Boyd

2005 Not by Genes Alone: How Culture Transformed Human Evolution. The

University of Chicago Press, Chicago, IL.

Saleeby, Becky M.

1983 Prehistoric Settlement Patterns in the Portland Basin of the Lower Columbia

River: Ethnohistoric, Archaeological, and Biogeographic Perspectives. Ph.D. dissertation, Department of Anthropology, University of Oregon, Eugene, OR.

Schalk, Randall F.

1977 The Structure of an Anadromous Fish Resource. In For Theory Building in Archaeology, edited by Lewis R. Binford, pp. 207-249. Academic Press, Orlando, FL.

1981 Land Use and Organizational Complexity among Foragers of Northwestern North America. Senri Ethnological Studies 9:53-75.

Schoener, Thomas W.

1979 Generality of the Size-Distance Relation in Models of Optimal Feeding. The

American Naturalist 114(6):902-914.

Schulz, Peter D. and Sherri M. Gust

1983 Faunal Remains and Social Status in $19^{\text {th }}$ Century Sacramento. Historical Archaeology 17(1):44-53.

Shepard, Emily Evelyn

2014 Building and Maintaining Plankhouses at Two Villages on the Southern

Northwest Coast of North America. M.A. thesis, Department of Anthropology,

Portland State University, Portland, OR.

Silverstein, Michael

1990 Chinookans of the Lower Columbia. In Northwest Coast, edited by Wayne

Suttles, pp. 533-546. Handbook of North American Indians, Vol. 7, Sturtevant, general editor, Smithsonian Institution, Washington, D.C.

Smith, Eric Alden

1983 Anthropological Applications of Optimal Foraging Theory: A Critical Review.

Current Anthropology 24(5):625-651.

1991 Inujjuamiut Foraging Strategies: Evolutionary Ecology of an Arctic Hunting

Economy. Aldine de Gruyter, New York. 
2004 Why Do Good Hunters Have Higher Reproductive Success? Human Nature 15(4):343-364.

Smith, Eric Alden and Rebecca L. Bliege Bird

2000 Turtle Hunting and Tombstone Opening: Public Generosity as Costly

Signaling. Evolution and Human Behavior 21:245-261.

Smith, Eric Alden and Bruce Winterhalder

1992 Natural Selection and Decision Making: Some Fundamental Principles. In

Evolutionary Ecology and Human Behavior, edited by Eric Alden Smith and

Bruce Winterhalder, pp. 25-60. Aldine de Gruyter, New York, NY.

Sobel, Elizabeth A.

2004 Social Complexity and Corporate Households on the Southern Northwest

Coast of North America, A.D. 1450-1855. Ph.D. dissertation, Department of

Anthropology, University of Michigan, Ann Arbor, MI.

2006 Household Prestige and Exchange in Northwest Coast Societies: A Case Study

from the Lower Columbia River Valley. In Household Archaeology on the

Northwest Coast, edited by Elizabeth A. Sobel, D. Ann Trieu Gahr, and Kenneth

M. Ames, pp. 159-199. International Monographs in Prehistory, Ann Arbor, MI.

2012 An Archaeological Test of the "Exchange Expansion Model" of Contact Era

Change on the Northwest Coast. Journal of Anthropological Archaeology 31:1-21.

Sobel, Elizabeth A., Kenneth M. Ames, and Robert J. Losey

2013 Environment and Archaeology of the Lower Columbia. In Chinookan Peoples

of the Lower Columbia, edited by Robert T. Boyd, Kenneth M. Ames, and Tony

A. Johnson, pp. 23-41. University of Washington Press, Seattle, WA.

Speller, Camilla F., Dongya Y. Yang, and Brian Hayden

2005 Ancient DNA Investigation of Prehistoric Salmon Resource Utilization at

Keatley Creek, British Columbia, Canada. Journal of Archaeological Science 32:1378-1389.

Stiner, Mary C., Steven L. Kuhn, Stephen Weiner, and Ofer Bar-Yosef

1995 Differential Burning, Recrystallization, and Fragmentation of Archaeological

Bone. Journal of Archaeological Science 22:223-237.

Suttles, Wayne

1968 Coping with Abundance: Subsistence on the Northwest Coast. In Man the

Hunter, edited by Richard B. Lee and Irven DeVore, pp. 56-68. Aldine Publishing, Chicago, IL.

1974 The Economic Life of the Coast Salish of Haro and Rosario Straits. Coast

Salish and Western Washington Indians I. Garland Publishing, New York.

Trosper, Ronald L.

2002 Northwest Coast Indigenous Institutions that Supported Resilience and

Sustainability. Ecological Economics 41:329-344.

Ugan, Andrew, Jason Bright, and Alan Rogers

2003 When is Technology Worth the Trouble? Journal of Archaeological Science 30:1315-1329.

Vibert, Elizabeth

1997 Traders' Tales: Narratives of Cultural Encounters in the Columbia Plateau, 1807-1846. University of Oklahoma Press, Norman, OK. 
Wessen, Gary C.

1988 The Use of Shellfish Resources on the Northwest Coast: The View from

Ozette. In Prehistoric Economies of the Pacific Northwest Coast, edited by Barry

Isaac, pp. 179-207. Research in Economic Anthropology, Supp. 3, JAI Press, Greenwich, CT.

1994 Subsistence Patterns as Reflected by Invertebrate Remains Recovered at the

Ozette Site. In Ozette Archaeological Project Research Reports Volume II: Fauna, edited by Stephan R. Samuels, pp. 93-196. Washington State University

Department of Anthropology, Pullman, WA.

Winterhalder, Bruce

1981a Foraging Strategies in the Boreal Forest: An Analysis of Cree Hunting and

Gathering. In Hunter-Gatherer Foraging Strategies, edited by Bruce

Winterhalder and Eric Alden Smith, pp. 66-98. The University of Chicago Press,

Chicago, IL.

1981b Optimal Foraging Strategies and Hunter-Gatherer Research in Anthropology:

Theory and Models. In Hunter-Gatherer Foraging Strategies, edited by Bruce

Winterhalder and Eric Alden Smith, pp. 13-35. The University of Chicago Press,

Chicago, IL.

2001 The Behavioural Ecology of Hunter Gatherers. In Hunter-Gatherers: An

Interdisciplinary Perspective, edited by Catherine Panter-Brick, Robert Layton,

and P. Rowley-Conwy, pp. 12-38. Cambridge University Press, Cambridge, UK.

van der Veen, Marijke and Nick Fieller

1982 Sampling Seeds. Journal of Archaeological Science 9:287-298.

Winterhalder, Bruce and Eric Alden Smith

1992 Evolutionary Ecology and the Social Sciences. In Evolutionary Ecology and

Human Behavior, edited by Eric Alden Smith and Bruce Winterhalder, pp. 3-23.

Aldine de Gruyter, New York, NY.

Wydoski, Richard S. and Richard R. Whitney

2003 Inland Fishes of Washington. University of Washington Press, Seattle, WA. 


\section{Appendices}

Appendix A: Excavation Units for each House/Compartment and Fish Bone Analyst for each Unit, 1/4" Mesh Samples.

\begin{tabular}{|c|c|c|}
\hline House Unit & Excavation Unit & Analyst* \\
\hline \multirow{10}{*}{ House 4} & N120-122, W96-98 & VB, SR \\
\hline & N124-126, W96-98 & VB, SR \\
\hline & N128-130, W96-98 & VB \\
\hline & N128-130, W99-101 & SR \\
\hline & N130-132, W99-101 & SR \\
\hline & N132-134, W96-98 & VB, SR \\
\hline & N132-134, W99-101 & $\mathrm{SR}$ \\
\hline & N134-136, W99-101 & SR \\
\hline & N136-138, W94-96 & VB, SR \\
\hline & N136-138, W96-98 & VB, SR \\
\hline \multicolumn{3}{|l|}{ House 1} \\
\hline \multirow[t]{14}{*}{ H1d } & N147-149, W86-88 & VB, SR \\
\hline & N149-151, W84-86 & VB, SR \\
\hline & N151-153, W86-88 & VB, SR \\
\hline & N153-155, W86-88 & VB, SR \\
\hline & N155-157, W84-86 & VB, SR \\
\hline & N155-157, W90-92 & SR \\
\hline & N157-159, W90-92 & SR \\
\hline & N159-160, W83-87 & SR \\
\hline & N159-160, W87-91 & VB, SR \\
\hline & N159-160, W91-95 & VB, SR \\
\hline & N160-162, W84-86 & $\mathrm{VB}, \mathrm{SR}$ \\
\hline & N160-162, W90-92 & SR \\
\hline & N160-164, W87-90 & $\mathrm{VB}, \mathrm{SR}$ \\
\hline & N164-168, W88-89 & SR \\
\hline \multirow[t]{4}{*}{$\mathrm{H} 1 \mathrm{c}$} & N168-172, W88-89 & VB, SR \\
\hline & N174-176, W88-90 & SR \\
\hline & N174-176, W90-92 & SR \\
\hline & N176-180, W88-89 & SR \\
\hline \multirow[t]{2}{*}{$\mathrm{H} 1 \mathrm{~b}$} & N180-182, W88-90 & SR \\
\hline & N180-182, W90-92 & SR \\
\hline
\end{tabular}

*VB $=$ Virginia Butler

$\mathrm{SR}=$ Shoshana Rosenberg 
Appendix B: Locations and Excavation Volumes (L) of Analyzed Bulk Samples.

\begin{tabular}{llllccc}
\hline Sample \# & House & Excavation Unit & $\begin{array}{l}\text { Unit Quad/ } \\
\text { Feature }\end{array}$ & $\begin{array}{c}\text { Unit } \\
\text { Level }\end{array}$ & $\begin{array}{c}\text { Time } \\
\text { Period* }\end{array}$ & Volume \\
\hline 26,961 & H1d & N151-153, W86-88 & NW quad & 8 & pre & 10 \\
31,955 & H4 & N132-134, W96-98 & NW quad & 5 & post & 10 \\
31,956 & H4 & N132-134, W96-98 & NW quad & 6 & post & 10 \\
34,956 & H4 & N120-122, W96-98 & NW quad & 9 & pre & 10 \\
42,954 & H1d & N160-162,W90-92 & SW quad & 7 & post & 2 \\
42,955 & H1d & N160-162, W90-92 & bench cellar & 8 & post & 20 \\
& & & feature & & & \\
42,956 & H1d & N160-162, W90-92 & bench cellar & 9 & post & 20 \\
& & & feature & & & \\
45,952 & H1c & N174-176, W88-90 & NW quad & 4 & post & 12 \\
45,953 & H1c & N174-176, W88-90 & NW quad & 3 & post & 8 \\
45,962 & H1c & N174-176, W88-90 & NW quad & 4 & post & 10.25 \\
45,963 & H1c & N174-176, W88-90 & NW quad & 3 & post & 9.6 \\
47,950 & H1b & N180-182, W88-90 & SW quad & 2 & post & 10 \\
47,951 & H1b & N180-182, W88-90 & SW quad & 2 & post & 6 \\
47,953 & H1b & N180-182, W88-90 & NW quad & 4 & post & 15 \\
48,952 & H1b & N180-182, W90-92 & NW quad & 4 & post & 15 \\
48,953 & H1b & N180-182, W90-92 & NE quad & 4 & post & 15 \\
49,956 & H1c & N174-176, W90-92 & NE quad & 4 & post & 9 \\
49,957 & H1c & N174-176, W90-92 & NE quad & 4 & post & 15 \\
\hline
\end{tabular}

*pre $=$ pre-contact

post $=$ post-contact 


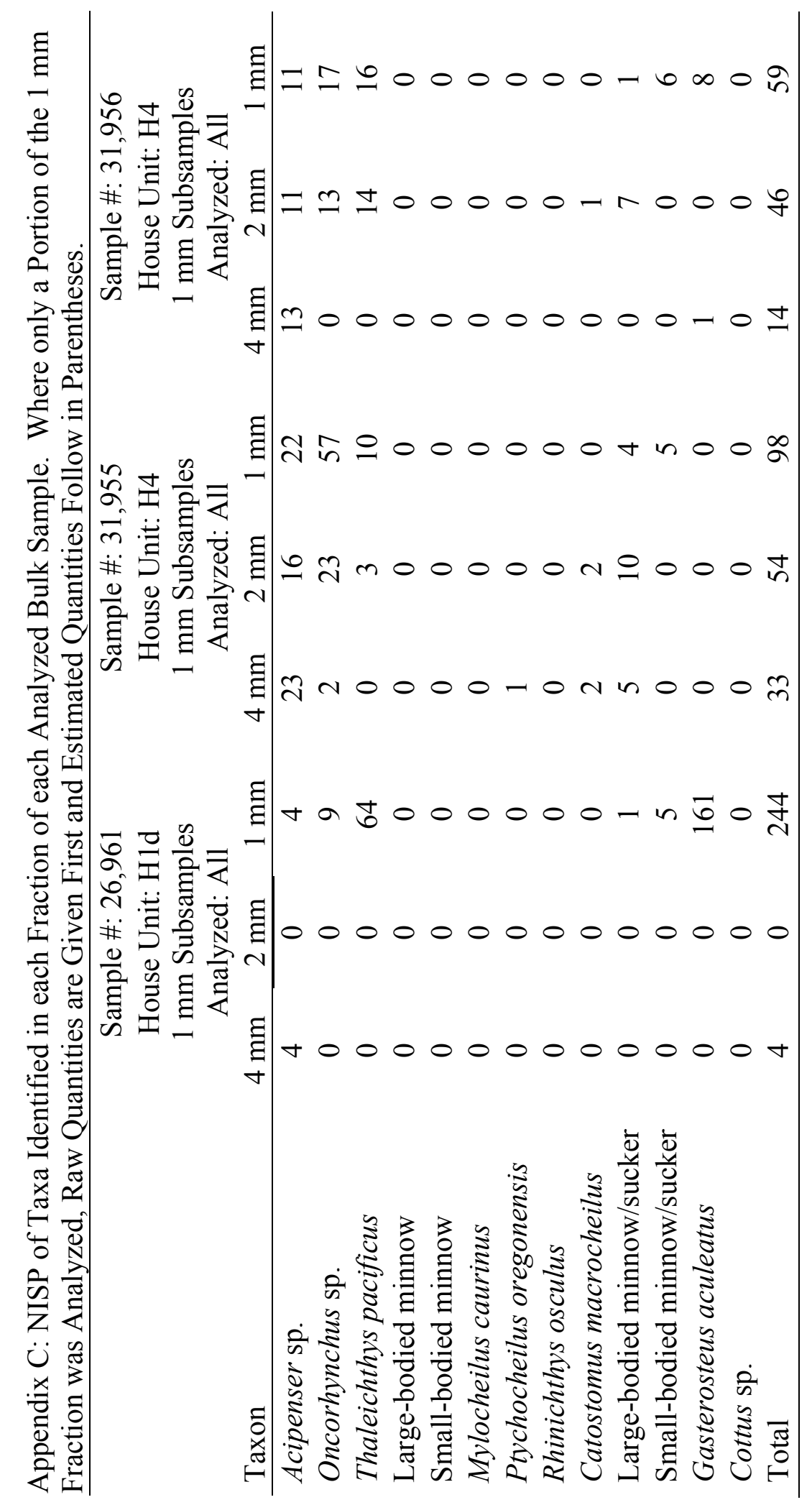




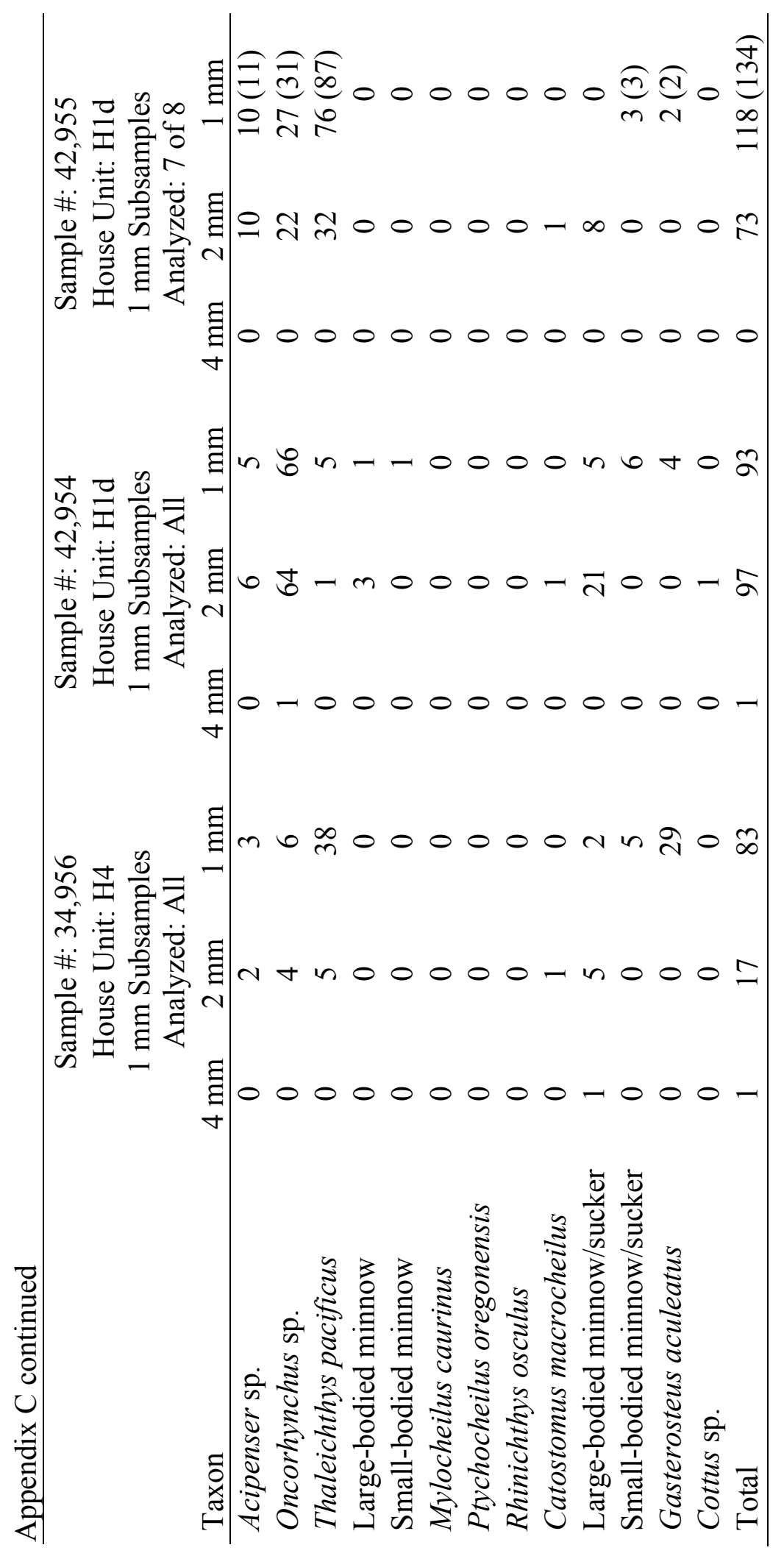




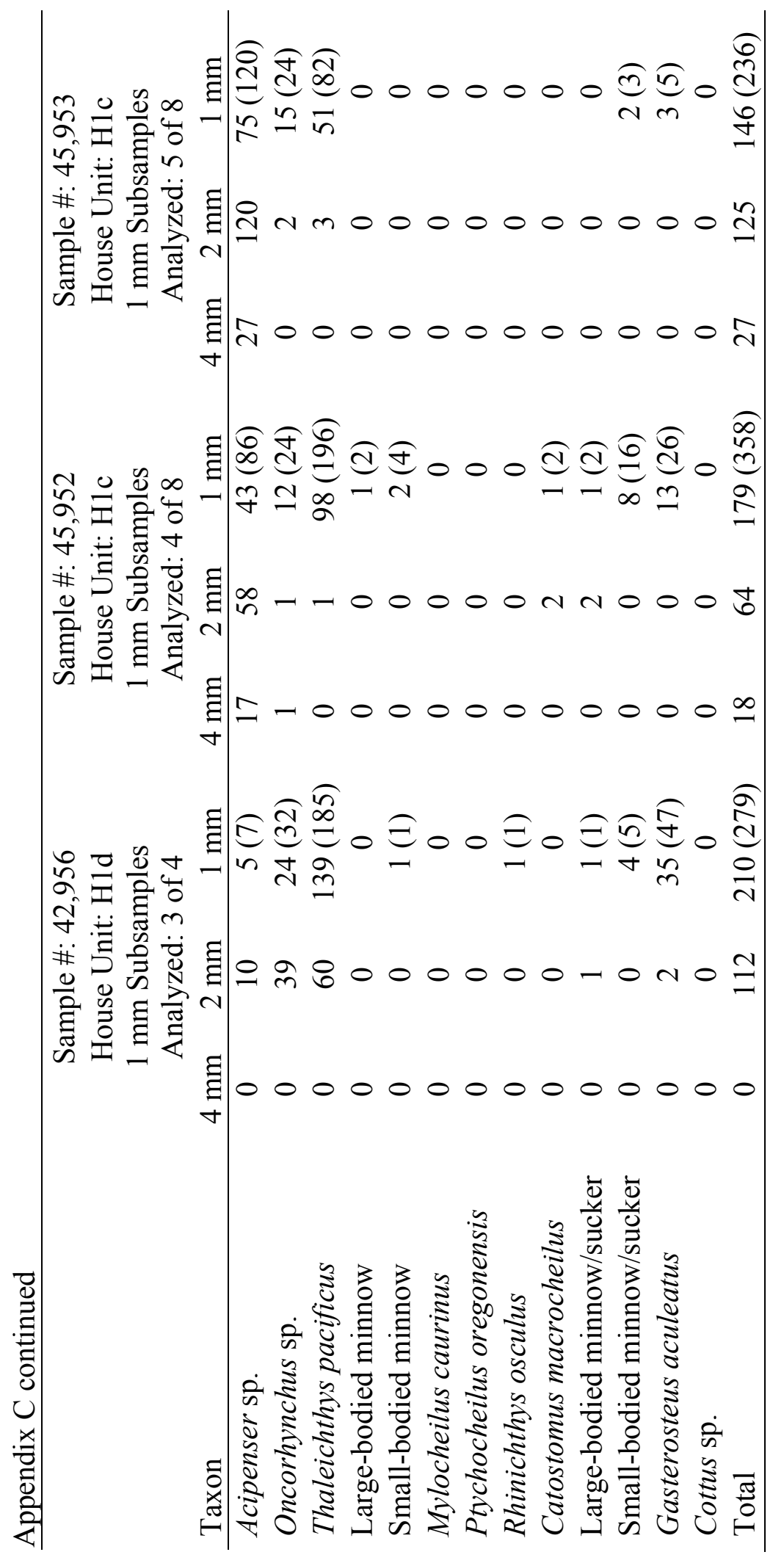




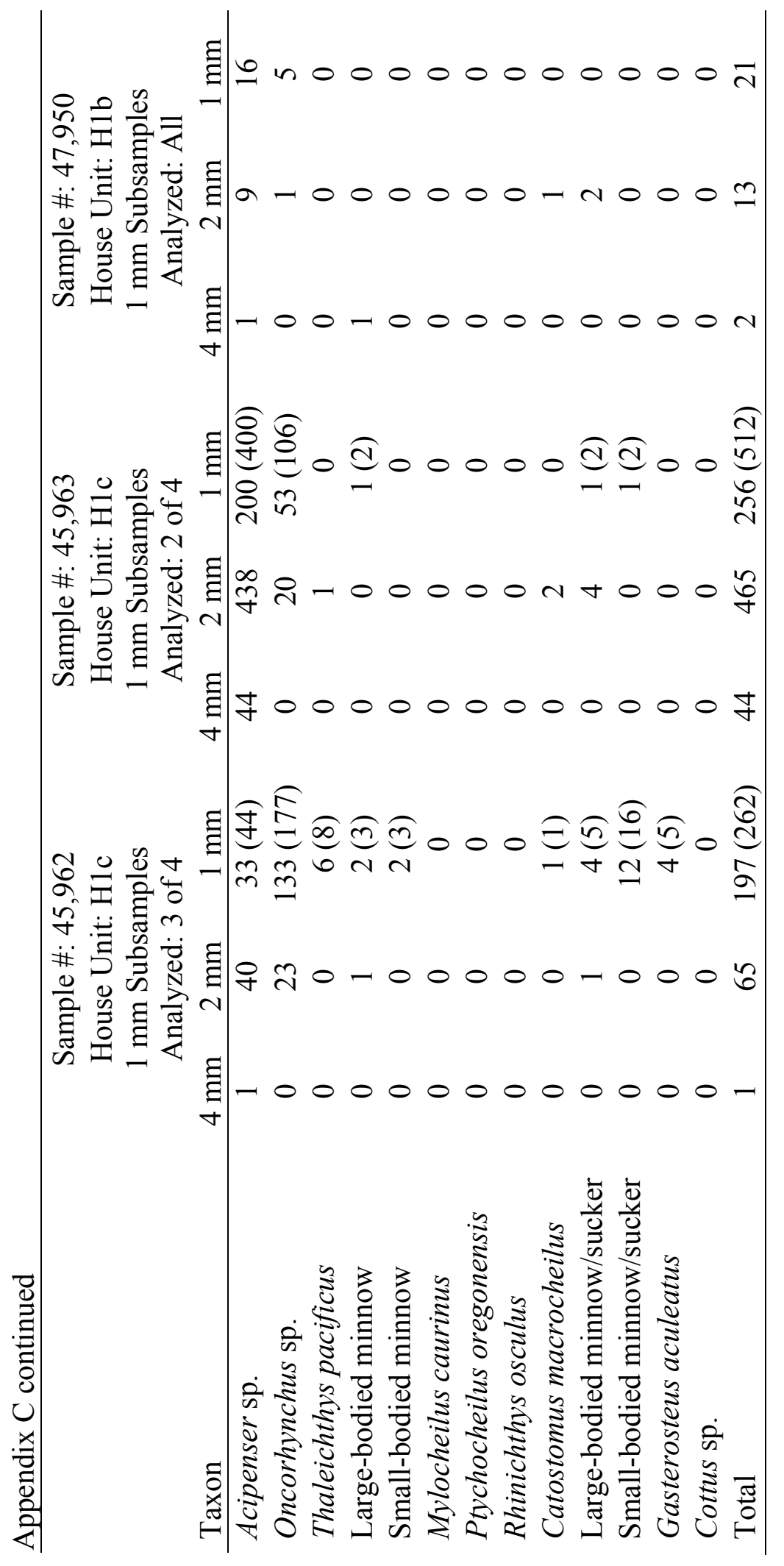




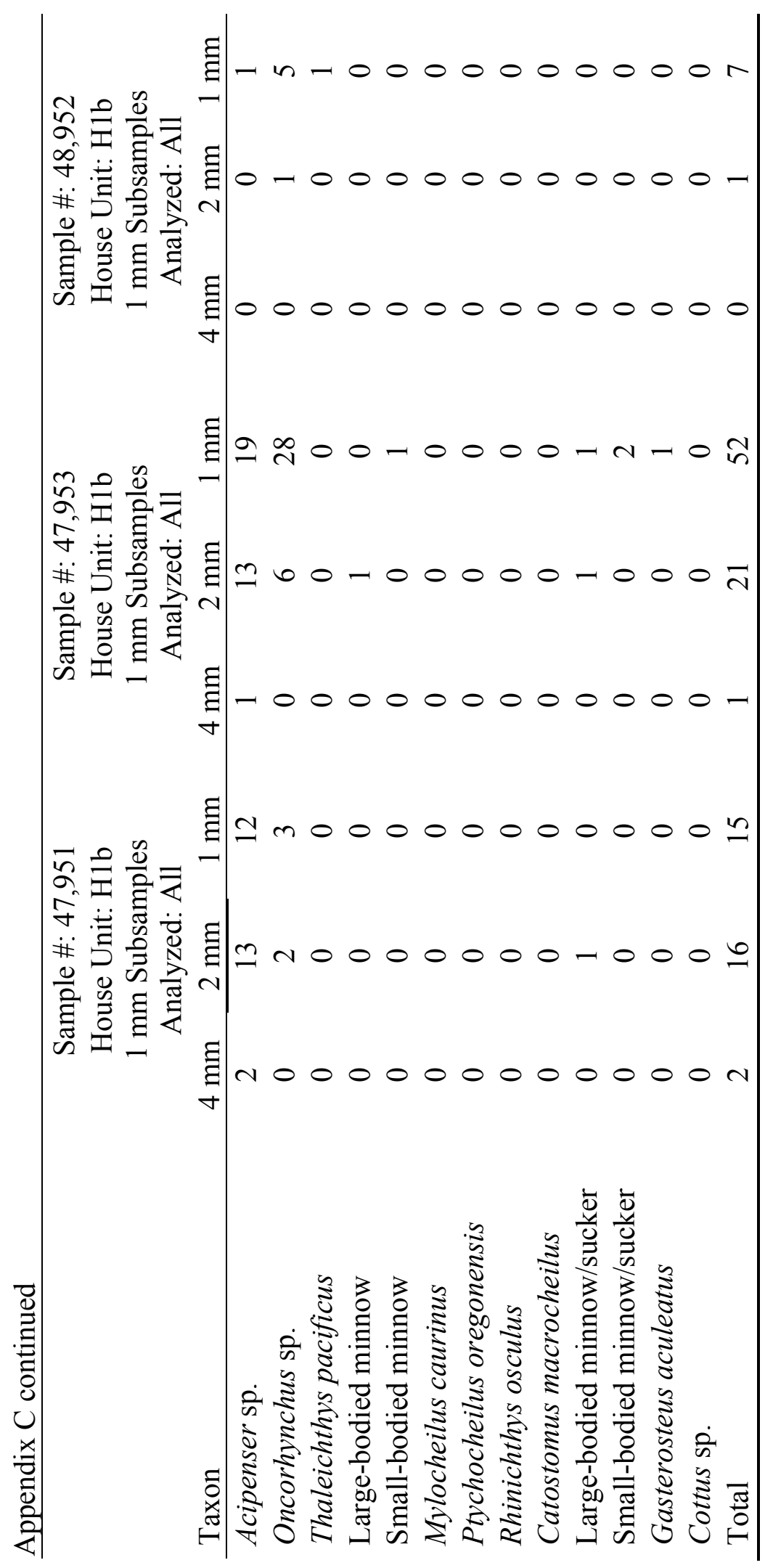




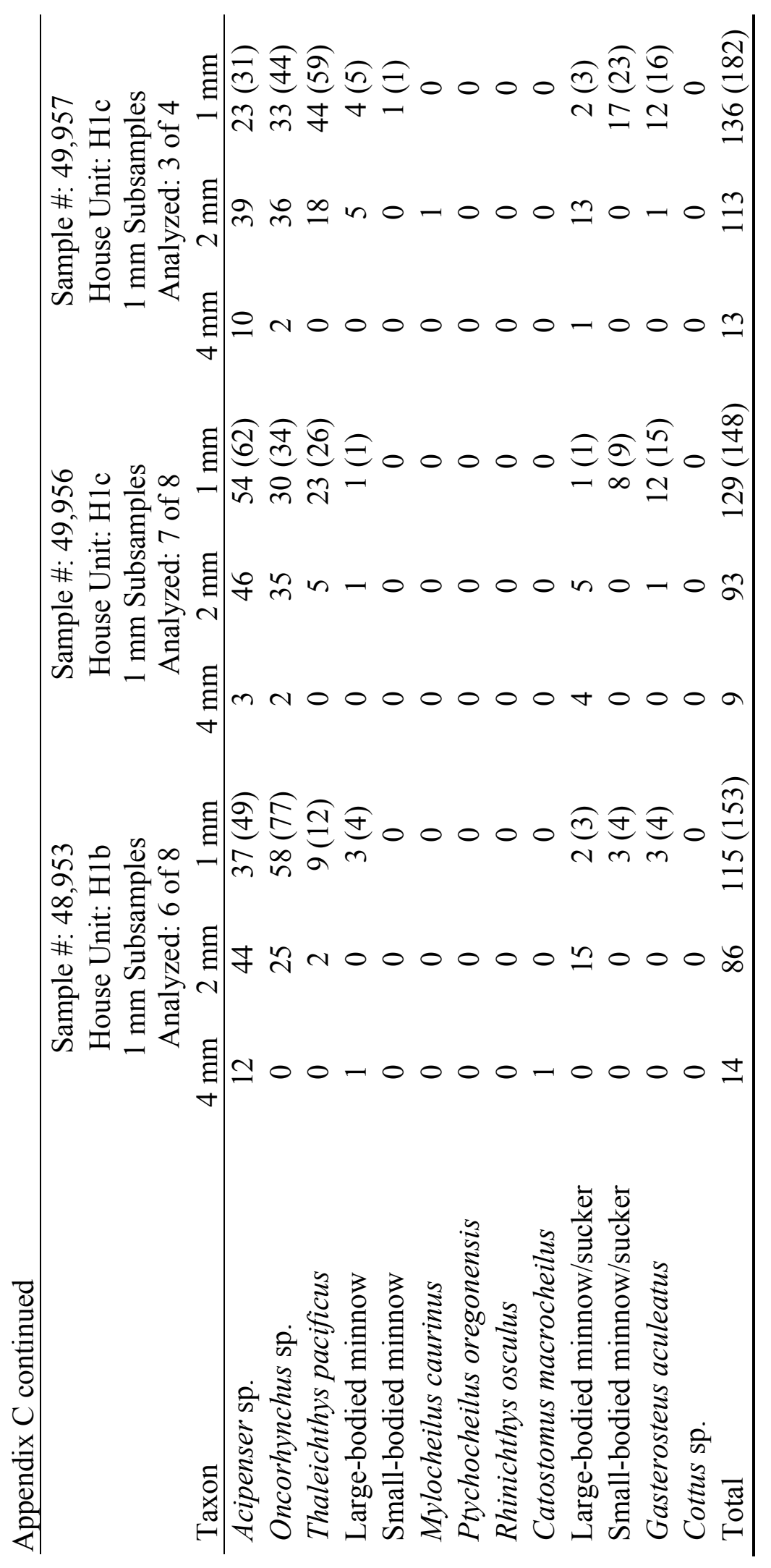

